Florida International University FIU Digital Commons

$12-5-2012$

\title{
Transcription-Coupled DNA Supercoiling in Escherichia Coli: Mechanisms and Biological Functions
}

Xiaoduo Zhi

Florida International University, xzhi001@fiu.edu

DOI: $10.25148 /$ etd.FI13042332

Follow this and additional works at: https://digitalcommons.fiu.edu/etd

Part of the Biochemistry Commons

\section{Recommended Citation}

Zhi, Xiaoduo, "Transcription-Coupled DNA Supercoiling in Escherichia Coli: Mechanisms and Biological Functions" (2012). FIU Electronic Theses and Dissertations. 865.

https://digitalcommons.fiu.edu/etd/865 


\section{FLORIDA INTERNATIONAL UNIVERSITY}

Miami, Florida

TRANSCRIPTION-COUPLED DNA SUPERCOILING IN ESCHERICHIA COLI:

MECHANISMS AND BIOLOGICAL FUNCTIONS

A dissertation submitted in partial fulfillment of

the requirements for the degree of

DOCTOR OF PHILOSOPHY

in

CHEMISTRY

by

Xiaoduo Zhi

2013 
To: Dean Kenneth G. Furton

College of Arts and Sciences

This dissertation, written by Xiaoduo Zhi, and entitled Transcription-coupled DNA supercoiling in Escherichia coli: Mechanisms and Biological functions, having been approved in respect to style and intellectual content, is referred to you for judgment.

We have read this dissertation and recommend that it be approved.

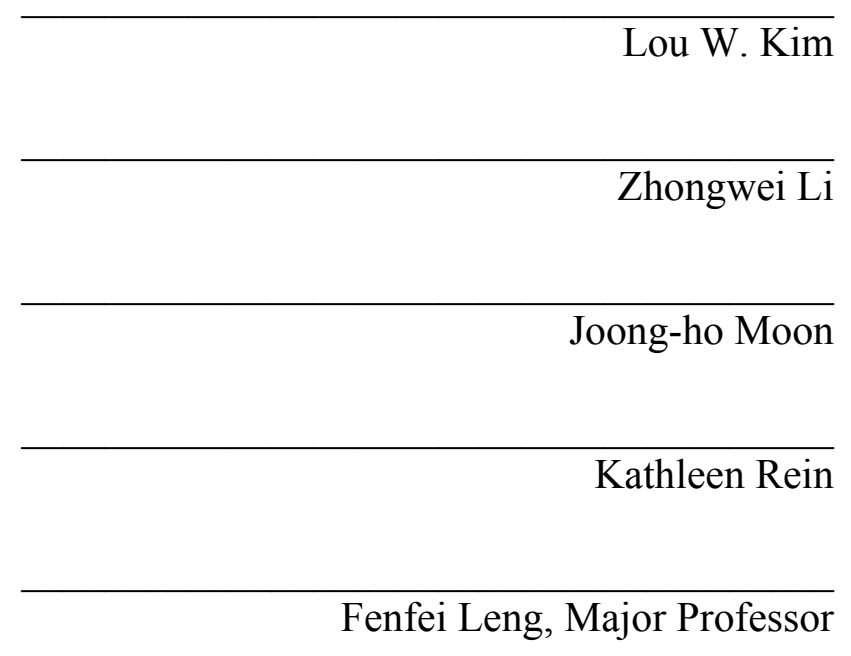

Date of Defense: December 5, 2012

The dissertation of Xiaoduo Zhi is approved.

\begin{tabular}{r} 
Dean Kenneth G. Furton \\
College of Arts and Sciences \\
\hline Dean Lakshmi N. Reddi \\
University Graduate School
\end{tabular}

Florida International University, 2013 


\section{ACKNOWLEDGMENTS}

I would like to thank my major professor, Dr. Fenfei Leng, for his suggestions and guidance through my graduate studies.

I would like to extend my appreciation to my committee members, Dr. Lou W. Kim, Dr. Zhongwei Li, Dr. Joong-ho Moon, and Dr. Kathleen Rein for their critical comments and suggestions.

It is my pleasure to acknowledge my group members, Bo Chen, Steven Eichelbaum, Geraldine Fulcrand, Suzanne Joynt, and Xiaozhou Xu for help they provided.

I also would like to thank Dr. DeEtta Mills and Ms Beatrice Kallifatidis for their help with real time PCR experiments and Dr. John C. Makemson for help with the luciferase assays.

I would like to thank the University Graduate School at Florida International University for the financial support of a Doctoral Evidence Acquisition Fellowship.

More acknowledgements must be given to my parents and my husband Zhiwei Duan for their support and understanding. 
ABSTRACT OF THE DISSERTATION

TRANSCRIPTION-COUPLED DNA SUPERCOILING IN ESCHERICHIA COLI: MECHANISMS AND BIOLOGICAL FUNCTIONS

\author{
by \\ Xiaoduo Zhi \\ Florida International University, 2013 \\ Miami, Florida \\ Professor Fenfei Leng, Major Professor
}

Transcription by RNA polymerase can induce the formation of hypernegatively supercoiled DNA both in vivo and in vitro. This phenomenon has been explained by a "twin-supercoiled-domain" model of transcription where a positively supercoiled domain is generated ahead of the RNA polymerase and a negatively supercoiled domain behind it. In E. coli cells, transcription-induced topological change of chromosomal DNA is expected to actively remodel chromosomal structure and greatly influence DNA transactions such as transcription, DNA replication, and recombination.

In this study, an IPTG-inducible, two-plasmid system was established to study transcription-coupled DNA supercoiling (TCDS) in E. coli topA strains. By performing topology assays, biological studies, and RT-PCR experiments, TCDS in E. coli topA strains was found to be dependent on promoter strength. Expression of a membraneinsertion protein was not needed for strong promoters, although co-transcriptional synthesis of a polypeptide may be required. More importantly, it was demonstrated that the expression of a membrane-insertion tet gene was not sufficient for the production of hypernegatively supercoiled DNA. These phenomenon can be explained by the "twin- 
supercoiled-domain" model of transcription where the friction force applied to E. coli RNA polymerase plays a critical role in the generation of hypernegatively supercoiled DNA.

Additionally, in order to explore whether TCDS is able to greatly influence a coupled DNA transaction, such as activating a divergently-coupled promoter, an in vivo system was set up to study TCDS and its effects on the supercoiling-sensitive leu-500 promoter. The leu-500 mutation is a single A-to-G point mutation in the -10 region of the promoter controlling the leu operon, and the AT to GC mutation is expected to increase the energy barrier for the formation of a functional transcription open complex. Using luciferase assays and RT-PCR experiments, it was demonstrated that transient TCDS, "confined" within promoter regions, is responsible for activation of the coupled transcription initiation of the leu-500 promoter. Taken together, these results demonstrate that transcription is a major chromosomal remodeling force in E. coli cells. 


\section{TABLE OF CONTENTS}

\section{CHAPTER}

PAGE

Chapter 1: Transcription-coupled DNA supercoiling in Escherichia coli topA mutants ... 1 1.1 Transcription-coupled DNA supercoiling (TCDS): the "twin-supercoiled-domain"

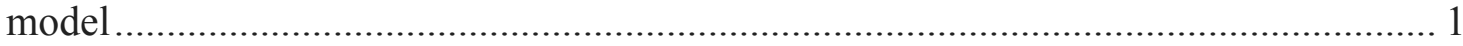

1.2 Transcription-coupled DNA supercoiling in E. coli top $A$ strains ........................... 5

1.3 Effects of transcription-coupled DNA supercoiling on the Salmonella typhimurium



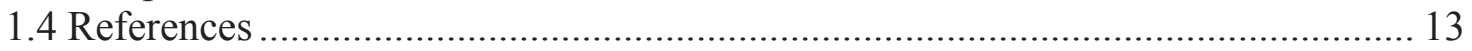

Chapter 2: Dependence of transcription-coupled DNA Supercoiling on promoter strength

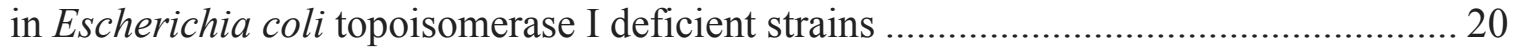

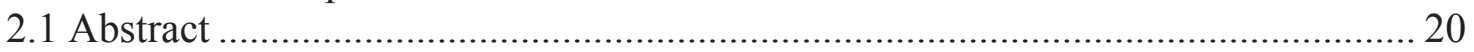

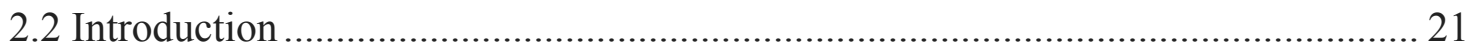

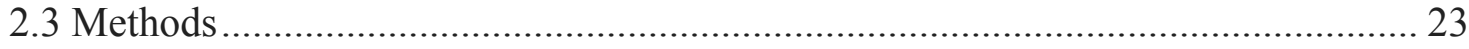

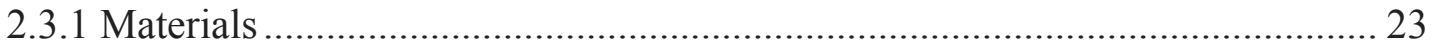

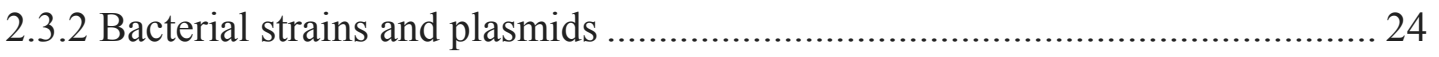

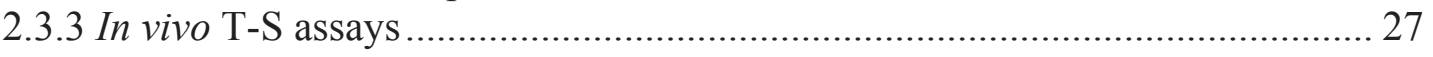

2.3.4 Western blotting experiments ............................................................. 28

2.3.5 RNA isolation, cDNA synthesis, and polymerase chain reaction (PCR) ........ 28

2.3.6 Real-time PCR Assays............................................................................. 30

2.4 Results and Discussion............................................................................... 30

2.4.1 Establish an IPTG-inducible, two-plasmid system to study TCDS in E. coli

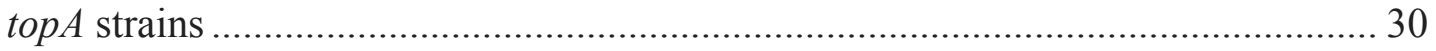

2.4.2 Transcription-coupled hypernegative supercoiling of plasmid DNA is

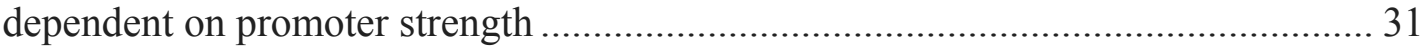

2.4.3 Transcription-coupled hypernegative supercoiling of plasmid DNA in E. coli top $A$ strains did not require the expression of a membrane-insertion protein for

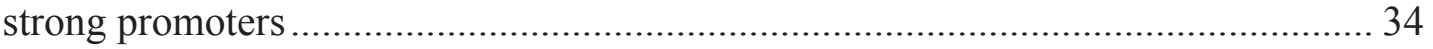



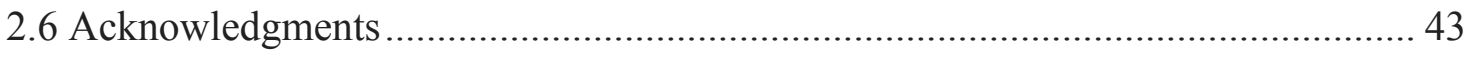

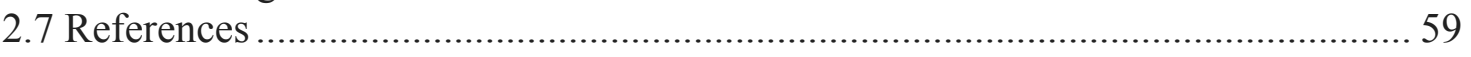

Chapter 3: Activating the Salmonella typhimurium leu-500 promoter by transcription-

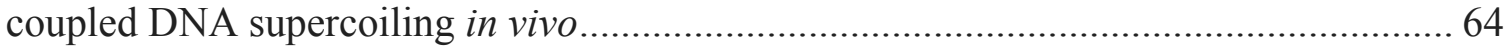



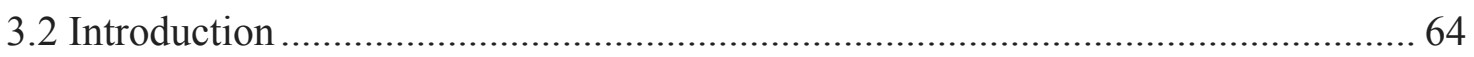

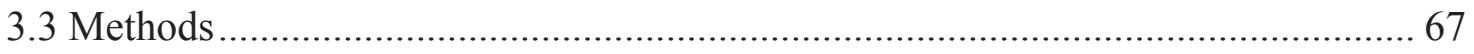

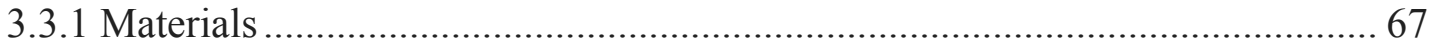

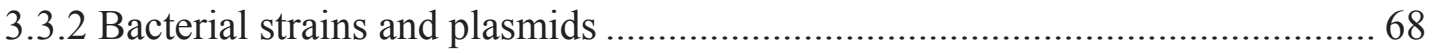

3.3.3 Luciferase Assay............................................................................. 70

3.3.4 RNA isolation, cDNA synthesis, and polymerase chain reaction (PCR) ........ 71



3.3.6 In vivo transcription-supercoiling (T-S) assay............................................. 73 
3.4 Results and Discussion................................................................................... 73

3.4.1 Design an in vivo system to examine the activation of the S. typhimurium leu-

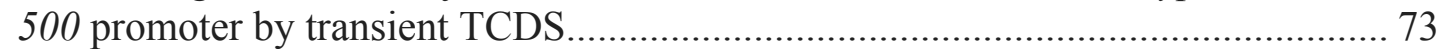

3.4.2 Transient TCDS is able to activate the supercoiling-sensitive leu-500 promoter

.

3.4.3 The distance and DNA sequence between the divergently-coupled leu-500 promoter and T7 promoter significantly influence the efficiency of TCDS and the activation of the $l e u-500$ promoter ........................................................................ 79

3.4.4 The activation of the leu-500 promoter is dependent on the promoter strength

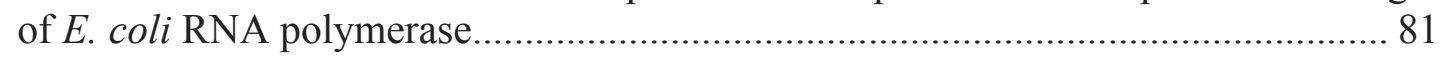

3.4.5 Transcription-coupled hypernegative supercoiling of plasmid is correlated with the activation of the leu-500 promoter in the circular plasmid DNA templates........ 82

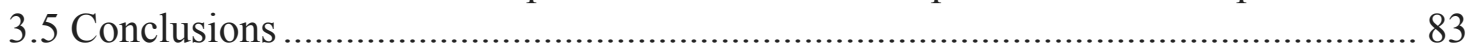

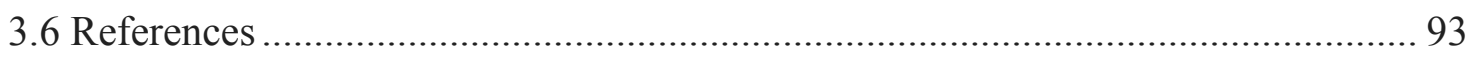

Chapter 4: Conclusions and Future Directions ……………....................................... 96

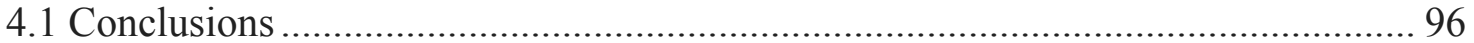

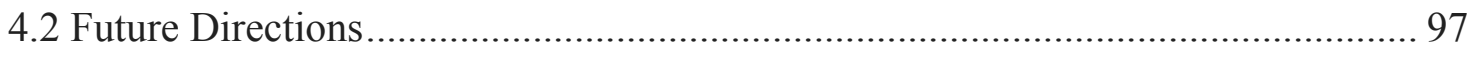

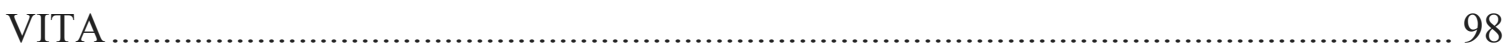




\section{LIST OF FIGURES}

FIGURE

PAGE

Figure 1.1 A two-barrier model to explain transcription-coupled DNA supercoiling (TCDS) on circular plasmids DNA...... 12

Figure 2.1 A two-plasmid system to study TCDS in vivo....................................... 46

Figure 2.2 RT-PCR analysis of cDNA products of mRNA transcribed from different supercoiling-reporter plasmids pZXD44, 50, 49, 47, and 48 in E. coli topA strain VS111 harboring the linear plasmid pZXD51 after 10 min of IPTG induction $(1 \mathrm{mM}) \ldots \ldots \ldots \ldots . . .47$

Figure 2.3 TCDS in E. coli strain VS111 is dependent on promoter strength.. ............... 48

Figure 2.4 For strong promoters, TCDS in E. coli topA strain VS111 did not require the expression of a membrane insertion protein....

Figure 2.5 TCDS in E. coli topA strain VS111 for different plasmid DNA templates with identical size carrying a strong, IPTG-inducible $\mathrm{P}_{\mathrm{T} 7 \mathrm{~A} 1 / \mathrm{O} 4}$ promoter. 50

Figure 2.6 RT-PCR analyses of cDNA products of mRNA transcribed from different supercoiling-reporter plasmids pZXD60, 60A, 61, 62, 63 and 63A in E. coli topA strain VS111 harboring the linear plasmid pZXD51 after 10 min of IPTG induction..... 51

Figure 2.7 The tetracycline sensitivity assays and cell growth curves of E. coli strains carrying different plasmids. 52

Figure 2.8 TCDS in E. coli topA strains is dependent on promoter strength................... 53

Figure 2.9 Plasmid maps of pZXD54, 55, 56, 57, 58, and 59.. 54

Figure 2.10 The expression level of GFPuv protein after IPTG induction in E. coli topA strain VS111/pZXD51 containing different plasmids is correlated with promoter strength..

Figure 2.11 Plasmid maps of pZXD60, 60A, 61, 62, 63, and 63A...... 56

Figure 2.12 TCDS in E. coli topA strains VS111/pZXD51 and DM800/pZXD51 for different plasmid DNA templates with identical size carrying a strong, IPTG-inducible $\mathrm{P}_{\mathrm{T} 7 \mathrm{~A} 1 / \mathrm{O} 4}$ promoter.. 57

Figure 2.13 RT-PCR experiments to analyze the cDNA products synthesized from mRNA of lacZ and tet genes. 58

Figure 3.1 Circular plasmid pZXD99 and linear plasmid pZXD103 were constructed to study TCDS in vivo. 86 
Figure 3.2 Luciferase activity was stimulated by the addition of IPTG in E. coli topA strain VS111(DE3) or wild type strain MG1655(DE3) containing circular plasmid pZXD99 or linear plasmid pZXD103..

Figure 3.3 Circular plasmids differ in the distance and DNA sequence composition between two promoters were constructed to examine the stimulation of luciferase activity by T7 RNA polymerase after the addition of IPTG in E. coli topA strain VS111(DE3).. 88

Figure 3.4 Luciferase activity was stimulated by the addition of IPTG in E. coli topA strain $\operatorname{VS111(DE3)}$ or wild type strain MG1655(DE3) containing circular plasmid pZXD77 or linear plasmid pZXD80. 89

Figure 3.5 An in vivo system to study E. coli RNA polymerase induced TCDS.. 90

Figure 3.6 Circular plasmids and linear plasmids were transformed into E. coli topA strain VS111 or wild type strain MG1655 to examine the stimulation of the luciferase activity by $E$. coli RNA polymerase after the addition of IPTG 91

Figure 3.7 Transient TCDS in E. coli strain VS111(DE3) is responsible for the activation of leu-500 promoter. 92 


\section{LIST OF ABBREVIATIONS AND ACRONYMS}

ABBREVIATIONS

ATP

$\mathrm{bp}$

BSA

DTT

IPTG

E. coli

LB

mRNA

$\mathrm{NIH}$

OD

RLU

RNA

S. typhimurium

SD

TCDS
FULL NAME

Adenosine triphosphate

Base pair

Bovine serum albumin

Dithiothreitol

Isopropyl- $\beta$-D-

thiogalactopyranoside

Escherichia coli

Luria broth

Messenger ribonucleic acid

National Institutes of Health

Optical density

Relative light units

Ribonucleic acid

Salmonella typhimurium

Shine-Dalgaron

Transcription-coupled DNA supercoiling 


\section{Chapter 1: Transcription-coupled DNA supercoiling in Escherichia coli topA mutants}

\subsection{Transcription-coupled DNA supercoiling (TCDS): the "twin-supercoiled- domain" model}

DNA is typically negatively supercoiled in bacteria (Cozzarelli, 1990; Bates and Maxwell, 2005). Changes in the level of DNA supercoiling have been found to play important roles on DNA transactions such as replication, transposition, transcription, and recombination (Cozzarelli, 1990; Kornberg and Baker, 1992; Wang, 1996; Champoux, 2001; Bates and Maxwell, 2005; Wang, 2009). It has been demonstrated that DNA supercoiling is tightly regulated by different DNA topoisomerases in vivo (Wang, 1996; Champoux, 2001). There are four DNA topoisomerases in Escherichia coli: topoisomerase I, gyrase, topoisomerase III and topoisomerase IV (Wang, 1996; Champoux, 2001). In bacteria, the DNA supercoiling level is tightly regulated by the opposing activities of two enzymes: topoisomerase I and gyrase (Pruss and Drlica, 1989; Zechiedrich et al., 2000; Snoep et al., 2002). They act differently on negatively and positively supercoiled DNA. Topoisomerase I (Massé and Drolet, 1999; Massé and Drolet, 1999), the product of the topA gene, functions to relax the negative supercoils in intracellular DNA while DNA gyrase (topo II) (Gellert et al., 1976), which is composed of GyrA and GyrB subunit proteins and has a tetrameric structure, acts to convert a fraction of the transient positive supercoils to "permanent" negative supercoils at the expense of ATP hydrolysis. Inactivating either enzyme results in the production of positive supercoiled DNA or hypernegative supercoiled DNA in vivo (Lockshon and 
Morris, 1983; Pruss, 1985; Pruss and Drlica, 1986; Wu et al., 1988; Lodge et al., 1989; Tsao et al., 1989; Lynch and Wang, 1993; Ma et al., 1994). Moreover, the linking number change caused by inactivation of either topoisomerase is directly related to the transcription of the DNA and relative orientation of the transcription units (Wu et al., 1988).

In E. coli, countervailing activities of topoisomerase I and gyrase are homeostatically regulated (Dinardo et al., 1982): an increase in the degree of negative supercoiling reduces the transcription of the gyr $A$ and $g y r B$ genes, which encodes the two subunits of gyrase, and elevates the transcription of the top $A$ gene, the gene that encodes DNA topoisomerase I; a decrease in the degree of negative supercoiling has the opposite effects on the expression of these genes (Menzel and Gellert, 1983; Tse-Dinh, 1985; TseDinh and Beran, 1988). It has been demonstrated that E. coli top $A$ strains are not viable unless they acquire compensatory mutations such as mutations in the gyrA and $g y r B$ that encode gyrase (Dinardo et al., 1982; Pruss et al., 1982; Raji et al., 1985; Dorman et al., 1989). The suppression of the lethal phenotype of topA by compensatory mutations indicates the proper level of supercoiling in E. coli is essential and is controlled by the diametric functions of enzymes.

Early studies have shown the effects of transcription on DNA topology in E. coli cells. The first case was a study by Lockshon and Morris in which a substantial fraction of the plasmid pBR322 isolated from E. coli cells after exposure to DNA gyrase inhibitors, such as oxolinic acid and novobiocin, became positively supercoiled (Lockshon and Morris, 1983). Effects of gyrase alone cannot explain the formation of the 
positively supercoiled plasmid (Liu and Wang, 1987). In a later study by Pruss (Pruss, 1985), it was demonstrated that pBR322 isolated from E. coli or Salmonella typhimurium topA mutants lacking DNA topoisomerase I is hypernegatively supercoiled. The distribution of the DNA topoisomers is much broader than that isolated from the wild type strains. In 1986, Pruss and Drlica showed that plasmid pBR322, but not pUC9 (a smaller high copy number plasmid, which is derived from $\mathrm{pBR} 322$ ), isolated from E. coli topA strains, became hypernegatively supercoiled (Pruss and Drlica, 1986). On the basis of these observations, Liu and Wang formulated an elegant model, the "twin-supercoileddomain" model of transcription, to explain these results (Liu and Wang, 1987). They hypothesized that during the transcription elongation, the transcribing complex (include the polymerase, its nascent RNA, and RNA associated proteins) becomes progressively more difficult to rotate around the DNA double helix as the size of the growing RNA transcript increases. At a critical point, it is more feasible for DNA to rotate around its own helical axis to generate a transient positively supercoiled domain ahead of the RNA polymerase and a transient negatively supercoiled domain behind it. The formation of twin domains during transcription elongation is manifested by a large decrease or increase in the linking number of an intracellular plasmid when topoisomerase I or gyrase, respectively, is inhibited. This "twin-supercoiled-domain" model indicated that the state of supercoiling inside bacterial DNA is strongly modulated by transcription, it also predicted that the accumulated supercoiled DNA can be relaxed by DNA topoisomerases or neutralized each other by diffusing along the DNA helix (Liu and Wang, 1987). 
Inside a bacterium, DNA gyrase and topoisomerase I act differentially on positively and negatively supercoiled domains (Wang, 1971; Gellert et al., 1976), therefore the supercoiling state of intracellular DNA is expected to be regulated by several processes, for instance, the transcription process which produces negative and positive supercoils at equal rates, the diffusion pathways which allow the cancellation of negative and positive supercoils, and the actions of DNA topoisomerases such as DNA topoisomerase I-catalyzed relaxation for negatively supercoiled DNA as well as gyrasecatalyzed negative supercoiling (Wu et al., 1988; Wang and Lynch, 1993)

There are several studies conducted to support the "twin-supercoiled-domain" model of transcription (Wu et al., 1988; Lodge et al., 1989; Tsao et al., 1989; Dröge and Nordheim, 1991; Cook et al., 1992; Dayn et al., 1992; Rahmouni and Wells, 1992; Dunaway and Ostrander, 1993; Lynch and Wang, 1993; Ma et al., 1994; Albert et al., 1996; Leng and McMacken, 2002; Leng et al., 2004; Stupina and Wang, 2005; Samul and Leng, 2007). Liu and Wang's model also suggested that in a dilute aqueous solution, the friction force applying to the transcription complex was too small to generate significant supercoiling of the DNA template that only contain one transcription unit (Liu and Wang, 1987). We now know that it is very viscous and crowded inside a living cell (Zimmerman and Minton, 1993; Richter et al., 2008), and TCDS should be different from the dilute solution situation. It has been demonstrated that increased viscosity was able to significantly induce the DNA supercoiling in a defined protein system (Leng et al., 2004), which supports the view that in vivo situation is more complicated than the dilute aqueous solution. Recently, several groups re-investigated the induced torsional stress by a 
transcribing RNA polymerase, they showed that even in a dilute aqueous solution, the torsional force of RNA polymerase was sufficient to generate the twin-supercoileddomains (Nelson, 1999; Mielke et al., 2004). For instance, Nelson demonstrated that small natural bends in the DNA helix backbone was able to increase a few thousand fold of torsional stress even in a linear unanchored DNA (Nelson, 1999), this torsional force is sufficient to generate a positively supercoiled domain in front of the RNA polymerase and a negatively supercoiled domain behind it (Nelson, 1999). Another case is a Brownian dynamic study conducted by Mielke et al. (Mielke et al., 2004). These studies clearly demonstrated that a transcribing RNA polymerase alone is able to drive the formation of positively and negatively domains in a naked plasmid DNA template.

So far, studies of TCDS in vivo and in vitro were almost solely dependent on the utilization of circular plasmid in which topology of DNA was determined after transcription (Wu et al., 1988; Leng and McMacken, 2002; Samul and Leng, 2007). It has been demonstrated that TCDS on plasmids DNA required two barriers (Liu and Wang, 1987; Lodge et al., 1989; Wang and Lynch, 1993; Leng and McMacken, 2002; Stupina and Wang, 2004). The first barrier is a friction barrier generated from preventing or retarding the transcription complex from rotating around the DNA double helix; the second barrier is a topology barrier that prevents the cancellation of the positive and negative supercoiling domains (Figure 1.1).

\subsection{Transcription-coupled DNA supercoiling in $E$. coli top $A$ strains}

In 1985, Pruss reported that hypernegatively supercoiled pBR322 was isolated from E. coli or S. typhimurium topA mutants lacking DNA topoisomerase I and the 
isolated pBR322 DNA is extremely heterogeneous in linking number (Pruss, 1985). In a latter study, Pruss and Drlica showed that plasmid pBR322, but not pUC9 (a smaller high copy number plasmid, which is derived from pBR322), isolated from E. coli topA strains, became hypernegatively supercoiled, suggesting tet gene was responsible for this hypernegative supercoiling in topA strain (Pruss and Drlica, 1986). Further studies demonstrated that anchoring the transcribing RNA polymerase to the cell membrane through a nascent membrane-bound peptide or protein was required for the generation of hypernegative supercoiling in topA strains (Lodge et al., 1989; Cook et al., 1992; Lynch and Wang, 1993). For instance, by analyzing the transcription induced DNA supercoiling of plasmid pBR322 and its derivatives, Lodge et al. found that transcription-driven twin supercoiled domains were generated only if the DNA template was anchored to a large cellular structure by coupled transcription, translation, and membrane insertion of a nascent protein (Lodge et al., 1989). Later, Lynch and Wang showed that hypernegative DNA supercoiling in topA strain required the anchorage of transcribing RNA polymerase to the cell membrane through a nascent membrane-bound peptide or protein (Wang and Lynch, 1993). Moreover, Cook et al. showed that transcription of membrane-associated gene products that are oppositely oriented, rapidly supercoiled the plasmid DNA in topA strains (Cook et al., 1992; Ma et al., 1994). In these studies, the membrane-bound transcriptional complex cannot rotate around the DNA double helix freely and therefore a friction barrier was produced which generates the twin-supercoiled domains on the DNA templates (Lodge et al., 1989; Wang and Lynch, 1993; Ma et al., 1994).

It should be pointed out that all these studies regarding TCDS in E. coli topA strains utilized a combination of E. coli RNA polymerase and its promoters. As 
demonstrated before, plasmid pBR322 and its derivatives contain several E. coli RNA polymerase promoters and the length and location of RNA transcripts cannot be controlled precisely (Sutcliffe, 1979; Bujard, 1981; Tomizawa and Som, 1984). In this case, TCDS may result from simultaneously transcribed of several transcriptional units on these plasmid DNA templates. Therefore, it was difficult to determine the factors that affect TCDS in E. coli topA strains. Apparently, a more specific model was required to identify the parameters that influence TCDS in E. coli.

In 2007, we established a new system to study TCDS in E. coli (Samul and Leng, 2007). This new system consists of a set of plasmids (i.e., the pLUC plasmids (Leng et al., 2004) ) that produced RNA transcripts of different lengths by T7 RNA polymerase (Leng et al., 2004) and a E. coli topA strain, VS111(DE3) or DM800(DE3), in which a $\lambda$ DE3 prophage containing a T7 RNA polymerase gene under the control of the lacUV5 promoter has been integrated into the chromosome. Compared to topA strain VS111(DE3), $D M 800(D E 3)$ has a compensatory mutation in the $\operatorname{gyr} B$ gene that produces a less active DNA gyrase (Sternglanz et al., 1981; McEachern and Fisher, 1989). Using this in vivo system, the length and location of RNA transcripts could be precisely controlled. We found that transcription by T7 RNA polymerase significantly induced the formation of hypernegatively supercoiled DNA. We also discovered that TCDS was dependent on the lengths of RNA transcripts, as predicted by the "twin-supercoiled-domain" model of transcription. More importantly, our results showed that hypernegative supercoiled DNA induced by T7 RNA polymerase did not require the anchorage of plasmid DNA to the bacterial cytoplasmic membrane, which is contrary to previous studies (Lodge et al., 1989; Cook et al., 1992; Lynch and Wang, 1993). This discovery indicated that a 
transcribing RNA polymerase along is sufficient to cause a change of local DNA superhelicity. These results can be explained by the "twin-supercoiled-domain" model of transcription (Figure 1.1). As discussed above, TCDS requires two barriers. The physical barrier comes from preventing or retarding the transcriptional complex (including the transcribing RNA polymerase and the newly synthesized RNA transcript) from rotating around the DNA double helix, which results in the generation of the twin supercoiled domains. In our study, a fast-moving T7 RNA polymerase was used to produce sufficient friction force in order to generate the twin supercoiled domains, which is the main reason why the anchorage of transcription complex to the membrane is not required in E. coli topA strains. The second barrier is a DNA topology barrier that prevents or retards the diffusion and merger of DNA supercoiling along the longitudinal helix axis of the DNA template. In this case, the positively supercoiled DNA and negatively supercoiled DNA produced during transcription cannot cancel each other. In addition, DNA gyrase functions to convert the positively supercoiled DNA into "permanent" negative supercoiled DNA to generate hypernegatively supercoiled DNA in E. coli topA strains. Initially, a big cellular structure such as cell membrane was thought to be required for the production of a topological barrier. However, as discussed above, recently, our group found that certain nucleoprotein complexes, for example, those that contain sharply bent DNA sites or unwound DNA sequences, could form such topology barrier to block the diffusion and merger of the oppositely DNA domains (Leng et al., 2011). For pLUC plasmids, each of them contain one or more DNA-binding sites for several sequencespecific DNA binding proteins, such as ArgR and IHF, which have potentials to form nucleoprotein complexes that can serve as a topological barrier. In addition, E. coli RNA 
polymerase may be able to associate with E. coli promoters on these DNA plasmids to stimulate the coupled supercoiling during transcription elongation. In summary, the topological barrier does exist for TCDS on pLUC plasmids. In this case, transcription by a fast-moving T7 RNA polymerase should significantly supercoil the DNA templates through the "twin-supercoiled-domain" mechanism (Figure 1.1).

\subsection{Effects of transcription-coupled DNA supercoiling on the Salmonella typhimurium leu-500 promoter}

DNA supercoiling plays a crucial role in transcription regulation, as demonstrated in several systems (Cozzarelli, 1990; Wang and Lynch, 1993). The supercoiling effects could also play an important role on promoter function in vivo (Chen et al., 1992). One of the best characterized examples is activation of the $S$. typhimurium leu-500 promoter by TCDS. The leu-500 promoter, isolated from leucine auxotroph of S. typhimurium, is a single A-to-G point mutation in the -10 region of the promoter which controls the leu operon (Mukai and Margolin, 1963; Dubnau and Margolin, 1972; Gemmill et al., 1984). The supX locus (initially named su leu 500) was first described by Mukai and Margolin (Mukai and Margolin, 1963). Mutation in the supX locus could restore the leucine prototrophy and the chromosomal location of $\sup X$ was identified between the tryptophan operon and cysteine B locus in S. typhimurium (Mukai and Margolin, 1963; Dubnau and Margolin, 1972). Later, the $\sup X$ gene was identified the same gene as top $A$ which encodes for topoisomerase I (Sternglanz et al., 1981; Trucksis and Depew, 1981; Trucksis et al., 1981; Wang and Becherer, 1983; Margolin et al., 1985). The AT to GC mutation was expected to increase the energy barrier to form a functional transcription 
complex and this barrier can be overcome by the mutation in topoisomerase I gene that causes the loss of topoisomerase I's activity (Trucksis et al., 1981; Richardson et al., 1984; Margolin et al., 1985; Richardson et al., 1988). Intriguingly, Lilley and Higgins showed that activation of the leu-500 promoter was only dependent on the topA background and did not correlate with global supercoiling, as measured from extracted DNA templates (Lilley and Higgins, 1991). In addition, when the leu-500 promoter was cloned into a plasmid, the topA background was no longer required for activation of the leu-500 promoter (Richardson et al., 1988; Lilley and Higgins, 1991; Chen et al., 1992). These phenomena suggested an unknown regulation factor rather than the topA background was responsible for the activation of the $l e u-500$ promoter. Studies conducted by Wu's group and Lilley's group pointed out leu-500 promoter could be activated when it was coupled to transcription of another divergently oriented promoter, suggested that transcription-driven localized supercoiling was responsible for the activation of the leu500 promoter (Chen et al., 1992; Chen et al., 1993; Tan et al., 1994; Mojica and Higgins, 1996; Spirito and Bossi, 1996; Chen et al., 1998). Furthermore, after analyzing the leuO operon and the surrounding elements in S. typhimurium chromosome, $\mathrm{Wu}$ and coworkers found that $i l v I H$ promoter and the $l e u O$ gene were located upstream of the leu500 promoter and they were transcribed divergently to the leu-500 promoter (Haughn et al., 1986; Wu et al., 1995). On the basis of these results, Wu et al. proposed a promoter relay mechanism to explain the expression of the ilvIH-leuO-leuABCD gene cluster that is coordinated in a sequential manner (Fang and Wu, 1998; Fang and Wu, 1998; Wu and Fang, 2003). In this model, leu $O$ promoter is activated by $i l v I H$ promoter, which is located within the $1.9 \mathrm{~kb}$ intervening sequence. Both the leuO promoter and expression of 
the LeuO protein are required for subsequent activation of the leu-500 promoter (Fang and $\mathrm{Wu}, 1998)$. The key component in this model is TCDS which generates transient changes on DNA templates. In addition, recently, Hanafi and Bossi showed the orientation of the DNA supercoiling could affect neighboring promoters: transcriptioninduced positively supercoiling suppressed the promoter function while transcriptiondriven negatively supercoiling could activate the leu-500 promoter (Hanafi and Bossi, 2000). 

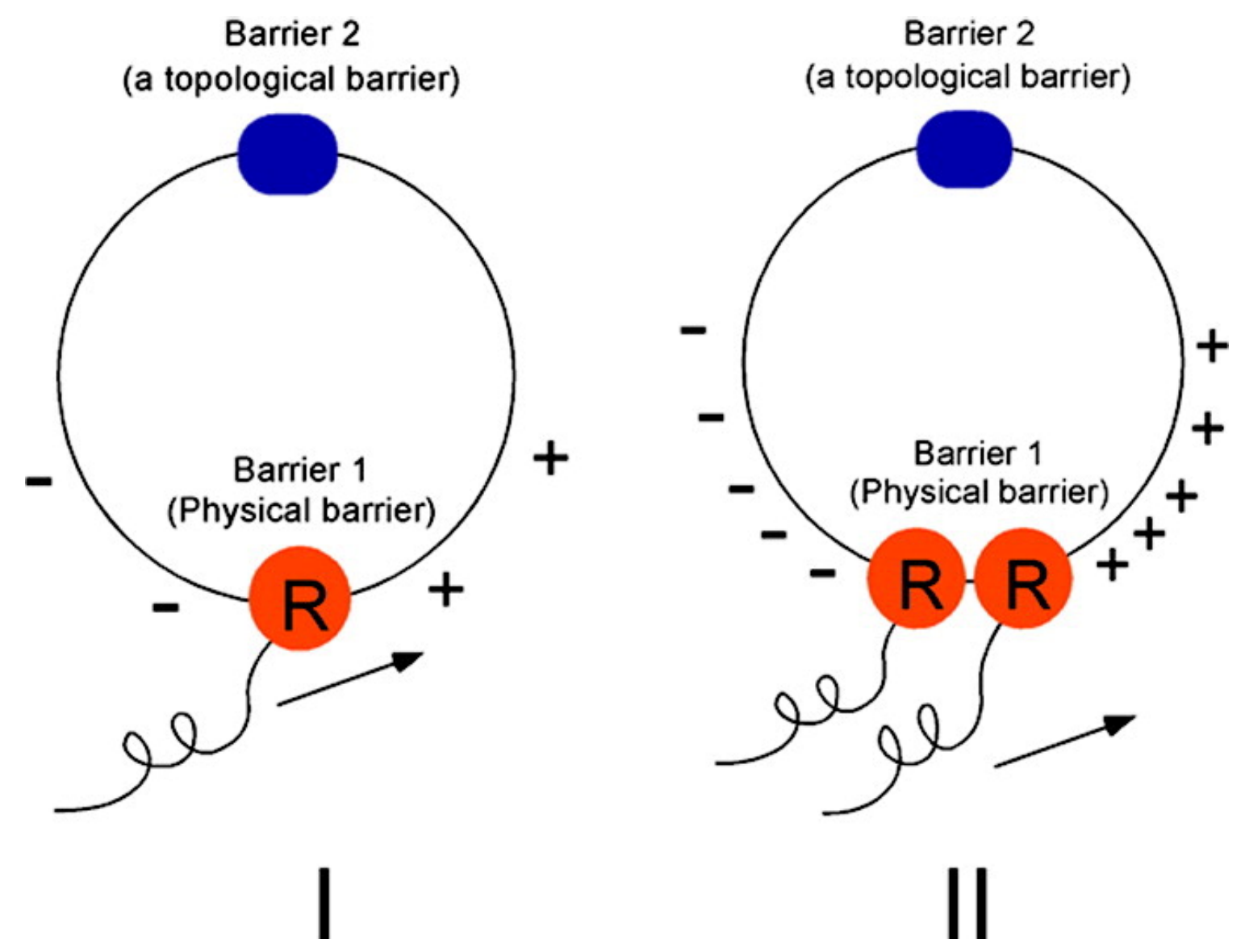

Figure 1.1 A two-barrier model to explain TCDS on circular plasmids DNA. As RNA polymerase binds to the DNA double helix and transcribed counterclockwise, positively supercoils will be generated ahead of the transcribing RNA polymerase and negatively supercoils behind it. A physical barrier (barrier 1) is formed by preventing or retarding of RNA polymerase from rotating around the DNA double helix. A topological barrier (barrier 2) may be generated from the formation of some nucleoprotein complexes. When there is more than one RNA polymerase present, greater extent of TCDS will be achieved. 


\subsection{References}

Adachi, Y., Käs, E., Laemmli, U. K., 1989. Preferential, cooperative binding of DNA topoisomerase II to scaffold-associated regions. EMBO J 8, 3997-4006.

Albert, A.-C., Spirito, F., Figueroa-Bossi, N., Bossi, L., Rahmouni, A. R., 1996. HyperNegative Template DNA Supercoiling During Transcription of the TetracyclineResistance Gene in topA Mutants is Largely Constrained in vivo. Nucleic Acids Research 24, 3093-3099.

Bates, A., Maxwell, A., 2005. DNA Topology, Oxford University Press, Oxford, UK.

Bauer, W. R., F. H. C. Crick, White, J. H., 1980. Supercoiled DNA. Sci. Am 243, 110143.

Brahms, J. G., Dargouge, O., Brahms, S., Ohara, Y., Vagner, V., 1985. Activation and inhibition of transcription by supercoiling. Journal of Molecular Biology 181, 455-465.

Bujard, D. S. a. H., 1981. Organization of transcriptional signals in plasmids pBR322 and pACYC184. Proc Natl Acad Sci U S A 78, 167-171.

Champoux, J. J., 2001. DNA Topoisomerases: Structure, Function, and Mechanism. Annual Review of Biochemistry 70, 369-413.

Chen, D., Bachellier, S., Lilley, D. M. J., 1998. Activation of the leu-500 Promoter by a Reversed Polarity tetA Gene. Journal of Biological Chemistry 273, 653-659.

Chen, D., Bowater, R., Dorman, C. J., Lilley, D. M., 1992. Activity of a plasmid-borne leu-500 promoter depends on the transcription and translation of an adjacent gene. Proceedings of the National Academy of Sciences 89, 8784-8788.

Chen, D., Bowater, R. P., Lilley, D. M. J., 1993. Activation of the leu-500 promoter: A topological domain generated by divergent transcription in a plasmid. Biochemistry 32, 13162-13170.

Chen, D., Lilley, D. M. J., 1999. Transcription-induced hypersupercoiling of plasmid DNA. Journal of Molecular Biology 285, 443-448.

Cook, D. N., Ma, D., Pon, N. G., Hearst, J. E., 1992. Dynamics of DNA supercoiling by transcription in Escherichia coli. Proceedings of the National Academy of Sciences of the United States of America 89, 10603-10607.

Cozzarelli, N. R., 1990. DNA Topology and Its Biological Effects. Cold Spring Harbor Laboratory Press, Cold Spring Harbor, NY. 
Dayn, A., Malkhosyan, S., Mirkin, S. M., 1992. Transcriptionally driven cruciform formation in vivo. Nucleic Acids Research 20, 5991-5997.

De Wet, J. R., Wood, K. V., Helinski, D. R., DeLuca, M., 1985. Cloning of firefly luciferase cDNA and the expression of active luciferase in Escherichia coli. Proceedings of the National Academy of Sciences 82, 7870-7873.

Deneke, J., Ziegelin, G., Lurz, R., Lanka, E., 2000. The protelomerase of temperate Escherichia coli phage N15 has cleaving-joining activity. Proceedings of the National Academy of Sciences 97, 7721-7726.

Dinardo, S., Voelkel, K. A., Sternglanz, R., Reynolds, A. E., Wright, A., 1982. Escherichia coli DNA topoisomerase I mutants have compensatory mutations in DNA gyrase genes. Cell 31, 43-51.

Dorman, C. J., Lynch, A. S., Bhriain, N. N., Higgins, C. F., 1989. DNA supercoiling in Escherichia coli: topA mutations can be suppressed by DNA amplifications involving the tolC locus. Molecular Microbiology 3, 531-540.

Dröge, P., 1994. Protein tracking-induced supercoiling of DNA: A tool to regulate DNA transactions in vivo? BioEssays 16, 91-99.

Dröge, P., Nordheim, A., 1991. Transcription-induced conformational change in a topologically closed DNA domain. Nucleic Acids Research 19, 2941-2946.

Drolet, M., Bi, X., Liu, L. F., 1994. Hypernegative supercoiling of the DNA template during transcription elongation in vitro. Journal of Biological Chemistry 269, 2068-2074.

Dubnau, E., Margolin, P., 1972. Suppression of promoter mutations by the pleiotropic supx mutations. Mol Gen Genet 117, 91-112.

Dunaway, M., Ostrander, E. A., 1993. Local domains of supercoiling activate a eukaryotic promoter in vivo. Nature 361, 746-748.

Fang, M., Wu, H.-Y., 1998. A Promoter Relay Mechanism for Sequential Gene Activation. Journal of Bacteriology 180, 626-633.

Fang, M., Wu, H.-Y., 1998. Suppression of leu-500 Mutation in top $A^{+}$Salmonella typhimurium Strains. Journal of Biological Chemistry 273, 29929-29934.

Fisher, L. M., 1984. Genetics: DNA supercoiling and gene expression. Nature 307, 686687.

Gellert, M., Mizuuchi, K., O'Dea, M., Nash, H., 1976. DNA gyrase: an enzyme that introduces superhelical turns into DNA. Proc Natl Acad Sci U S A 73, 3872-3876. 
Gemmill, R. M., Tripp, M., Friedman, S. B., Calvo, J. M., 1984. Promoter mutation causing catabolite repression of the Salmonella typhimurium leucine operon. Journal of Bacteriology 158, 948-953.

Gralla, J. D., 1996. Activation and repression of E. coli promoters. Current Opinion in Genetics \&amp; Development 6, 526-530.

Hanafi, D. E., Bossi, L., 2000. Activation and silencing of leu-500 promoter by transcription-induced DNA supercoiling in the Salmonella chromosome. Molecular Microbiology 37, 583-594.

Haughn, G. W., Wessler, S. R., Gemmill, R. M., Calvo, J. M., 1986. High A + T content conserved in DNA sequences upstream of leuABCD in Escherichia coli and Salmonella typhimurium. Journal of Bacteriology 166, 1113-1117.

Kornberg, A., Baker, T., 1992. DNA Replication. W.H. Freeman and Company, New york.

Lanzer, M., Bujard, H., 1988. Promoters largely determine the efficiency of repressor action. Proceedings of the National Academy of Sciences 85, 8973-8977.

Leng, F., Amado, L., McMacken, R., 2004. Coupling DNA Supercoiling to Transcription in Defined Protein Systems. Journal of Biological Chemistry 279, 47564-47571.

Leng, F., Chen, B., Dunlap, D. D., 2011. Dividing a supercoiled DNA molecule into two independent topological domains. Proceedings of the National Academy of Sciences 108, 19973-19978.

Leng, F., McMacken, R., 2002. Potent stimulation of transcription-coupled DNA supercoiling by sequence-specific DNA-binding proteins. Proceedings of the National Academy of Sciences 99, 9139-9144.

Lilley, D. M. J., Higgins, C. F., 1991. Local DNA topology and gene expression: the case of the leu-500 promoter. Molecular Microbiology, Blackwell Publishing Ltd. 5, 779-783.

Liu, L. F., Wang, J. C., 1987. Supercoiling of the DNA template during transcription. Proceedings of the National Academy of Sciences 84, 7024-7027.

Lockshon, D., Morris, D. R., 1983. Positively supercoiled plasmid DNA is produced by treatment of Escherichia coli with DNA gyrase inhibitors. Nucleic Acids Research 11, 2999-3017.

Lodge, J. K., Kazic, T., Berg, D. E., 1989. Formation of supercoiling domains in plasmid pBR322. Journal of Bacteriology 171, 2181-2187. 
Lynch, A. S., Wang, J. C., 1993. Anchoring of DNA to the bacterial cytoplasmic membrane through cotranscriptional synthesis of polypeptides encoding membrane proteins or proteins for export: a mechanism of plasmid hypernegative supercoiling in mutants deficient in DNA topoisomerase I. Journal of Bacteriology 175, 1645-1655.

Ma, D., Cook, D. N., Pon, N. G., Hearst, J. E., 1994. Efficient anchoring of RNA polymerase in Escherichia coli during coupled transcription-translation of genes encoding integral inner membrane polypeptides. Journal of Biological Chemistry $269,15362-15370$.

Margolin, P., Zumstein, L., Sternglanz, R., Wang, J. C., 1985. The Escherichia coli supX locus is topA, the structural gene for DNA topoisomerase I. Proceedings of the National Academy of Sciences 82, 5437-5441.

Massé, E., Drolet, M., 1999. Escherichia coli DNA Topoisomerase I Inhibits R-loop Formation by Relaxing Transcription-induced Negative Supercoiling. Journal of Biological Chemistry 274, 16659-16664.

Massé, E., Drolet, M., 1999. Relaxation of Transcription-induced Negative Supercoiling is an Essential Function of Escherichia coli DNA Topoisomerase I. Journal of Biological Chemistry 274, 16654-16658.

McEachern, F., Fisher, L. M., 1989. Regulation of DNA supercoiling in Escherichia coli: Genetic basis of a compensatory mutation in DNA gyrase. FEBS Letters 253, 6770.

Menzel, R., Gellert, M., 1983. Regulation of the genes for E. coli DNA gyrase: Homeostatic control of DNA supercoiling. Cell 34, 105-113.

Mielke, S. P., Fink, W. H., Krishnan, V. V., Gronbech-Jensen, N., Benham, C. J., 2004. Transcription-driven twin supercoiling of a DNA loop: A Brownian dynamics study. The Journal of Chemical Physics 121, 8104-8112.

Mojica, F. J. M., Higgins, C. F., 1996. Localized domains of DNA supercoiling: topological coupling between promoters. Molecular Microbiology 22, 919-928.

Mukai, F. H., Margolin, P., 1963. Analysis of unlinked suppressors of an $0^{\circ}$ mutation in Salmonella. Proc Natl Acad Sci U S A. 50, 140-148.

Ravin, N, V., Ravin, V. K., 1999. Use of a linear multicopy vector based on the minireplicon of temperate coliphage N15 for cloning DNA with abnormal secondary structures. Nucleic Acids Research 27, e13.

Nelson, P., 1999. Transport of torsional stress in DNA. Proceedings of the National Academy of Sciences 96, 14342-14347. 
Pruss, G. J., 1985. DNA topoisomerase I mutants: Increased heterogeneity in linking number and other replicon-dependent changes in DNA supercoiling. Journal of Molecular Biology 185, 51-63.

Pruss, G. J., Drlica, K., 1986. Topoisomerase I mutants: the gene on pBR322 that encodes resistance to tetracycline affects plasmid DNA supercoiling. Proceedings of the National Academy of Sciences 83, 8952-8956.

Pruss, G. J., Drlica, K., 1989. DNA supercoiling and prokaryotic transcription. Cell 56, $521-523$.

Pruss, G. J., Manes, S. H., Drlica, K., 1982. Escherichia coli DNA topoisomerase I mutants: Increased supercoiling is corrected by mutations near gyrase genes. Cell $31,35-42$.

Rahmouni, A. R., Wells, R. D., 1992. Direct evidence for the effect of transcription on local DNA supercoiling in vivo. Journal of Molecular Biology 223, 131-144.

Raji, A., Zabel, D. J., Laufer, C. S., Depew, R. E., 1985. Genetic analysis of mutations that compensate for loss of Escherichia coli DNA topoisomerase I. Journal of Bacteriology 162, 1173-1179.

Ravin, N., Lane, D., 1999. Partition of the Linear Plasmid N15: Interactions of N15 Partition Functions with the sop Locus of the F Plasmid. Journal of Bacteriology 181, 6898-6906.

Ravin, N. V., 2003. Mechanisms of replication and telomere resolution of the linear plasmid prophage N15. FEMS Microbiology Letters 221, 1-6.

Ravin, V., Ravin, N., Casjens, S., Ford, M. E., Hatfull, G. F., Hendrix, R. W., 2000. Genomic sequence and analysis of the atypical temperate bacteriophage N15. Journal of Molecular Biology 299, 53-73.

Richardson, S. M., Higgins, C. F., Lille, y. M., 1984. The genetic control of DNA supercoiling in Salmonella typhimurium. EMBO J 3, 1745-1752.

Richardson, S. M., Higgins, C. F., Lilley, D. M., 1988. DNA supercoiling and the leu-500 promoter mutation of Salmonella typhimurium. EMBO J 7, 1863-1869.

Richter, K., Nessling, M., Lichter, P., 2008. Macromolecular crowding and its potential impact on nuclear function. Biochimica et Biophysica Acta (BBA) - Molecular Cell Research 1783, 2100-2107.

Samul, R., Leng, F., 2007. Transcription-coupled Hypernegative Supercoiling of Plasmid DNA by T7 RNA Polymerase in Escherichia coli Topoisomerase I-Deficient Strains. Journal of Molecular Biology 374, 925-935. 
Snoep, J. L., van der Weijden, C. C., Andersen, H. W., Westerhoff, H. V., Jensen, P. R., 2002. DNA supercoiling in Escherichia coli is under tight and subtle homeostatic control, involving gene-expression and metabolic regulation of both topoisomerase I and DNA gyrase. European Journal of Biochemistry 269, 16621669.

Spirito, F., Bossi, L., 1996. Long-distance effect of downstream transcription on activity of the supercoiling-sensitive leu-500 promoter in a topA mutant of Salmonella typhimurium. J Bacteriol 178, 7129-7137.

Sternglanz, R., DiNardo, S., Voelkel, K. A., Nishimura, Y., Hirota, Y., Becherer, K., Zumstein, L., Wang, J. C., 1981. Mutations in the gene coding for Escherichia coli DNA topoisomerase I affect transcription and transposition. Proceedings of the National Academy of Sciences of the United States of America 78, 27472751.

Stupina, V. A., Wang, J. C., 2004. DNA axial rotation and the merge of oppositely supercoiled DNA domains in Escherichia coli: Effects of DNA bends. Proceedings of the National Academy of Sciences of the United States of America $101,8608-8613$.

Stupina, V. A., Wang, J. C., 2005. Viability of Escherichia coli topA Mutants Lacking DNA Topoisomerase I. Journal of Biological Chemistry 280, 355-360.

Sutcliffe, J. G., 1979. Complete Nucleotide Sequence of the Escherichia coli Plasmid pBR322. Cold Spring Harbor Symposia on Quantitative Biology 43, 77-90.

Tan, J., Shu, L., Wu, H. Y., 1994. Activation of the leu-500 promoter by adjacent transcription. Journal of Bacteriology 176, 1077-1086.

Tomizawa, J., Som, T., 1984. Control of ColE1 plasmid replication: enhancement of binding of RNA I to the primer transcript by the Rom protein. Cell 38, 871-878.

Trucksis, M., Depew, R. E., 1981. Identification and localization of a gene that specifies production of Escherichia coli DNA topoisomerase I. Proc Natl Acad Sci U S A 78, 2164-2168.

Trucksis, M., Golub, E. I., Zabel, D. J., Depew, R. E., 1981. Escherichia coli and Salmonella typhimurium sup $X$ genes specify deoxyribonucleic acid topoisomerase I. J Bacteriol 147, 679-681.

Tsao, Y.-P., Wu, H.-Y., Liu, L. F., 1989. Transcription-driven supercoiling of DNA: Direct biochemical evidence from in vitro studies. Cell 56, 111-118.

Tse-Dinh, Y.-C., 1985. Regulation of the Escherichia coli DNA topoisomerase I gene by DNA supercoiling. Nucleic Acids Research 13, 4751-4763. 
Tse-Dinh, Y.-C., Beran, R. K., 1988. Multiple promoters for transcription of the Escherichia coli DNA topoisomerase I gene and their regulation by DNA supercoiling. Journal of Molecular Biology 202, 735-742.

Vologodskii, A. V., 1992. Topology and physics of circular DNA. CRC Press, Boca Roton.

Wang, J., 1971. Interaction between DNA and an Escherichia coli protein omega. J Mol Biol 55, 523-533.

Wang, J. C., 1996. DNA Topoisomerases. Annual Review of Biochemistry 65, 635-692.

Wang, J. C., 2009. Untangling the Double Helix: DNA Entanglement and the Action of the DNA Topoisomerases. Cold Spring Harbor Laboratory Press, NY.

Wang, J. C., Becherer, K., 1983. Cloning of the gene top $A$ encoding for DNA topoisomerase 1 and the physical mapping of the cysB-topA-trpAregion of Escherichia colt. Nucleic Acids Research 11, 1773-1790.

Wang, J. C., Lynch, A. S., 1993. Transcription and DNA supercoiling. Current Opinion in Genetics \&amp; Development 3, 764-768.

Wang, J. C., Gartenbarg, M, R., 1992. Positive supercoiling of DNA greatly diminishes mRNA synthesis in yeast. Proc Natl Acad Sci U S A 89, 11461-11465.

Wu, H.-Y., Shyy, S., Wang, J. C., Liu, L. F., 1988. Transcription generates positively and negatively supercoiled domains in the template. Cell 53, 433-440.

Wu, H.-Y., Tan, J., Fang, M., 1995. Long-range interaction between two promoters: Activation of the leu-500 promoter by a distant upstream promoter. Cell 82, 445451.

Wu, H., Fang, M., 2003. DNA supercoiling and transcription control: a model from the study of suppression of the leu-500 mutation in Salmonella typhimurium top $A^{-}$ strains. Prog Nucleic Acid Res Mol Biol 73, 43-68.

Zechiedrich, E. L., Khodursky, A. B., Bachellier, S., Schneider, R., Chen, D., Lilley, D. M. J., Cozzarelli, N. R., 2000. Roles of Topoisomerases in Maintaining Steadystate DNA Supercoiling in Escherichia coli. Journal of Biological Chemistry 275, 8103-8113.

Zimmerman, S. B., Minton, A. P., 1993. Macromolecular Crowding: Biochemical, Biophysical, and Physiological Consequences. Annual Review of Biophysics and Biomolecular Structure 22, 27-65. 


\section{Chapter 2: Dependence of transcription-coupled DNA Supercoiling on promoter strength in Escherichia coli topoisomerase I deficient strains}

The work described in this chapter has been published in the Gene (2013) 514(2), 82-90.

\subsection{Abstract}

Transcription by RNA polymerase can induce the formation of hypernegatively supercoiled DNA in vitro and in vivo. This phenomenon has been nicely explained by a "twin-supercoiled-domain" model of transcription where a positively supercoiled domain is generated ahead of the RNA polymerase and a negatively supercoiled domain behind it. In Escherichia coli topA strains, DNA gyrase selectively converts the positively supercoiled domain into negative supercoils to produce hypernegatively supercoiled DNA. In this article, in order to examine whether promoter strength affects transcriptioncoupled DNA supercoiling (TCDS), we developed a two-plasmid system in which a linear, non-supercoiled plasmid was used to express lac repressor constitutively while a circular plasmid was used to gage TCDS in E. coli cells. Using this two-plasmid system, we found that TCDS in top $A$ strains is dependent on promoter strength. We also demonstrated that transcription-coupled hypernegative supercoiling of plasmid DNA did not need the expression of a membrane-insertion protein for strong promoters; however, it might require co-transcriptional synthesis of a polypeptide. Furthermore, we found that for weak promoters the expression of a membrane-insertion tet gene was not sufficient for the production of hypernegatively supercoiled DNA. Our results can be explained by the "twin-supercoiled-domain" model of transcription where the friction force applied to E. coli RNA polymerase plays a critical role in the generation of hypernegatively supercoiled DNA. 


\subsection{Introduction}

DNA supercoiling plays fundamental roles in a number of essential DNA metabolic pathways, such as DNA replication, recombination, and transcription (Bates and Maxwell, 2005; Cozzarelli and Wang, 1990; Wang, 2009). In Escherichia coli, DNA is typically negatively supercoiled. DNA supercoiling status inside E. coli cells is primarily set by counter actions of two DNA topoisomerases, DNA gyrase, and topoisomerase I (Champoux, 2001; Snoep et al., 2002; Wang, 1996; Zechiedrich et al., 2000). Inactivating DNA gyrase or topoisomerase I results in the production of positively (Lockshon and Morris, 1983) or hypernegatively (Pruss, 1985) supercoiled DNA, respectively.

Since the 1980s, it has been demonstrated that transcription by RNA polymerase could introduce supercoils to plasmid DNA templates in vitro and in vivo (Leng and McMacken, 2002; Leng et al., 2004; Lockshon and Morris, 1983; Pruss, 1985; Tsao et al., 1989; Wu et al., 1988). Liu and Wang proposed a "twin-supercoiled-domain" model of transcription to explain how transcription by RNA polymerase is able to supercoil the plasmid DNA templates (Liu and Wang, 1987). This elegant model hypothesizes that a transcribing RNA polymerase becomes increasingly more difficult to rotate around the axis of the DNA double helix as the size of the growing RNA transcript increases. At a critical point, energetically, it is more feasible for the DNA molecule to rotate around its own helix axis to produce a positively supercoiled domain in front of the RNA polymerase and a negatively supercoiled domain behind it. These two transient supercoiled domains may be relaxed by DNA topoisomerases or cancel each other by 
diffusion (Leng and McMacken, 2002; Mielke et al., 2004; Nelson, 1999; Tsao et al., 1989; Wu et al., 1988).

So far, there is substantial experimental evidence to support the "twinsupercoiled-domain" model of transcription (Albert et al., 1996; Cook et al., 1992; Dunaway and Ostrander, 1993; Leng and McMacken, 2002; Lodge et al., 1989; Lynch and Wang, 1993; Ma et al., 1994; Stupina and Wang, 2004; Tsao et al., 1989; Wu et al., 1988). For instance, in E. coli topoisomerase I-deficient (topA) strains, transcription by RNA polymerases is capable of driving the plasmid DNA templates to hypernegatively supercoiled status (Cook et al., 1992; Lodge et al., 1989; Pruss, 1985; Wang and Lynch, 1993). It was shown that transcription-coupled hypernegative supercoiling of plasmid DNA required co-transcriptional synthesis of a membrane-associated protein or polypeptide for plasmid pBR322 and derivatives (Cook et al., 1992; Lodge et al., 1989; Lynch and Wang, 1993; Ma et al., 1994). A possible explanation for this requirement is that co-transcriptional synthesis of a membrane-associated protein or polypeptide substantially increased the friction force against the transcribing RNA polymerase. In this scenario, a significant amount of "twin-supercoiled-domains" is generated. After the positively supercoiled domain is converted into negative supercoils by DNA gyrase, the transcribed DNA templates become hypernegatively supercoiled.

Using a similar approach, we recently demonstrated that transcription by T7 RNA polymerase strikingly stimulated DNA supercoiling; transcription-coupled DNA supercoiling (TCDS) was dependent on the length of RNA transcripts in E. coli topA strains VS111(DE3) and DM800(DE3) (Samul and Leng, 2007). Additionally, we found that hypernegative supercoiling of plasmid DNA by T7 RNA polymerase did not require 
anchoring of DNA to the bacterial cytoplasmic membrane (Samul and Leng, 2007). We attributed these results to the fact that a much stronger $\mathrm{T} 7$ promoter and a much faster $\mathrm{T} 7$ RNA polymerase (comparing with E. coli RNA polymerase (Seidel and Dekker, 2007)) were used in our transcription-supercoiling (T-S) assays. In this case, the "twinsupercoiled-domains" were efficiently generated and, as a result, TCDS did not need transcriptional machinery to couple to translation and membrane-insertion. These results also suggested that promoter strength is important to TCDS in E. coli cells. In order to further study how promoter strength affects the efficiency of TCDS in E. coli topA strains, herein we developed a new two-plasmid system: the first plasmid is a linear plasmid derived from coliphage N15 (Ravin and Ravin, 1999) and was used to express lac repressor constitutively. In addition, the linear plasmids cannot be supercoiled (Deneke et al., 2000) and therefore will not interfere with the supercoiling assays; the second plasmid is a circular plasmid that was used to examine TCDS by E. coli RNA polymerase. Using this unique two-plasmid system, we found that transcription-coupled hypernegative supercoiling of plasmid DNA templates was dependent on promoter strength and did not require the expression of a membrane-insertion protein for strong promoters, which is consistent with our results for T7 RNA polymerase (Samul and Leng, 2007).

\subsection{Methods}

\subsubsection{Materials}

Ethidium bromide, kanamycin, lysozyme, and chloroquine were purchased from Sigma-Aldrich Corp. (St. Louis, MO). Ampicillin and bovine serum albumin (BSA) were 
obtained from Fisher Scientific (Fairlawn, NJ). Tetracycline was purchased from EMI Science (Gibbstown, NJ). Isopropyl- $\beta$-D-thiogalactopyranoside (IPTG) was obtained from Anatrace, Inc. (Maumee, Ohio). All restriction enzymes, T4 DNA ligase, and T4 polynucleotide kinase were bought from New England Biolabs, Inc. (Beverly, MA). Pfu DNA polymerase was purchased from Stratagene, Inc. (La Jolla, CA). All synthetic oligonucleotides used as primers were obtained from MWG-Biotech, Inc. (Huntsville, AL). QIAprep Spin Miniprep Kit, QIAquick Gel Extraction Kit, RNeasy Mini Kit, and QIAquick Nucleotide Removal Kit were bought from QIAGEN, Inc. (Valencia, CA). ThermoScript RT-PCR System plus Platinum ${ }^{\circledR}$ Taq DNA polymerase was purchased from Invitrogen, Inc. (Carlsbad, CA). Power SYBR Green PCR Master Mix was obtained from Applied Biosystems, Inc. (Carlsbad, CA). GFP-Ab2 Mouse Monoclonal Antibody is a product of Thermo Fisher Scientific, Inc. (Fremont, CA). Horseradish peroxidase (HRP)-conjugated anti-mouse antibody was obtained from EMD Biosciences, Inc. (Madison, WI). Supersignal West Pico Chemiluminescent Substrate was bought from Thermo Scientific, Inc. (Rockford, IL).

\subsubsection{Bacterial strains and plasmids}

E. coli strain VS111 [F-LAM-rph-I $\triangle$ topA] as described in Stupina and Wang (2005) was obtained from the Coli Genetic Stock Collection/E. coli Genetic Resource Center (CGSC) at Yale University. E. coli strain DM800 [F-A(topAcysB)204 arcA13 gyrB225] was kindly provided by Dr. Marc Drolet at Universite de Montreal. All linear plasmids were derived from coliphage N15-based, linear plasmid pG591 (Ravin and Ravin, 1999), which was kindly provided by Dr. Nikolai V. Ravin at Centre 
"Bioengineering" RAS, Russia. Plasmid pZXD4 was constructed by inserting a $33 \mathrm{bp}$ synthetic DNA fragment containing a multiple cloning site into the unique BglII site of pG591. Plasmid pZXD51 (Figure 2.1A) was constructed in two steps. First, promoter $\mathrm{P}_{\text {laci }}$ controlling the expression of LacI in pET-30a $(+)$ was mutated to the strong promoter $\mathrm{P}_{\text {lacl }}{ }^{\mathrm{q}}$ using PCR-based, site-directed mutagenesis. Then the laci gene including promoter $\mathrm{P}_{\text {laci }}{ }^{\mathrm{q}}$ was amplified by PCR and inserted between NheI and AflII sites of pZXD4 to generate plasmid pZXD51. E. coli strains carrying pZXD51 express LacI constitutively.

All circular plasmids constructed in this work were derived from plasmid pBR322. Plasmid pBR322se1 was constructed by converting the -35 region of promoter $\mathrm{P}_{\text {anti-tet }}$ into an XhoI site using PCR based, site-directed mutagenesis. In this case, promoter $\mathrm{P}_{\text {anti- }}$ tet was removed. Plasmid pBR322se2 was created after a Shine-Dalgarno sequence (5'AAGGAGG-3') was inserted to the upstream region of the open reading frame of the tet gene. Plasmid pBR322se3 was made by introducing KpnI and SacI sites into the plasmid surrounding the weak promoter $\mathrm{P}_{\text {bla. }}$. In this scenario, promoter $\mathrm{P}_{\text {bla }}$ may easily be replaced by other promoters. Plasmid pZXD7 was created by removing a Dcm sequence of pBR322se3 associated with the unique MscI recognition site using PCR-based, sitedirected mutagenesis. Plasmid pZXD8 was generated after a BglII site was inserted to the downstream region of the tet gene of plasmid pZXD7. A 37 bp synthetic deoxyoligonucleotide containing a multiple cloning site was then inserted into the unique KpnI site of pZXD8 to yield plasmid pZXD9. Plasmid pZXD11 was constructed after a 36 bp synthetic DNA fragment containing a T7 promoter was inserted into the EcoRI and XhoI sites to replace promoter $\mathrm{P}_{\text {tet. }}$ Plasmid pZXD12 was made after a 64 bp synthetic DNA fragment containing an inactive promoter $\mathrm{P}_{\text {leu-500 }}$ was inserted into the HindIII and 
KpnI sites of pZXD11. Plasmid pZXD14 was created when an 813 bp DNA fragment of pLUC1 carrying four tandem copies of rrnB $\mathrm{T} 1$ transcription terminators (Leng and McMacken, 2002) was inserted into the unique MscI site of pZXD12. Plasmids pZXD44, $50,49,47$, and 48 were constructed by replacing the T7 promoter with E. coli promoters $\mathrm{P}_{\mathrm{T7A} / \mathrm{O} 4}, \mathrm{P}_{\mathrm{tac}}, \mathrm{P}_{\text {lacUV5}}, \mathrm{P}_{\mathrm{lac}}$, and $\mathrm{P}_{\mathrm{lac} 8}$, respectively, between the EcoRI and XhoI sites of pZXD14.

Plasmids pZXD57, 58, 56, 55, and 54, each carrying a GFPuv gene under the control of E. coli promoters $\mathrm{P}_{\mathrm{T} 7 \mathrm{~A} 1 / 04}, \mathrm{P}_{\mathrm{tac}}, \mathrm{P}_{\text {lacUV55 }}, \mathrm{P}_{\text {lac }}$, and $\mathrm{P}_{\text {lacL8}}$, respectively, were constructed in a few steps. First, an AgeI site was introduced between the ShineDalgarno sequence and the start codon of the tet gene of plasmid pXZD48 to generate plasmid pXZD52 using PCR-based, site-directed mutagenesis. Second, the unique XhoI site in the GFPuv gene of plasmid pGFPuv (Stratagene, Inc., La Jolla, CA) was silently removed without changing the open reading frame of GFPuv gene using PCR-based, sitedirected mutagenesis to yield plasmid pZXD53. Third, a 737 bp PCR product containing the GFPuv gene was cloned into the AgeI and BsmI sites of plasmid pZXD52 to produce plasmid pZXD54. In this case, the tet gene was replaced by the GFPuv gene under the control of $E$. coli promoter $\mathrm{P}_{\text {lacL8. }}$ Plasmids pZXD57, 58, 56, and 55 were constructed by replacing the E. coli promoter $\mathrm{P}_{\text {lacL8 }}$ with promoters $\mathrm{P}_{\mathrm{T} 7 \mathrm{~A} 1 / 04}, \mathrm{P}_{\mathrm{tac}}, \mathrm{P}_{\mathrm{lacUV}}$, and $\mathrm{P}_{\text {lac }}$ between the EcoRI and XhoI sites of pZXD54, respectively.

Plasmid pZXD59 was created when a 735 bp DNA fragment containing the GFPuv gene in reverse orientation amplified from plasmid pZXD53 was inserted into the AgeI and BsmI sites of plasmid pZXD57. In this scenario, E. coli cells carrying pZXD59 are not able to express GFPuv protein after IPTG induction. Plasmids pZXD60 and 61 
were produced when lac $Z$ gene in the forward and reverse orientations was amplified from plasmid $\mathrm{pYC} / \mathrm{CT} / \mathrm{lacZ}$ and inserted into the AgeI and BsmI sites of pZXD57. In this case, E. coli cells carrying pZXD60 are able to express $\beta$-galactosidase after IPTG induction. However, E. coli cells carrying pZXD61 are not able to express $\beta$ galactosidase after IPTG induction. Plasmid pZXD62 was constructed after a $2.3 \mathrm{~kb}$ PCR fragment of lacZ gene was inserted between the HindIII and KpnI sites of pZXD57. Plasmid pZXD63 was produced after a $1.8 \mathrm{~kb}$ PCR fragment of lacZ gene was inserted into the HindIII and KpnI sites of pZXD44. Plasmids pZXD60A and pZXD63A were constructed where the start codon (ATG) of the lacZ and tet genes were, respectively, mutated to the stop codon TAG using PCR-based, site-directed mutagenesis. In this scenario, E. coli cells carrying plasmids pZXD60A and 63A are not able to express $\beta$ galactosidase and tetracycline resistance protein, respectively. Please notice that plasmids pZXD60, 61, 62, 63, 60A, and 63A have the same size, i.e., 7055 bp.

\subsubsection{In vivo T-S assays}

Escherichia coli cells carrying different plasmids were grown overnight in LB containing $50 \mu \mathrm{g} / \mathrm{ml}$ of ampicillin and kanamycin. The overnight culture was then diluted (1:100) in fresh LB containing $50 \mu \mathrm{g} / \mathrm{ml}$ of ampicillin and kanamycin, and grown until optical density of the cells at $600 \mathrm{~nm}$ reached approximately 0.5. IPTG (final concentration, $1 \mathrm{mM}$ ) was added to the cell culture to initiate transcription by different promoters, i.e., $\mathrm{P}_{\mathrm{T} 7 \mathrm{~A} / \mathrm{O} 4}, \mathrm{P}_{\mathrm{tac}}, \mathrm{P}_{\mathrm{lac} U V 5}, \mathrm{P}_{\text {lac }}$, and $\mathrm{P}_{\text {lacL8 }}$. Plasmid DNA was purified using QIAGEN Miniprep Kit. The topological state of each DNA preparation was analyzed by electrophoresis in a $1 \%$ agarose gel in $1 \times$ TAE buffer ( $40 \mathrm{mM}$ Tris-acetate, $1 \mathrm{mM}$ EDTA, and $\mathrm{pH}$ 7.8) containing $2.5 \mu \mathrm{g} / \mathrm{ml}$ of chloroquine. After electrophoresis, agarose gels were 
stained with ethidium bromide, destained, and photographed under UV light. The net intensity of DNA topoisomers was determined using KODAK 1D Image Analysis Software. The percentage of hypernegative DNA supercoils was calculated by dividing the intensity of the hypernegatively supercoiled DNA band by the total intensity of all DNA topoisomers.

\subsubsection{Western blotting experiments}

Western blotting experiments were used to verify the expression of GFPuv protein in E. coli topA strain VS111 after $1 \mathrm{mM}$ of IPTG induction. Total protein purified from E. coli cells was analyzed by electrophoresis in a $15 \%$ SDS-PAGE and electrophoretically transferred to a $0.45 \mu \mathrm{m}$ nitrocellulose membrane. The membrane blot was then blocked with a solution containing 5\% nonfat skim milk in TBST (50mM Tris$\mathrm{HCl}, \mathrm{pH} 8.0,138 \mathrm{mM} \mathrm{NaCl}, 2.7 \mathrm{mM} \mathrm{KCl}$, and $0.05 \%$ Tween-20) for $45 \mathrm{~min}$ at room temperature and incubated with the primary antibody, GFP Ab-2 mouse monoclonal antibody, diluted 1:1000 in TBST solution overnight at $4{ }^{\circ} \mathrm{C}$. After the overnight incubation, the membrane blot was washed three times with TBST, blocked with a solution containing 5\% nonfat skim milk in TBST for $15 \mathrm{~min}$ at room temperature, and then incubated for $1 \mathrm{~h}$ with an HRP-conjugated anti-mouse IgG secondary antibody (diluted 1:5000) at room temperature. The immunoreactive GFPuv protein was detected with Supersignal West Pico Chemiluminescent Substrate.

\subsubsection{RNA isolation, cDNA synthesis, and polymerase chain reaction (PCR)}

Total RNA was isolated from E. coli cells using QIAGEN RNeasy Kit as described by the manufacturer. To determine the integrity of the total RNA samples, $16 \mathrm{~S}$ 
and $23 \mathrm{~S}$ rRNA were resolved by electrophoresis in a $1.2 \%$ agarose gel in $1 \times$ MOPS buffer containing formaldehyde (20 mM MOPS, $8 \mathrm{mM}$ sodium acetate, $1 \mathrm{mM}$ EDTA, 1\% formaldehyde, and $\mathrm{pH}$ 7.0). After electrophoresis, agarose gels were stained with ethidium bromide, destained, and photographed under UV light. cDNA were synthesized from total RNA samples using ThermoScript RT-PCR System. $2.76 \mu \mathrm{g}$ of RNA was mixed with a sequence-specific primer (final concentration, $0.5 \mu \mathrm{M}$ ) or random hexamer primers $(50 \mathrm{ng} / \mu \mathrm{l})$ and four deoxynucleotide triphosphates (dNTPs; final concentration, 1 $\mathrm{mM})$. The mixtures were incubated at $65^{\circ} \mathrm{C}$ for $5 \mathrm{~min}$ and transferred to ice for another 5 min to remove secondary structures of RNA. The denatured RNA samples were then mixed with $1 \times$ cDNA synthesis buffer with a total volume of $20 \mu$ containing $5 \mathrm{mM}$ DTT, 40 units of RNaseOut, and 15 units of ThermoScript Reverse Transcriptase, and incubated at $60{ }^{\circ} \mathrm{C}$ for $1 \mathrm{~h}$ to synthesize cDNA. The cDNA synthesis mixtures were transferred to an $85^{\circ} \mathrm{C}$ water bath for 5 min to terminate the reactions. After the synthesis step, 2 units of RNase $\mathrm{H}$ were added to the reaction mixtures and incubated at $37^{\circ} \mathrm{C}$ for 20 min to remove the RNA templates.

PCR reactions were carried out using cDNA samples synthesized as described above. A $50 \mu \mathrm{PCR}$ reaction contains $1 \times$ PCR Buffer without $\mathrm{Mg}^{2+}, 1.58 \mathrm{mM} \mathrm{MgCl}_{2}, 0.2$ mM dNTPs, $0.2 \mu \mathrm{M}$ of each primer (Table 2.1), $0.5 \mu \mathrm{l}$ cDNA, and 2 units of Platinum Taq DNA polymerase. The reactions started at $94{ }^{\circ} \mathrm{C}$ for $2 \mathrm{~min}$, proceeded for 16 cycles of $94{ }^{\circ} \mathrm{C}$ for $30 \mathrm{~s}, 55^{\circ} \mathrm{C}$ for $30 \mathrm{~s}$ and $72{ }^{\circ} \mathrm{C}$ for $1 \mathrm{~min}$, and terminated at $72{ }^{\circ} \mathrm{C}$ for $10 \mathrm{~min}$. Subsequently, the PCR products were analyzed by electrophoresis in a $12 \%$ polyacrylamide gel in $1 \times \mathrm{TAE}$ buffer. After electrophoresis, polyacrylamide gels were 
stained with ethidium bromide or SYBR gold, destained, and photographed under UV light.

\subsubsection{Real-time PCR Assays}

Real-time PCR assays were carried out using MiniOpticon Real-time PCR system (Bio-Rad, Hercules, CA). A $20 \mu \mathrm{l}$ reaction contains $0.5 \mu \mathrm{l}$ cDNA, $0.5 \mu \mathrm{M}$ of each primer (Table 2.1), and $10 \mu \mathrm{l}$ of Power SYBR Green PCR Master Mix (2×). The reaction started at $95{ }^{\circ} \mathrm{C}$ for $10 \mathrm{~min}$ and continued for 40 cycles at $95{ }^{\circ} \mathrm{C}$ for $15 \mathrm{~s}$ and $60{ }^{\circ} \mathrm{C}$ for $1 \mathrm{~min}$. The $\mathrm{C}_{\mathrm{q}}$ values (quantification cycle values) were calculated from the exponential phase of each PCR amplification reaction as recommended by the manufacturer.

\subsection{Results and Discussion}

\subsubsection{Establish an IPTG-inducible, two-plasmid system to study TCDS in $E$. coli top $A$ strains}

In this study we established a two-plasmid system to examine effects of different factors on TCDS in E. coli topA strains VS111 and DM800. The first plasmid pZXD51 (Figure 2.1A) is a linear plasmid derived from coliphage N15-based, low-copy-number plasmid pG591 (Ravin and Ravin, 1999) where a laci gene was cloned under the control

of the strong $\mathrm{P}_{\text {laci }}{ }^{\mathrm{q}}$ promoter. In this case, E. coli strains carrying pZXD51 produce $\sim 3000$ molecules of LacI per cell constitutively (Lutz and Bujard, 1997). The second plasmid is a circular plasmid that serves as a supercoiling-reporter (Figure 2.1B). Here we constructed a series of plasmid DNA templates that contain different strengths of $E$. coli promoters (Lanzer and Bujard, 1988), i.e., $\mathrm{P}_{\mathrm{T7A} / \mathrm{O} 4}, \mathrm{P}_{\text {tac }}, \mathrm{P}_{\text {lacUV55 }}, \mathrm{P}_{\text {lac }}$, and $\mathrm{P}_{\text {lacL8 }}$ (Figure 2.1C), to examine effects of promoter strength on TCDS by E. coli RNA polymerase. 
Since each promoter region contains a lac Ol operator (Figure 2.1C), transcription initiated from these promoters is IPTG-inducible in E. coli cells overexpressing LacI, e.g., E. coli cells carrying the linear plasmid pZXD51. We also added a set of Rhoindependent, rrnB $\mathrm{T} 1$ transcription terminators to each plasmid. The presence of multiple rrnB $\mathrm{T} 1$ terminators enabled us to restrict transcription to selected regions of supercoiling-reporter plasmids and to modulate the length of RNA transcripts produced. Since supercoiling-reporter plasmids have a different DNA replication origin (pMB1 origin), they can co-exist with the linear plasmid pZXD51 in E. coli cells. Indeed, these two types of plasmids were able to simultaneously transform E. coli topA strains VS111 and DM800. Additionally, as mentioned above, an advantage of using a linear plasmid to express LacI is that linear plasmids cannot be supercoiled (Deneke et al., 2000) and, as a result, will not interfere with the supercoiling assays. In this case, this new system will be ideal for our in vivo supercoiling studies. Plasmids constructed in this study are summarized in Figure 2.1 and Table 2.2.

\subsubsection{Transcription-coupled hypernegative supercoiling of plasmid DNA is dependent on promoter strength}

Having established the two-plasmid system, we proceeded to examine whether TCDS is dependent on promoter strength after IPTG induction. As mentioned above, we simultaneously introduced the linear plasmid pZXD51 and a supercoiling-reporter plasmid into E. coli topA strains VS111 and DM800. Since previous studies showed that hypernegative supercoiling of plasmid pBR322 and its derivatives is dependent on the expression of the co-transcription and translation of membrane-associated tet gene (Cook 
et al., 1992; Lodge et al., 1989; Lynch and Wang, 1993; Ma et al., 1994; Pruss, 1985; Pruss and Drlica, 1986; Stupina and Wang, 2005), we decided to use a set of five supercoiling-reporter plasmids that carry a tet gene under the control of an IPTGinducible promoter with different strengths, i.e., promoters $\mathrm{P}_{\mathrm{T} 7 \mathrm{~A} 1 / 04}, \mathrm{P}_{\text {tac }}, \mathrm{P}_{\text {lacUV55 }}, \mathrm{P}_{\text {lac }}$, and

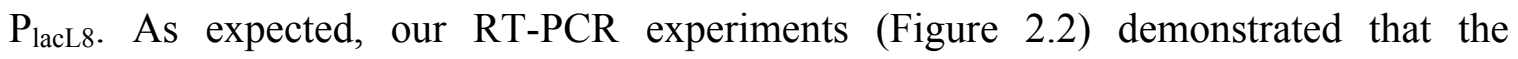
transcription level of E. coli strains harboring different plasmids after IPTG induction is correlated with promoter strength in vivo (Lanzer and Bujard, 1988). Interestingly, E. coli cells carrying plasmids pZXD44 and 50 were able to grow on agar plates containing 10 $\mu \mathrm{g} / \mathrm{ml}$ of tetracycline even in the absence of IPTG (Figure 2.7A). This resistance is most likely due to the leaky expression of the tetracycline resistance protein from the strong $\mathrm{P}_{\mathrm{T} 7 \mathrm{~A} 1 / 04}$ and $\mathrm{P}_{\text {tac }}$ promoters, since pZXD44 and 50 contain $\mathrm{P}_{\mathrm{T} 7 \mathrm{~A} 1 / \mathrm{O} 4}$ and $\mathrm{P}_{\text {tac }}$, respectively. However, only E. coli cells carrying plasmids pZXD50 and 49 were able to grow on agar plates containing $10 \mu \mathrm{g} / \mathrm{ml}$ of tetracycline and $1 \mathrm{mM}$ of IPTG (Figure 2.7B). As demonstrated previously, overexpression of tetracycline resistance protein results in cell death (Eckert and Beck, 1989), which is likely the reason for E. coli cells harboring plasmid pZXD44 carrying the strong $\mathrm{P}_{\mathrm{T} 7 \mathrm{~A} 1 / 04}$ promoter being unable to grow on agar plates in the presence of $1 \mathrm{mM}$ of IPTG. Indeed, our results showed that IPTG was able to inhibit cell growth for E. coli strains VS111 and MG1655 harboring plasmid pZXD44 (Figure 2.7C and D). Because promoters $\mathrm{P}_{\mathrm{lac}}$ and $\mathrm{P}_{\mathrm{lacL} 8}$ are too weak, E. coli cells carrying plasmids pZXD47 and 48 could not produce enough tetracycline resistance protein to overcome the antimicrobial activities of tetracycline.

We next determined the topological status of the set of five supercoiling-reporter plasmids pZXD44, 50, 49, 47, and 48 in E. coli topA strain VS111 harboring the linear 
plasmid pZXD51. Figure 2.3 shows the results. Before IPTG induction, plasmid pZXD44, which carries a strong $\mathrm{P}_{\mathrm{T} 7 \mathrm{~A} / \mathrm{O} 4}$ promoter, had a superhelical density, $\sigma$, of approximately -0.06 to -0.07 (Figure $2.3 \mathrm{~A}$ and $\mathrm{B}$, lane 1). In the presence of the DNA intercalator chloroquine $(2.5 \mu \mathrm{g} / \mathrm{ml})$, this plasmid migrated during agarose gel electrophoresis as if it contained a few negative supercoils. After IPTG induction, as expected, some topoisomers quickly became hypernegatively supercoiled (estimated $\sigma<-0.09$; hypernegatively supercoiled DNA is the fastest moving band in the gels where DNA topoisomers are no longer resolvable under our experimental conditions): the amount of hypernegatively supercoiled DNA was dependent on the IPTG concentration added to the cell culture (Figure 2.3A and 2.8) and the induction time (Figure 2.3B and 2.8). These results clearly demonstrated that the induction of expression of the membrane-insertion tet gene under the control of the strong $\mathrm{P}_{\mathrm{T} 7 \mathrm{~A} 1 / 04}$ promoter was able to drive the formation of hypernegatively supercoiled DNA, which is consistent with previous published results (Cook et al., 1992; Lynch and Wang, 1993; Pruss, 1985). Similar results were obtained for plasmids pZXD50 and 49 which carry $\mathrm{P}_{\text {tac }}$ and $\mathrm{P}_{\text {lacUv5 }}$, respectively (Figure 2.3C and 2.8). However, to our surprise, IPTG was not able to induce the production of hypernegatively supercoiled DNA for plasmids pZXD47 and 48, which harbor the weak promoters, $\mathrm{P}_{\text {lac }}$ and $\mathrm{P}_{\text {lacL8}}$, respectively (lanes 4 and 5 of Figure 2.3C). These results demonstrated that the expression of a membrane-insertion tet gene is not sufficient for the production of hypernegatively supercoiled DNA. Intriguingly, our results showed that transcription-coupled hypernegative supercoiling of plasmid DNA is dependent on promoter strength: the stronger the promoter, the more hypernegatively-supercoiled DNA 
produced (Figure 2.3C and D). Similar results were also obtained using E. coli topA strain $D M 800$ as the host strain (Figure 2.8G).

\subsubsection{Transcription-coupled hypernegative supercoiling of plasmid DNA in E. coli topA strains did not require the expression of a membrane-insertion protein for strong promoters}

As mentioned above, we recently found that hypernegative supercoiling of plasmid DNA by T7 RNA polymerase did not require anchoring of DNA to bacterial cytoplasmic membrane (Samul and Leng, 2007). Thus, we decided to examine whether TCDS by E. coli RNA polymerase in E. coli topA strains VS111 and DM800 requires anchoring of DNA to bacterial cytoplasmic membrane through co-transcriptional synthesis of polypeptides encoding membrane proteins in this new two-plasmid system. Our results showed that, for strong promoters, TCDS did not require anchoring of DNA to bacterial cytoplasmic membrane through the expression of a membrane-insertion protein.

We first constructed a set of five supercoiling-reporter plasmids, pZXD57, 58, 56, 55 , and 54 that carry a cytosolic green fluorescence protein UV (GFPuv) gene under the control of IPTG-inducible promoters with different strengths, i.e., promoters $\mathrm{P}_{\mathrm{T} 7 \mathrm{~A} 1 / 04}, \mathrm{P}_{\mathrm{tac}}$, $\mathrm{P}_{\text {lacUv5, }} \mathrm{P}_{\text {lac }}$, and $\mathrm{P}_{\text {lacL8 }}$ (Figure 2.9 and Table 2.2). These plasmids were introduced to $E$. coli topA strains VS111 and DM800 that also harbor the linear plasmid pZXD51. As expected, after IPTG induction, GFPuv gene products in E. coli strains harboring different plasmids at transcription and expression levels were correlated with promoter strength (Figure 2.10). Interestingly and also as expected, IPTG was able to induce the 
generation of hypernegatively supercoiled DNA for plasmid pZXD57 that carries a strong $\mathrm{P}_{\mathrm{T} 7 \mathrm{~A} / \mathrm{O} 4}$ promoter (Figure 2.4). These results suggest that the expression of a cytosolic GFPuv protein was sufficient to induce the production of hypernegatively supercoiled DNA although the amount of generating hypernegatively supercoiled DNA was lower than that for plasmid pZXD44 (compare Figure 2.3A and 2.4A; also compare Figure $2.8 \mathrm{~F}$ and $2.4 \mathrm{C}$ ). Consistent with above described results, transcription-coupled hypernegative supercoiling of plasmid DNA for this set of five supercoiling-reporter plasmids, i.e., pZXD57, 58, 56, 55, and 54, was also dependent on promoter strength (Figure 2.4B and D). Similar results were obtained for plasmids by using E. coli topA strain $D M 800$ as the host strain (data not shown).

In order to further study transcription-coupled hypernegative supercoiling of plasmid DNA in our two-plasmid system, we next constructed six supercoiling-reporter plasmids of identical size which also carry a strong, IPTG-inducible $\mathrm{P}_{\mathrm{T} 7 \mathrm{~A} 1 / 04}$ promoter controlling the expression of different genes (Figure 2.11 and Table 2.2). Plasmid pZXD60 carries a lacZ gene under the control of $\mathrm{P}_{\mathrm{T} 7 \mathrm{~A} 1 / 04}$. E. coli cells carrying pZXD60 are able to overexpress $\beta$-galactosidase after IPTG induction. Plasmid pZXD60A is identical with pZXD60 except the start codon (ATG) of lacZ was mutated to the stop codon TAG (amber mutation). In this case, IPTG is not able to induce the expression of $\beta$-galactosidase for E. coli cells harboring pZXD60A although the transcripts from both plasmids should be almost identical. Plasmid pZXD61 contains a lacZ gene in the reverse orientation, which cannot direct the expression of $\beta$-galactosidase. Plasmid pZXD62 carries a GFPuv gene under the control of $\mathrm{P}_{\mathrm{T} 7 \mathrm{~A} 1 / 04}$, which is able to direct the overexpression of GFPuv protein after IPTG induction. Plasmids pZXD63 and 63A are 
identical except for the start codon of tet gene. pZXD63 carries a tet gene under the control of $\mathrm{P}_{\mathrm{T} 7 \mathrm{~A} 1 / 04}$ and is able to direct the overexpression of membrane insertion, tetracycline resistance protein. pZXD63A, however, has an amber mutation in the start codon of the tet gene (ATG to TAG). In this scenario, E. coli cells containing pZXD63A are not able to express tetracycline resistance protein. These six plasmids were transformed into E. coli topA strain VS111 carrying the linear plasmid pZXD51 and their superhelical states were examined after IPTG induction. Figure 2.5 shows the results of these in vivo T-S assays. As expected, IPTG was able to induce the production of hypernegatively supercoiled DNA for plasmids pZXD60, 62, and 63 which express $\beta$ galactosidase, GFPuv protein, and tetracycline resistance protein, respectively (Figure 2.5A, B, and C; Figure 2.12A). Interestingly, our results showed that IPTG was not able to induce the generation of hypernegatively supercoiled DNA for plasmids pZXD60A, 61, and 63A although transcription added a few negative supercoils to these plasmids (Figure 2.5D, E, and F). Since plasmids pZXD60A, 61, and 63A are not able to direct the expression of a polypeptide after IPTG induction, although each plasmid carries a strong $\mathrm{P}_{\mathrm{T} 7 \mathrm{~A} 1 / 04}$ promoter, these results suggest that the co-transcriptional synthesis of a protein is able to facilitate the generation of hypernegatively supercoiled DNA. Nevertheless, a close inspection of these gel images revealed that transcription added 5 to 6 negative supercoils to plasmids pZXD60A and 63A, and only 2 supercoils to pZXD61.We examined the DNA sequences of these plasmid DNA templates and found a downstream open reading frame for both $\mathrm{pZXD60A}$ and pZXD63A but not for pZXD61. Although both open reading frames do not contain a SD sequence, it is possible that they are still able to direct the synthesis of a polypeptide with low efficiency. These downstream open 
reading frames may be the reason for the topological difference among these DNA templates. Alternatively, the different amounts of friction torque caused by various mRNA secondary structures may also result in the topological difference. Similar results were also obtained when E. coli topA strain DM800 was used as the host strain (Figure 2.12B).

It has been demonstrated that the stability of $E$. coli mRNA was strongly affected by their association with ribosomes and ribosome-free mRNA was rapidly degraded in vivo (Deana and Belasco, 2005; Nilsson et al., 1987; Pedersen et al., 2011). Therefore, we decided to examine whether transcription-coupled hypernegative supercoiling of DNA in the new two-plasmid system is correlated with the stability of mRNA produced by these plasmids after IPTG induction. Figure 2.6 shows the results of our RT-PCR experiments. E. coli cells harboring plasmids pZXD60, 62 and 63, which are able to direct the overexpression of a polypeptide, i.e., $\beta$-galactosidase, GFPuv protein, and tetracycline resistance protein, respectively, produced almost the same amount of mRNA after $10 \mathrm{~min}$ of IPTG induction (compare lanes 1 to 3 of Figure 2.6A), suggesting that mRNA of the lacZ, GFPuv, and tet genes had similar stability. The introduction of an amber mutation to the start codon of lac $Z$ and tet genes or reversing the orientation of the open reading frame of lacZ and GFPuv gene greatly reduced the stability of the RNA transcripts (Figure 2.6 and 2.13). Coincidently, transcription was not able to drive these plasmids into hypernegatively supercoiled status (Figure $2.5 \mathrm{D}, \mathrm{E}$, and F). These results suggest that transcription-coupled hypernegative supercoiling of DNA is related to the stability of mRNA produced by these plasmids after IPTG induction. 


\subsection{Conclusions}

In this article, we have presented strong evidence demonstrating that transcription-coupled hypernegative supercoiling of plasmid DNA in E. coli topA strains is dependent on promoter strength, a functional property that has not been revealed previously. Not only did we show that transcription-coupled hypernegative supercoiling of plasmids carrying a tet gene encoding a membrane-insertion protein required a strong promoter (Figure 2.3 and 2.8), but also we demonstrated that transcription from strong promoters, such as $\mathrm{P}_{\mathrm{T} 7 \mathrm{~A} 1 / \mathrm{O} 4}$ and $\mathrm{P}_{\text {tac }}$, was able to induce plasmid DNA templates into hypernegatively supercoiled status for those harboring a GFPuv or a lacZ gene encoding a cytosolic protein in E. coli topA strains VS111 and DM800 (Figure 2.4, 2.5, and 2.12). Transcription from weak promoters, such as $\mathrm{P}_{\text {lac }}$ and $\mathrm{P}_{\text {lacL8, }}$, however, was not able to induce topological changes to plasmids carrying either a membrane-associated tet gene (Figure 2.3 and 2.8) or a cytosolic-associated gene, such as GFPuv or lacZ (Figure 2.4). Since promoter strength is correlated with transcription initiation (Brunner and Bujard, 1987; Lutz et al., 2001; McClure, 1985; Saecker et al., 2011), these results suggest that transcription initiation plays a critical role in TCDS in E. coli cells. However, our results also showed that transcription initiation alone was not capable of inducing plasmid DNA templates into hypernegatively supercoiled status. For instance, transcription from the strong $\mathrm{P}_{\mathrm{T} 7 \mathrm{~A} 1 / \mathrm{O} 4}$ promoter was not able to induce plasmids pZXD60A, 61, and 63A into hypernegatively supercoiled status although transcription added a few supercoils to these plasmids after IPTG induction (Figure 2.5D, E, and F). Nevertheless, our results are consistent with the "twin-supercoiled-domain" model of transcription (Liu and Wang, 1987) (please see below for more discussion). 
In this study, we also showed that, for strong promoters, transcription-coupled hypernegative supercoiling of plasmid DNA in E. coli topA strains did not need the expression of a membrane-insertion protein although it required co-transcriptional synthesis of a polypeptide (Figure 2.4, 2.5, and 2.12). These results are consistent with our previously published results for T7 RNA polymerase where the strong T7 RNA polymerase efficiently drove plasmid DNA templates to hypernegatively supercoiled status even when the transcriptional machinery did not couple to translation and membrane insertion (Samul and Leng, 2007). We noticed that these results appear inconsistent with the previously published results showing that plasmid hypernegative supercoiling by E. coli RNA polymerase required the anchoring or insertion of the coupled transcription-translation complex into the cytoplasmic membrane (Cook et al., 1992; Lodge et al., 1989; Lynch and Wang, 1993; Ma et al., 1994; Pruss, 1985; Pruss and Drlica, 1986; Stupina and Wang, 2005). However, a careful analysis showed that both situations can be explained by the "twin-supercoiled-domain" model of transcription where the friction force (Liu and Wang, 1987) applied to E. coli RNA polymerase is different for promoters with different strengths. Under our experimental conditions, weak promoters with very low rates of transcription initiation might not lead to the formation of an active transcriptional ensemble including a transcribing RNA polymerase, a newly transcribed RNA, the associated ribosomes, and a newly generated polypeptide for most plasmids, which are not capable of generating sufficient friction force on E. coli RNA polymerase to produce the "twin-supercoiled-domains" on plasmids. In this case, TCDS is negligible. For example, recent studies showed that a synthetic weak promoter $\mathrm{P}_{\text {lar }}$, a derivative of $\mathrm{P}_{\text {lac, }}$, only produced 4 RNAs on average in $1 \mathrm{~h}$ in $E$. coli cells after maximum 
induction (Golding et al., 2005; Kandhavelu et al., 2011). For most times, there was no transcription initiation from $\mathrm{P}_{\text {lar }}$ promoter (Kandhavelu et al., 2011). Since DNA gyrase is also limited in E. coli cells (Taniguchi et al., 2010), the chance for weak promoters to drive the plasmid DNA templates to hypernegatively supercoiled status is low. Promoters with moderate strength, such as the $\mathrm{P}_{\text {tet }}$ promoter (Stuber and Bujard, 1981), may be able to generate one or two transcriptional ensembles per plasmid. Because the transcription elongation rate of E. coli RNA polymerase is relatively low (Golding and Cox, 2004; Uptain et al., 1997), it is possible that transcription alone may not be able to generate enough friction torque to fully prevent $E$. coli RNA polymerase from rotating against the DNA double helix and therefore cannot induce the formation of significant amounts of localized supercoiled domains. In this case, in order to generate "twin-supercoileddomains," the transcriptional ensemble has to anchor to the bacterial cytoplasmic membrane through co-transcriptional synthesis of polypeptide encoding membrane proteins to maximize friction resistance. This interpretation explains why TCDS for plasmid pBR322 and its derivatives carrying the $\mathrm{P}_{\text {tet }}$ promoter depends on the expression of a membrane-insertion tetracycline resistance protein in E. coli topA strains (Cook et al., 1992; Lodge et al., 1989; Lynch and Wang, 1993; Ma et al., 1994; Pruss, 1985; Pruss and Drlica, 1986; Stupina and Wang, 2005). For strong promoters, such as $\mathrm{P}_{\mathrm{T} 7 \mathrm{~A} 1 / 04}$ and $\mathrm{P}_{\mathrm{tac}}, E$. coli RNA polymerase is able to rapidly initiate transcription from them (Brunner and Bujard, 1987; Lanzer and Bujard, 1988). Therefore, each plasmid may have multiple RNA polymerases (more than two RNA polymerases) simultaneously transcribing along the DNA template. It is possible that the friction force against multiple transcribing RNA polymerases is significantly increased and sufficient to cause the formation of the "twin- 
supercoiled-domains." In this scenario, transcription-coupled hypernegative supercoiling of plasmid DNA did not need the expression of a membrane-insertion protein. Regardless, our results showed that co-transcriptional synthesis of a polypeptide is still required for the formation of hypernegative supercoiling of plasmid DNA in E. coli topA strains (Figure 2.5). There are two possibilities for this requirement. The first possibility is that co-transcriptional synthesis of a polypeptide significantly increases the size of a transcriptional ensemble (including a transcribing RNA polymerase, the newly synthesized RNA transcript, the associated ribosomes, and the newly synthesized polypeptides) and therefore increases the friction torque against the transcription ensemble, which prevents or retards the transcribing RNA polymerase from rotating around the DNA double helix and helps generate the "twin-supercoiled-domains." If this explanation is correct, anchoring of plasmid DNA to bacterial cytoplasmic membrane should increase the efficiency of TCDS. Indeed, our results showed that the efficiency of TCDS is higher for plasmids expressing tetracycline resistance protein than that for plasmids expressing GFPuv protein although the sizes of both proteins are similar (compare Figure 2.3D and 2.4D). The second possibility is that ribosomes protect mRNA from degradation by ribonucleases. Because the length of RNA transcripts, which should be proportional to the friction force applied to E. coli RNA polymerase, plays a critical role in the production of the "twin-supercoiled-domains" (Leng et al., 2004; Liu and Wang, 1987; Samul and Leng, 2007), co-transcriptional synthesis of a polypeptide should greatly stabilize the mRNA (Deana and Belasco, 2005; Pedersen et al., 2011) and therefore increase the efficiency of TCDS in E. coli cells. Our results demonstrating that transcription-coupled hypernegative supercoiling of DNA is correlated with the stability 
of mRNA produced by these plasmids after IPTG induction strongly support this explanation (Figure 2.6). Additionally, the facts that transcription alone added a few supercoils to plasmids pZXD60A, 61, and 63A also support this interpretation (Figure 2.5D, E, and F). Nevertheless, these two possibilities are not mutually exclusive and may contribute together to TCDS in vivo.

RNA polymerases are powerful motor proteins (Bai et al., 2006; Seidel and Dekker, 2007; Wang et al., 1998) which are able to rapidly move along chromosomes and remodel chromosome structures through TCDS (Albert et al., 1996; Cook et al., 1992; Dunaway and Ostrander, 1993; Leng and McMacken, 2002; Lodge et al., 1989; Lynch and Wang, 1993; Ma et al., 1994; Stupina and Wang, 2004; Tsao et al., 1989; Wu et al., 1988). The chromosomal remodeling by RNA polymerase in E. coli cells is directly link to the activation of transcription and DNA replication. For example, in the $i l v Y C$ operon of $E$. coli, the $i l v Y$ promoter is divergently coupled to the $i l v C$ promoter (Rhee et al., 1999). Results from Hatfield Laboratory clearly demonstrated that the transcriptional activities of the $i l v Y$ and $i l v C$ promoters are dependent on the localized superhelical density around the promoter region and can be activated by each other (Opel and Hatfield, 2001; Rhee et al., 1999). Another well-characterized example is the activation of the Salmonella typhimurium leu-500 promoter by divergently-coupled transcription. Results from Wu's and Lilley's Laboratories showed that transcription-driven localized supercoiling rather than the global superhelical density is responsible for activation of the leu-500 promoter (Chen et al., 1992; Tan et al., 1994). An additional example demonstrating the biological functions of TCDS stems from the studies of bacteriophage $\lambda$ DNA replication initiation. Previous studied showed that bacteriophage $\lambda$ DNA 
replication initiation is dependent on transcription in a nearby promoter in vivo (Hase et al., 1989). Our recent results showed that TCDS is responsible for the activation of $\lambda$ DNA replication (Leng et al., 2011). Specifically, the O-some assembled from the DNA replication initiator O protein binding to the DNA replication origin functions as a DNA topological barrier blocks, confines, and captures TCDS. In this scenario, $\lambda$ DNA replication origin is unwound and DNA replication is initiated. All these examples demonstrated that TCDS plays a critical role in certain biological events.

\subsection{Acknowledgments}

We would like to thank Dr. Sankar Adhya for helpful discussion and suggestions. We also thank Steven Eichelbaum for technical support and for critical reading of the manuscript before submission. We are grateful to Drs. Marc Drolet and Nikolai V. Ravin for providing us with E. coli strain DM800 and linear plasmid pG591, respectively. This

work was supported by grant 1SC1HD063059-01A1 from the NIH (to F.L.). 
Table 2.1. DNA oligonucleotides used for primers of the RT-PCR experiments

\begin{tabular}{|c|c|c|c|c|}
\hline Oligo $^{a}$ & Sequence (5'-3') & Location in the gene & Gene & PCR products \\
\hline FL594F & ATTATGGCCCACACCAGTGGCGC & $2917-2939$ & LacZ & $173 b p$, distal $^{\mathrm{b}}$ \\
\hline FL594R & TGACGGGCTCCAGGAGTCGTC & 3069-3089 & $L a c Z$ & $173 \mathrm{bp}$, distal $^{\mathrm{b}}$ \\
\hline FL654F & CACCGATCGCCCTTCCCAACAGTTG & $212-236$ & $L a c Z$ & $172 \mathrm{bp}$, proximal $^{\mathrm{c}}$ \\
\hline FL654R & GTAGATGGGCGCATCGTAACCG & $362-383$ & $L a c Z$ & $172 \mathrm{bp}$, proximal $^{\mathrm{c}}$ \\
\hline FL580F & GCGAGGCTGGATGGCCTTCC & $990-1009$ & tet & $176 \mathrm{bp}$, distal $^{\mathrm{b}}$ \\
\hline FL580R & CCGTGACGATCAGCGGTCCAG & $1145-1165$ & tet & $176 b p$, distal $^{\mathrm{b}}$ \\
\hline FL657F & GGCCTCTTGCGGGATATCGTCCATTCC & $184-210$ & tet & $168 \mathrm{bp}$, proximal $^{\mathrm{c}}$ \\
\hline FL657R & GATAGTGGCTCCAAGTAGCGAAGCG & $327-351$ & tet & $168 \mathrm{bp}$, proximal $^{\mathrm{c}}$ \\
\hline FL590F & TCCAATTGGCGATGGCCCTGT & $660-680$ & GFPuv & $101 \mathrm{bp}$ \\
\hline FL590R & GGACCATGTGGTCACGCTTTTCGT & $737-760$ & GFPuv & $101 \mathrm{bp}$ \\
\hline FL586F & AGTTATCCСССТCCATCAGG & $154-135$ & $16 \mathrm{~S}$ rRNA & $99 \mathrm{bp}$ \\
\hline FL586R & TGCAAGTCGAACGGTAACAG & $56-75$ & 16S rRNA & $99 b p$ \\
\hline
\end{tabular}

${ }^{a}$ FLXXXF and FLXXXR represent the forward and reverse primers of the PCR reactions, respectively. ${ }^{b}$ Distal indicates the PCR products that locate in the distal region of the gene. ${ }^{\mathrm{c}}$ Proximal indicates the PCR products locating in the proximal region of the gene. 
Table 2.2. Plasmids constructed in this study

\begin{tabular}{|c|c|c|}
\hline Plasmid & E. coli Promoter & $\begin{array}{l}\text { Gene under control of the } \\
\text { cloned promoter }\end{array}$ \\
\hline pZXD44 & T7A1/O4 & $t e t^{\mathrm{a}}$ \\
\hline pZXD50 & tac & $t e t^{\mathrm{a}}$ \\
\hline pZXD49 & lacUV5 & $t e t^{\mathrm{a}}$ \\
\hline pZXD47 & lac & $t e t^{\mathrm{a}}$ \\
\hline pZXD48 & lacL8 & $t_{t} t^{\mathrm{a}}$ \\
\hline pZXD57 & T7A1/O4 & $G F P u v^{\mathrm{b}}$ \\
\hline pZXD58 & tac & $G F P u v^{\mathrm{b}}$ \\
\hline pZXD56 & lacUV5 & $G F P u v^{\mathrm{b}}$ \\
\hline pZXD55 & lac & $G F P u v^{\mathrm{b}}$ \\
\hline pZXD54 & lacL8 & $G F P u v^{\mathrm{b}}$ \\
\hline pZXD59 & T7A1/O4 & Reverse $G F P u v^{\mathrm{b}}$ \\
\hline pZXD60 & T7A1/O4 & $\operatorname{lac} Z^{\mathrm{c}}$ \\
\hline pZXD60A & T7A1/O4 & $\mathrm{N} / \mathrm{A}^{\mathrm{d}}$ \\
\hline pZXD61 & T7A1/O4 & Reverse $l a c Z^{c}$ \\
\hline pZXD62 & $\mathrm{T} 7 \mathrm{~A} 1 / \mathrm{O} 4$ & $G F P u v^{\mathrm{b}}$ \\
\hline pZXD63 & T7A1/O4 & $t e t^{\mathrm{a}}$ \\
\hline pZXD63A & T7A1/O4 & $\mathrm{N} / \mathrm{A}^{\mathrm{d}}$ \\
\hline
\end{tabular}

Plasmid pZXD60A and 63A have an amber mutation in the start codon of lacZ and tet, respectively. ${ }^{a}$ The tetracycline resistance gene of pBR322 (tet) encodes a $41 \mathrm{kD}$ transmembrane protein TetA. ${ }^{\mathrm{b}}$ The green fluorescence protein UV (GFPuv) gene encodes a cytosolic protein GFPuv. ${ }^{\mathrm{c}}$ The $l a c Z$ gene encodes a cytosolic protein $\beta$-D-galactosidase. ${ }^{\mathrm{d}} \mathrm{N} / \mathrm{A}$ represents not applicable. 


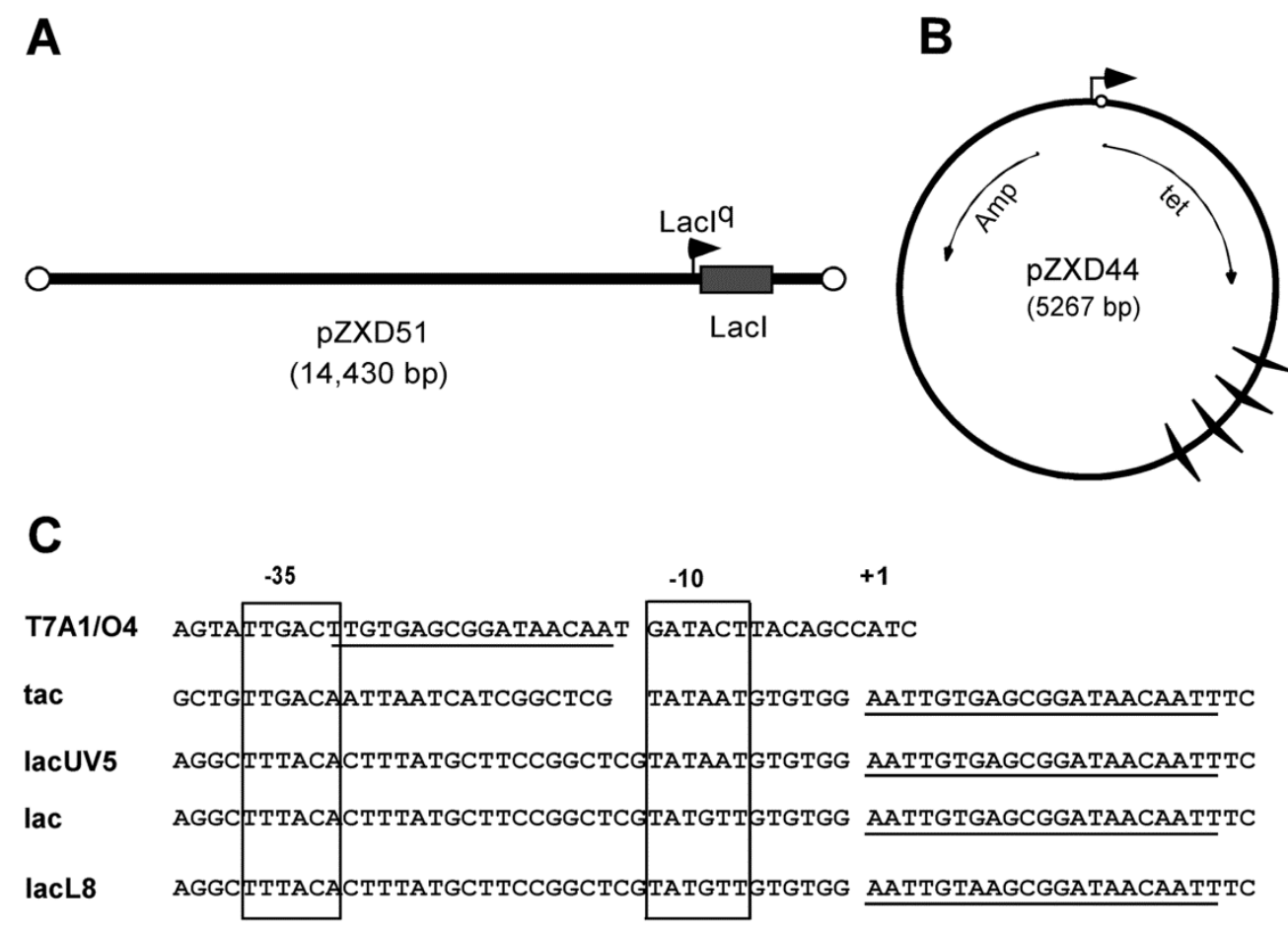

Figure 2.1 A two-plasmid system to study TCDS in vivo. This system contains two plasmids, a linear plasmid (A), i.e., pZXD51 and a circular, supercoiling-reporter plasmid (B), such as pZXD44. The linear plasmid is derived from linear coliphage N15-based plasmid pG591 and carries a laci gene under the control of the strong $\mathrm{P}_{\text {lacI }}{ }^{\mathrm{q}}$ promoter. $E$. coli cells containing pZXD51 over-express lac repressor (LacI) constitutively, which binds to the lac $O 1$ operator (the open circle) on the supercoiling-reporter plasmids. The supercoiling-reporter plasmids were derived from plasmid pBR322 and constructed as detailed under Material and methods. They harbor an IPTG-inducible promoter with different strengths and a transcription unit between the promoter and a set of 4 Rhoindependent E. coli rrnB T1 terminators (winged triangles). (C) The DNA sequence of five different E. coli promoters $\mathrm{P}_{\mathrm{T} 7 \mathrm{~A} 1 / 04}, \mathrm{P}_{\text {tac }}, \mathrm{P}_{\text {lacUv55}}, \mathrm{P}_{\text {lac }}$, and $\mathrm{P}_{\text {lacL8 }}$. The underlines represent the lac $\mathrm{Ol}$ operators. 


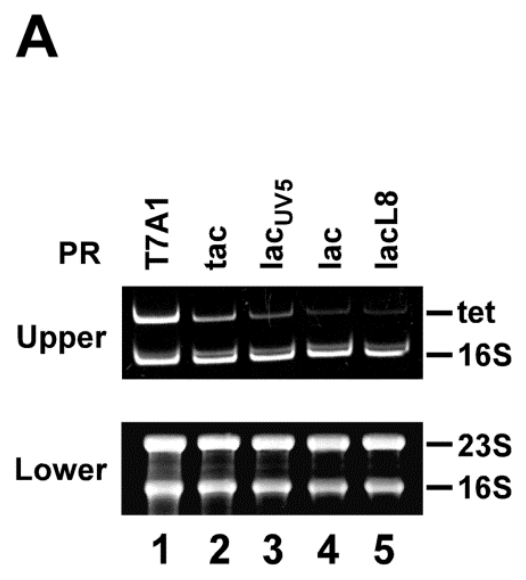

B

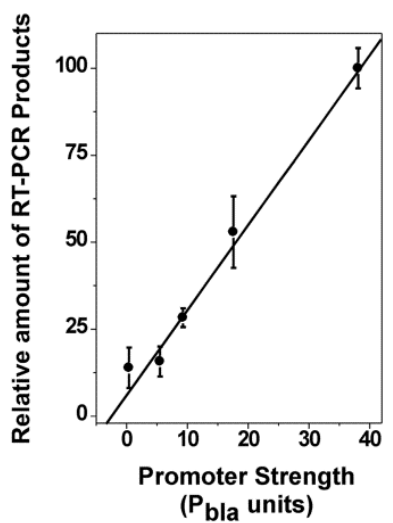

Figure 2.2 RT-PCR analysis of cDNA products of mRNA transcribed from different supercoiling-reporter plasmids pZXD44, 50, 49, 47, and 48 in E. coli topA strain VS111 harboring the linear plasmid pZXD51 after 10 min of IPTG induction (1 mM). (A) RTPCR experiments were performed as described under Materials and Methods. The lower panel is a $1.2 \%$ agarose gel containing $1 \%$ formaldehyde to show the integrity of the RNA samples used for the RT-PCR experiments. The upper panel is a $12 \%$ polyacrylamide gel in $1 \times \mathrm{TAE}$ buffer to show the PCR products of $16 \mathrm{~S}$ rRNA and tet gene cDNA synthesized from the RNA samples isolated from E. coli strain VS111 carrying supercoiling-reporter plasmids pZXD44, 50, 49, 47, and 48 after $10 \mathrm{~min}$ of IPTG induction (lanes 1-5 respectively). Labels: PR, promoter; T7A1, the T7A1/O4 promoter; tac, the tac promoter; lacUV5, the lacUV5 promoter; lac, the lac promoter; lacL8, the lacL8 promoter. (B) Real-time RT-PCR analyses of the tet gene mRNA for $E$. coli strain VS111 carrying different supercoiling-reporter plasmids pZXD44, 50, 49, 47, and 48 after $10 \mathrm{~min}$ of IPTG induction (mean $\pm \mathrm{SD}$, three independent experiments). The relative level of RT-PCR products is proportional to the promoter strength. Promoter strength in $P_{b l a}$ units was obtained from Lanzer and Bujard (1988). 
A

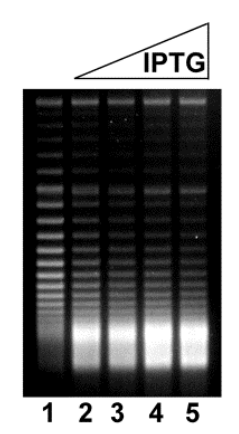

C

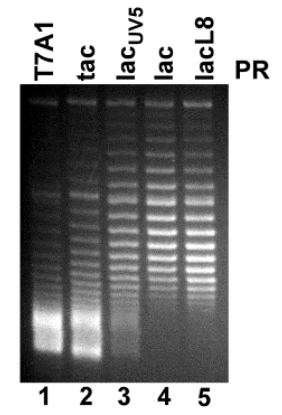

B

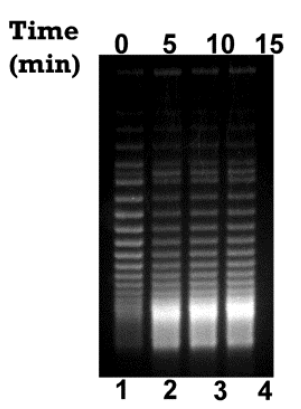

D

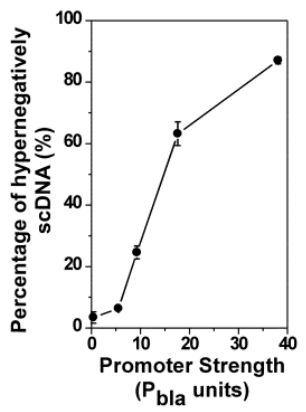

Figure 2.3 TCDS in E. coli strain VS111 is dependent on promoter strength. The in vivo T-S assays were performed as described under Materials and Methods. DNA topoisomers were resolved by electrophoresis in a $1 \%$ agarose gel containing $2.5 \mu \mathrm{g} / \mathrm{ml}$ chloroquine and stained with ethidium bromide. The fastest moving band in the gels where DNA topoisomers are no longer resolvable under our experimental conditions represents the hypernegatively supercoiled DNA. (A) Dependence of TCDS on IPTG concentration for plasmid pZXD44 carrying a tet gene under the control of the strong $\mathrm{P}_{\mathrm{T} 7 \mathrm{~A} 1 / \mathrm{O} 4}$ promoter. Lane 1 contained the DNA sample isolated from $E$. coli cells prior to IPTG induction. Lanes 2-5 contained the DNA samples isolated from E. coli cells after $10 \mathrm{~min}$ of induction with 25, 50, 100, and $1000 \mu \mathrm{M}$ IPTG, respectively. (B) Time course of the hypernegative supercoiling of plasmid pZXD44 in E. coli strain VS111 after $1 \mathrm{mM}$ of IPTG induction. Lanes 1-4 contained, respectively, DNA samples isolated from VS111 after $0,5,10$, and 15 min of IPTG induction. (C) Dependence of TCDS on promoter strength. Lanes 1-5 contained, respectively, DNA samples isolated from E. coli topA strain VS111 containing plasmids pZXD44, 50, 49, 47, and 48 after 5 min of IPTG (1 $\mathrm{mM}$ ) induction. These plasmids carry a tet gene under the control of IPTG-inducible promoters with different strengths, i.e., promoters $\mathrm{P}_{\mathrm{T} 7 \mathrm{~A} 1 / \mathrm{O} 4}, \mathrm{P}_{\mathrm{tac}}, \mathrm{P}_{\text {lacUV5 }}, \mathrm{P}_{\text {lac }}$, and $\mathrm{P}_{\text {lacL8. }}$ Labels: PR, promoter; T7A1, the T7A1/O4 promoter; tac, the tac promoter; lacUV5, the lacUV5 promoter; lac, the lac promoter; lacL8, the lacL8 promoter. (D) The percentage of hypernegatively supercoiled DNA is proportional to promoter strength (the values are the average of at least three independent determinations and the standard deviations are shown). These results were calculated as described under Material and methods using the TCDS data shown in (C). Promoter strength in $P_{b l a}$ units was obtained from Lanzer and Bujard (1988). 
A
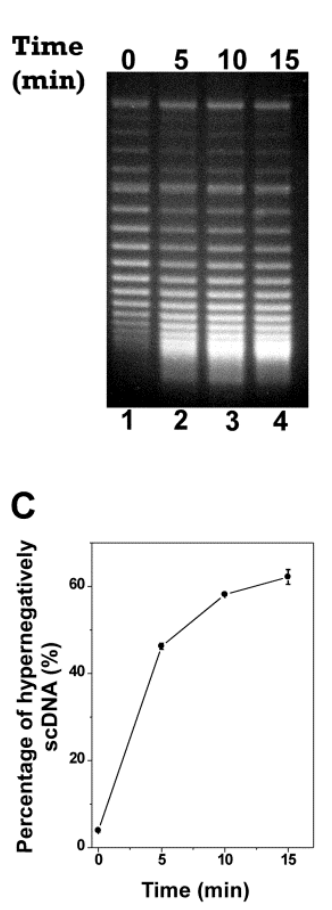

B
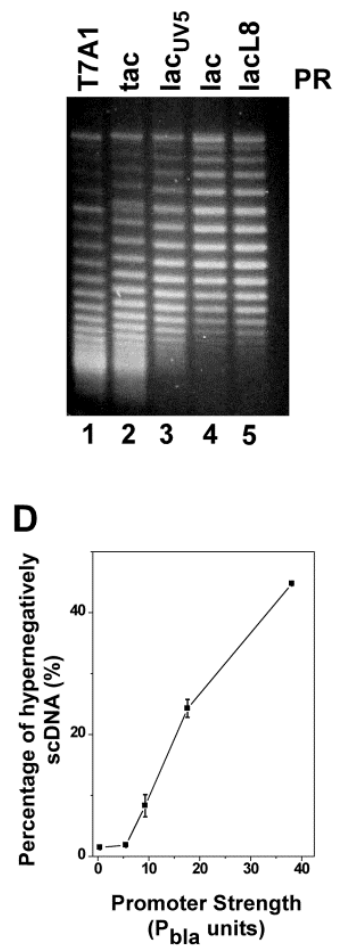

Figure 2.4 For strong promoters, TCDS in E. coli topA strain VS111 did not require the expression of a membrane insertion protein. The in vivo T-S assays for plasmids carrying a $G F P_{U V}$ gene under the control of IPTG-inducible promoters with different strengths were performed as described under Materials and Methods. DNA topoisomers were resolved by electrophoresis in a $1 \%$ agarose gel containing $2.5 \mu \mathrm{g} / \mathrm{ml}$ chloroquine and stained with ethidium bromide. (A) and (C) The time course of the hypernegative supercoiling of plasmid pZXD57 carrying a $G F P_{U V}$ gene under the control of the strong $\mathrm{P}_{\mathrm{T} 7 \mathrm{~A} 1 / 04}$ promoter in E. coli strain VS111 after $1 \mathrm{mM}$ of IPTG induction. Lanes 1-4 contained, respectively, DNA samples isolated from VS111 after 0, 5, 10, and 15 min of IPTG induction. (B) and (D) Dependence of TCDS on promoter strength. Lanes 1-5 contained, respectively, DNA samples isolated from E. coli topA strain VS111 containing plasmids pZXD57, 58, 56, 55, and 54, that carry a cytosolic GFPuv gene under the control of IPTG-inducible promoters with different strengths, i.e., promoters $\mathrm{P}_{\mathrm{T} 7 \mathrm{~A} 1 / \mathrm{O} 4}, \mathrm{P}_{\mathrm{tac}}$, $\mathrm{P}_{\text {lacUv5 }}, \mathrm{P}_{\text {lac }}$, and $\mathrm{P}_{\text {lacL8 }}$ after $5 \mathrm{~min}$ of IPTG $(1 \mathrm{mM})$ induction. Labels: PR, promoter; T7A1, the T7A1/O4 promoter; tac, the tac promoter; lacUV5, the lacUV5 promoter; lac, the lac promoter; lacL8, the lacL8 promoter. (C) The percentage of hypernegatively supercoiled DNA for pZXD57 is a function of IPTG induction time. These results were calculated as described under Material and methods using the TCDS data shown in (A). (D) The percentage of hypernegatively supercoiled DNA is proportional to promoter strength (the values are the average of at least three independent determinations and the standard deviations are shown). These results were calculated as described under Material and methods using the TCDS data shown in (B). The promoter strength in $P_{b l a}$ units was obtained from Lanzer and Bujard (1988). 


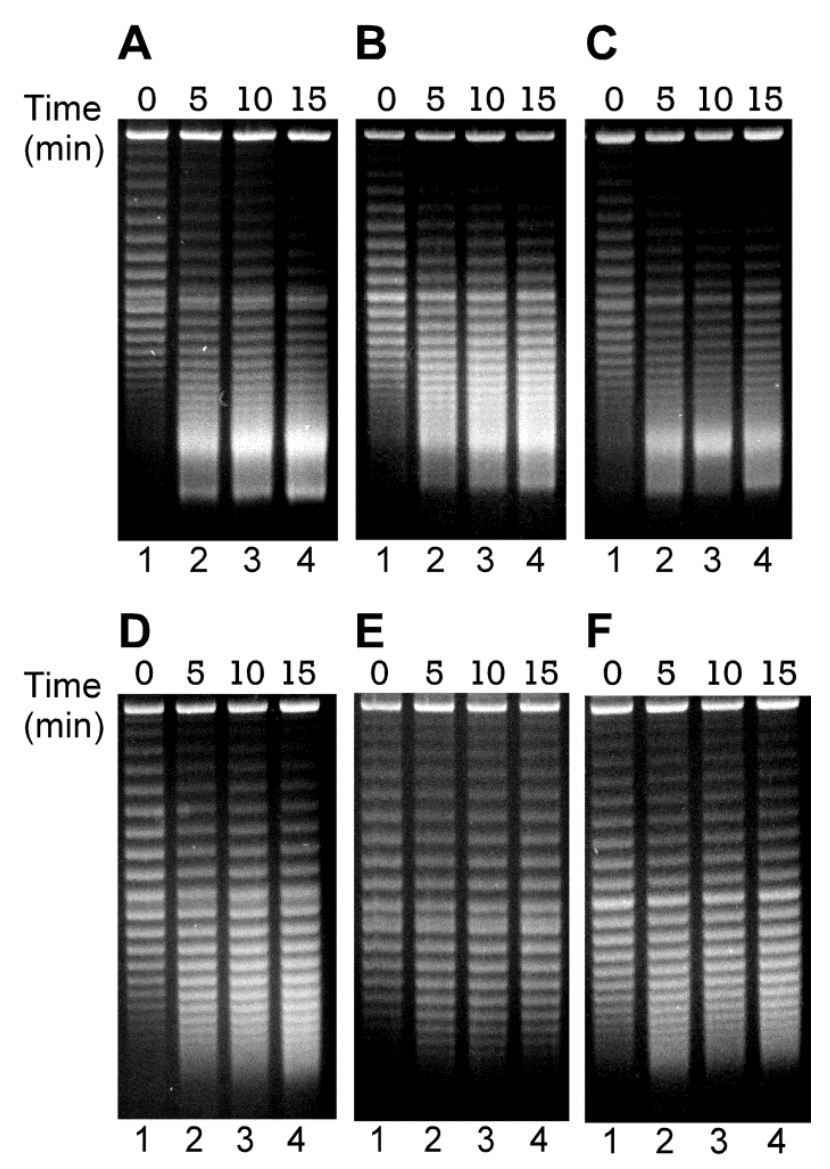

Figure 2.5 TCDS in E. coli topA strain VS111 for different plasmid DNA templates with identical size carrying a strong, IPTG-inducible $\mathrm{P}_{\mathrm{T} 7 \mathrm{~A} / \mathrm{O} 4}$ promoter. The in vivo T-S assays were performed as described under Materials and Methods. Transcription was induced with $1 \mathrm{mM}$ of IPTG. Lane 1 contained the DNA sample before IPTG induction. Lanes 24 contained the plasmid DNA samples after 5, 10, and 15 min of IPTG induction, respectively. DNA topoisomers were resolved by electrophoresis in a $1 \%$ agarose gel containing $2.5 \mu \mathrm{g} / \mathrm{ml}$ chloroquine and stained with ethidium bromide. Plasmids pZXD60 (A), 62 (B), and 63 (C) carry a lacZ, GFPuv, and tet gene under the control of the strong $\mathrm{P}_{\mathrm{T} 7 \mathrm{~A} 1 / 04}$ promoter, respectively. (D) Plasmid pZXD60A is identical with pZXD60 except the start codon (ATG) of lac $Z$ was mutated to the stop codon TAG (amber mutation). (E) Plasmid pZXD61 contains a lac $Z$ gene in the reverse orientation, which cannot direct the expression of $\beta$-galactosidase. (F) Plasmid pZXD63A is similar to pZXD63 except the start codon of the tet gene was mutated to the stop codon TAG (amber mutation). 

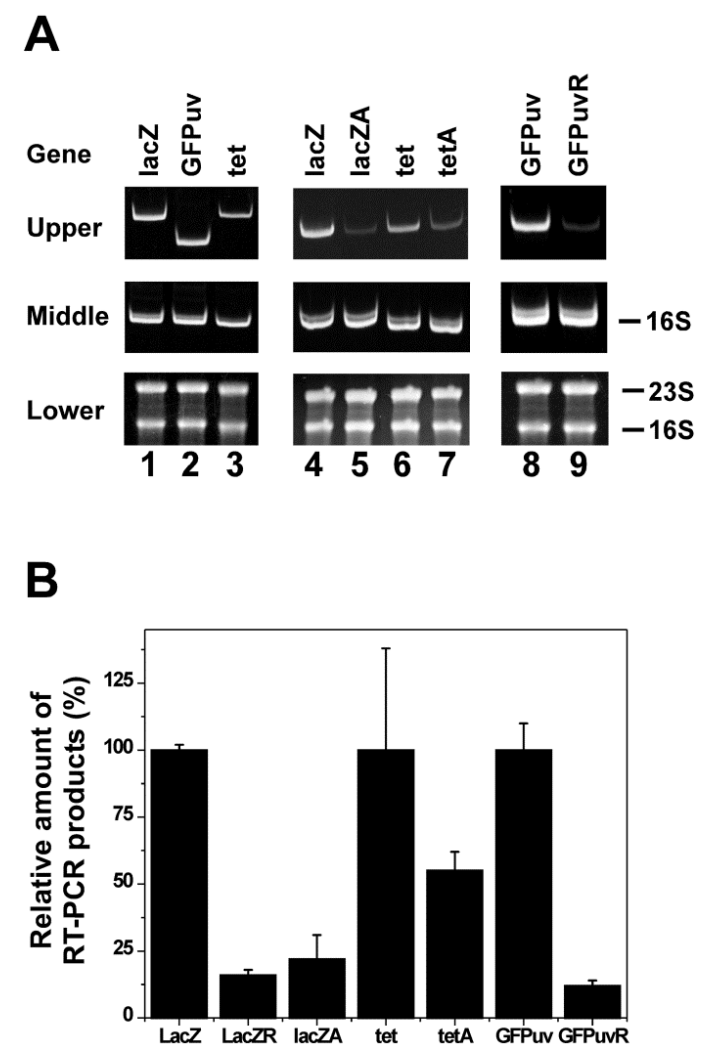

Figure 2.6 RT-PCR analyses of cDNA products of mRNA transcribed from different supercoiling-reporter plasmids pZXD60, 60A, 61, 62, 63 and 63A in E. coli topA strain VS111 harboring the linear plasmid pZXD51 after $10 \mathrm{~min}$ of IPTG induction. (A) RTPCR experiments were performed as described under Materials and Methods. The lower panel is a $1.2 \%$ agarose gel containing $1 \%$ formaldehyde to show the integrity of the RNA samples used for the RT-PCR experiments. The middle panel is a $12 \%$ polyacrylamide gel in $1 \times \mathrm{TAE}$ buffer to show the PCR products of the cDNA synthesized from 16S rRNA samples isolated from E. coli strain VS111 carrying different supercoiling-reporter plasmids pZXD60, 60A, 62, 63, 63A, 57, and 59 after 10 min of IPTG induction. The upper panel is also a $12 \%$ polyacrylamide gel in $1 \times \mathrm{TAE}$ buffer to show the PCR products of the cDNA samples synthesized from the mRNA samples isolated from E. coli strain VS111 carrying different supercoiling-reporter plasmids pZXD60 (lanes 1 and 4), 60A (lane 5), 62 (lane 2), 63 (lanes 3 and 6), 63A (lane 7), 57 (lane 8), and 59 (lane 9) after 10 min of IPTG induction. (B) Real-time RT-PCR analyses of the mRNA samples for E. coli strain VS111 carrying different supercoiling-reporter plasmids pZXD60, 60A, 61, 62, 63, 63A, and 59 after $10 \mathrm{~min}$ of IPTG induction (mean $\pm \mathrm{SD}$, three independent experiments). Labels: lacZ, the lacZ gene; lacZA, the lacZ gene with an amber mutation in the start codon; lacZR, the lacZ gene in the reverse orientation; GFPuv, the GFPuv gene; GFPuvR, the GFPuv gene in the reverse orientation; tet, the tet gene; tetA, the tet gene with an amber mutation in the start codon. 

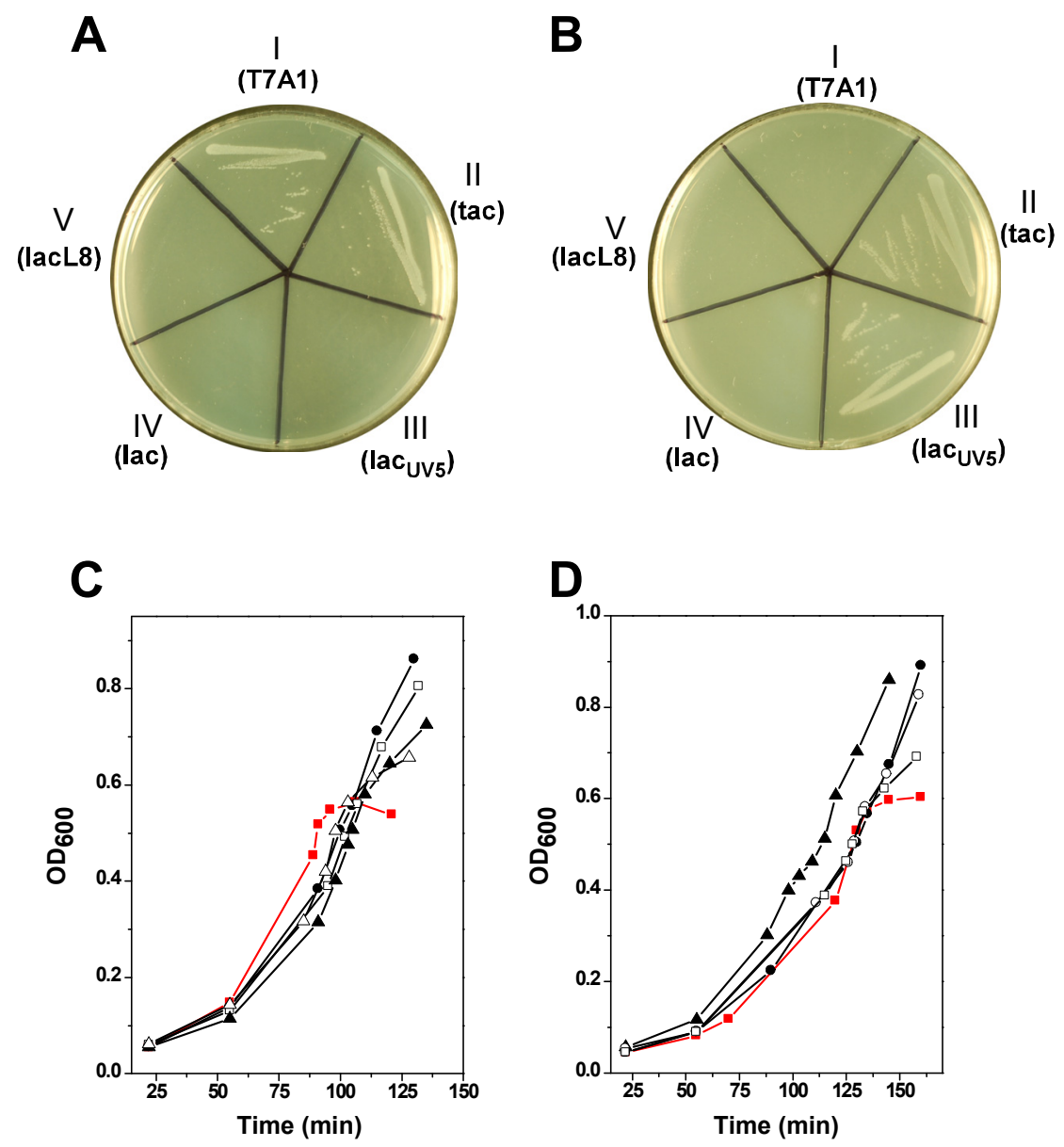

Figure 2.7 The tetracycline sensitivity assays. E. coli topA strain VS111/pZXD51 containing different plasmid DNA templates was grown at $37^{\circ} \mathrm{C}$ overnight on LB agar plates containing $10 \mu \mathrm{g} / \mathrm{ml}$ of tetracycline in the absence (A) or presence (B) of $1 \mathrm{mM}$ of IPTG. These agar plates also contained $50 \mu \mathrm{g} / \mathrm{ml}$ of kanamycin and ampicillin. Sections I-V contained VS111/pZXD51 carrying plasmids pZXD44, pZXD50, 49, 47, and 48, respectively. (C) and (D) are cell growth curves of E. coli strains $M G 1655 / p Z X D 51$ and $V S 111 / p Z X D 51$ carrying different plasmids in the absence of tetracycline, monitored at OD600. $1 \mathrm{mM}$ of IPTG was added to the cell cultures when OD600 reached $\sim 0.5$. The red lines and squares represent cell growth curves for E. coli strains carrying plasmid pZXD44 that harbors a tet gene under the control of the strong $\mathrm{P}_{\mathrm{T} 7 \mathrm{~A} 1 / \mathrm{O} 4}$ promoter. Other symbols represent cell growth curves for E. coli strains carrying plasmids pZXD50 (open triangles), 49 (solid triangles), 47 (solid circles), and 48 (open squares). 



Figure 2.8 TCDS in E. coli top $A$ strains is dependent on promoter strength. The in vivo T$\mathrm{S}$ assays were performed as described under Materials and Methods. DNA topoisomers were resolved by electrophoresis in a $1 \%$ agarose gel containing $2.5 \mu \mathrm{g} / \mathrm{ml}$ chloroquine and stained with ethidium bromide. (A), (B), (C), and (D) Time courses of the hypernegative supercoiling of plasmid pZXD50, 49, 47, and 48 in E. coli strain VS111/pZXD51 after $1 \mathrm{mM}$ of IPTG induction, respectively. Lanes 1-4 contained DNA samples isolated from $V S 111 / p Z X D 51$ after $0,5,10$ and $15 \mathrm{~min}$ of IPTG induction. (E) The percentage of hypernegative supercoiled DNA of plasmid pZXD44 is a function of IPTG concentration. These results were calculated as described under Materials and Methods using the TCDS data shown Figure 2.3A. (F) The percentage of hypernegatively supercoiled DNA for pZXD44 (squares), 50 (circles), and 49 (triangles) is a function of IPTG induction time. These results were calculated as described under Materials and Methods using the TCDS data shown in (A) and (B) and Figure 2.3B. (G) Dependence of TCDS on promoter strength. Lanes 1-5 contained, respectively, DNA samples isolated from E. coli topA strain DM800/pZXD51 containing plasmids pZXD44, 50, 49, 47, and 48 after $5 \mathrm{~min}$ of IPTG $(1 \mathrm{mM})$ induction. These plasmids carry a tet gene under the control of IPTG-inducible promoters with different strengths, i.e., promoters $\mathrm{P}_{\mathrm{T} 7 \mathrm{~A} 1 / 04}, \mathrm{P}_{\mathrm{tac}}$, $\mathrm{P}_{\text {lacUv5, }} \mathrm{P}_{\text {lac }}$, and $\mathrm{P}_{\text {lacL8. }}$ Labels: PR, promoter; T7A1, the T7A1/O4 promoter; tac, the tac promoter; lacUV5, the lacUV5 promoter; lac, the lac promoter; lacL8, the lacL8 promoter. 

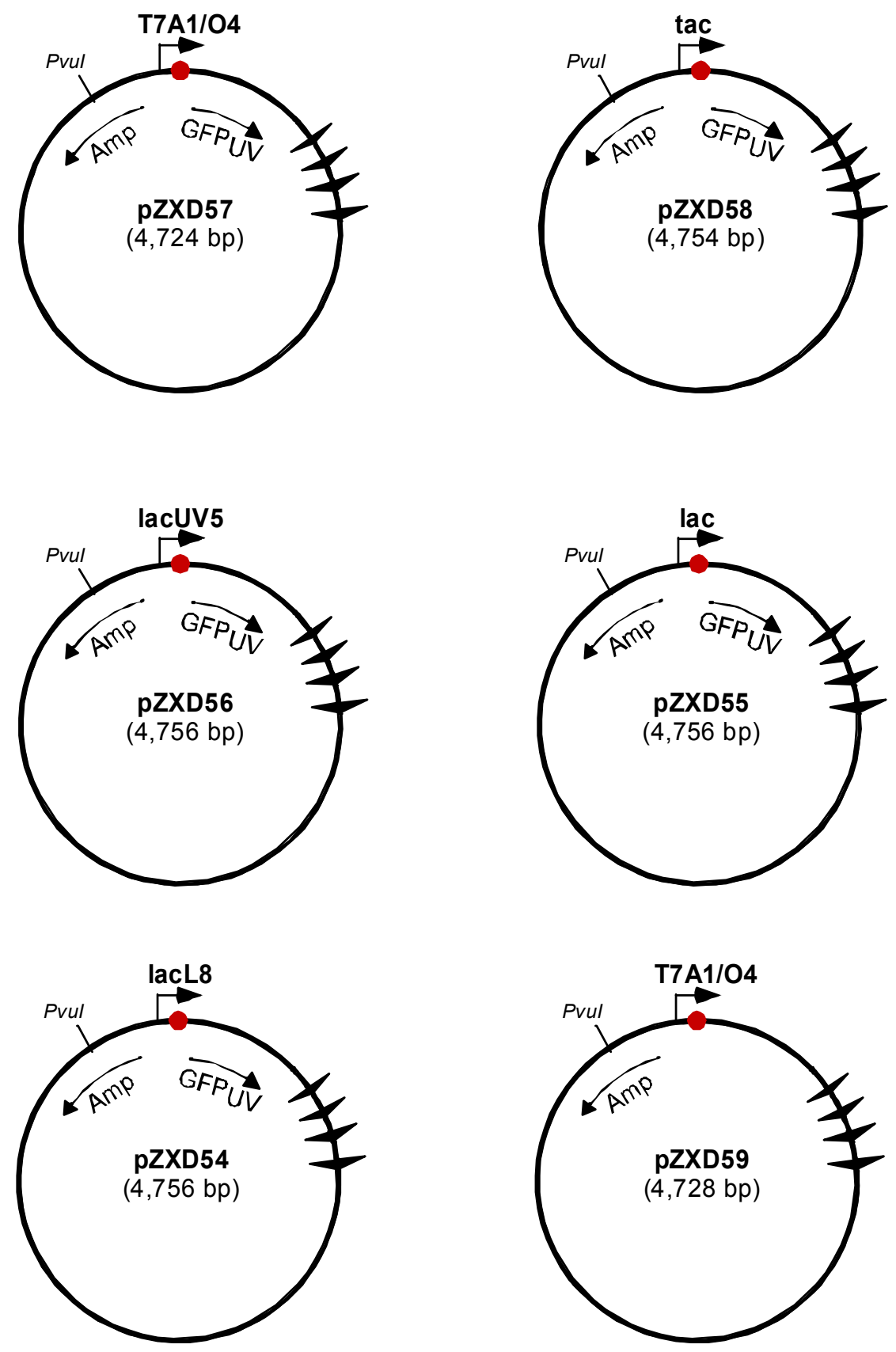

Figure 2.9 Plasmid maps of pZXD54, 55, 56, 57, 58, and 59. This series of plasmids were constructed as described under Materials and Methods. Each plasmid carries a GFPUV gene under the control of an IPTG-inducible promoter, i.e., $\mathrm{P}_{\mathrm{T} 7 \mathrm{~A} 1 / \mathrm{O} 4}, \mathrm{P}_{\mathrm{tac}}, \mathrm{P}_{\text {lacUV5 }}, \mathrm{P}_{\text {lac }}$, and $\mathrm{P}_{\text {lacL8 }}$ and a set of four copies of Rho-independent $\operatorname{rrnB} \mathrm{T} 1$ transcription terminators (winged triangles). The arrow on each plasmid indicates the direction of transcription from the IPTG-inducible promoter. The red circle indicates the lac Ol operator in the promoter. 
A

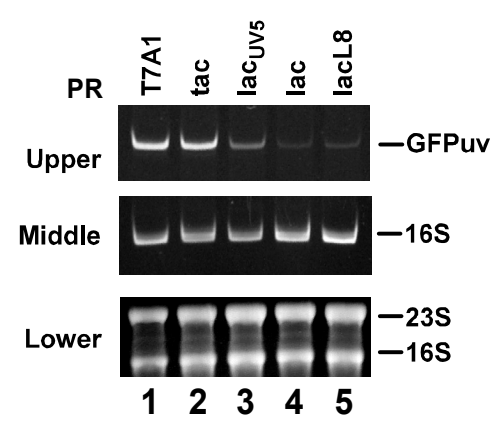

B

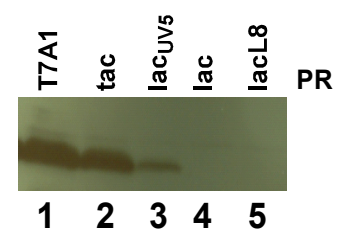

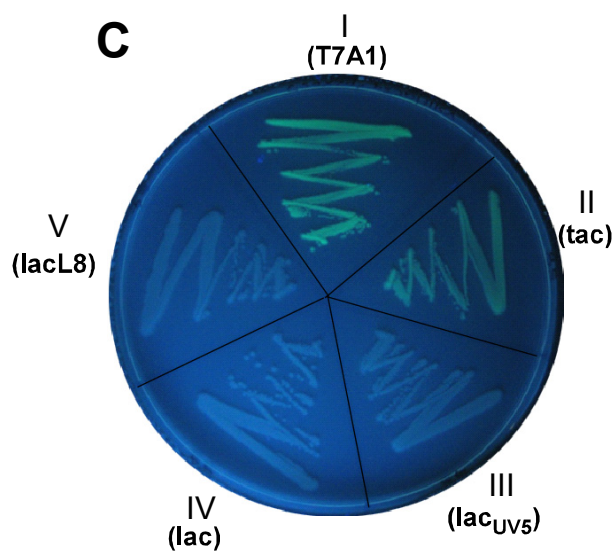

Figure 2.10 The expression level of GFPuv protein after IPTG induction in E. coli topA strain VS111/pZXD51 containing different plasmids is correlated with promoter strength. (A) RT-PCR experiments were performed as described under Materials and Methods. The lower panel is a $1.2 \%$ agarose gel containing $1 \%$ formaldehyde to show the integrity of the RNA samples used for the RT-PCR experiments. The middle panel is a $12 \%$ polyacrylamide gel in $1 \times \mathrm{TAE}$ buffer to show the PCR products of the cDNA synthesized from 16S rRNA samples isolated from E. coli strain VS111/pZXD51 carrying different supercoiling-reporter plasmids. The upper panel is also a $12 \%$ polyacrylamide gel in $1 \times$ TAE buffer to show the PCR products of GFPuv gene cDNA synthesized from the RNA samples isolated from E. coli strain VS111/pZXD51 carrying different supercoilingreporter plasmids pZXD57 (lane 1), 58 (lane 2), 56 (lane 3), 55 (lane 4) and 54 (lane 5) after 10 min of IPTG induction. (B) Western blotting experiments were performed as described under Experimental Procedures. Lanes 1-5 contained, respectively, protein samples isolated from E. coli VS111/pXD51 cells carrying plasmids pZXD57, 58, 56, 55, and 54 after 3 hours of $1 \mathrm{mM}$ IPTG induction. (C) E. coli topA strain VS111/pZXD51 containing different plasmid DNA templates was grown at $37{ }^{\circ} \mathrm{C}$ overnight on LB agar plates containing $50 \mu \mathrm{g} / \mathrm{ml}$ of ampicillin in the presence of $1 \mathrm{mM}$ of IPTG and photographed under UV light. Sections I-V contained pZXD57, 58, 56, 55, and 54, respectively. Labels: PR, promoter; T7A1, the T7A1/O4 promoter; tac, the tac promoter; lacUV5, the lacUV5 promoter; lac, the lac promoter; lacL8, the lacL8 promoter. 



Figure 2.11 Plasmid maps of pZXD60, 60A, 61, 62, 63, and 63A. This series of plasmids of identical size were constructed as described under Materials and Methods. Each plasmid carries a strong, IPTG-inducible $\mathrm{P}_{\mathrm{T} 7 \mathrm{~A} 1 / 04}$ promoter and a set of four copies of Rho-independent $r r n B \mathrm{~T} 1$ transcription terminators (winged triangles). The arrow on each plasmid indicates the direction of transcription from the $\mathrm{P}_{\mathrm{T} 7 \mathrm{~A} 1 / \mathrm{O} 4}$ promoter. The red circle indicates the lac $\mathrm{Ol}$ operator in the promoter. 



Figure 2.12 TCDS in E. coli topA strains VS111/pZXD51 and DM800/pZXD51 for different plasmid DNA templates with identical size carrying a strong, IPTG-inducible $\mathrm{P}_{\mathrm{T} 7 \mathrm{~A} 1 / 04}$ promoter. (A) The percentage of hypernegatively supercoiled DNA for pZXD60 (squares), 62 (circles), and 63 (triangles) is a function of IPTG induction time. These results were calculated as described under Material and methods using the TCDS data shown in Figure 2.5A, B, and C. (B) The in vivo T-S assays for E. coli topA strain DM800/pZXD51 were performed as described under Material and methods. Transcription was induced with $1 \mathrm{mM}$ of IPTG for $10 \mathrm{~min}$. Lanes 1-3 contained the DNA sample for plasmids pZXD60, 62, and 63, respectively. DNA topoisomers were resolved by electrophoresis in a $1 \%$ agarose gel containing $2.5 \mu \mathrm{g} / \mathrm{ml}$ chloroquine and stained with ethidium bromide. 

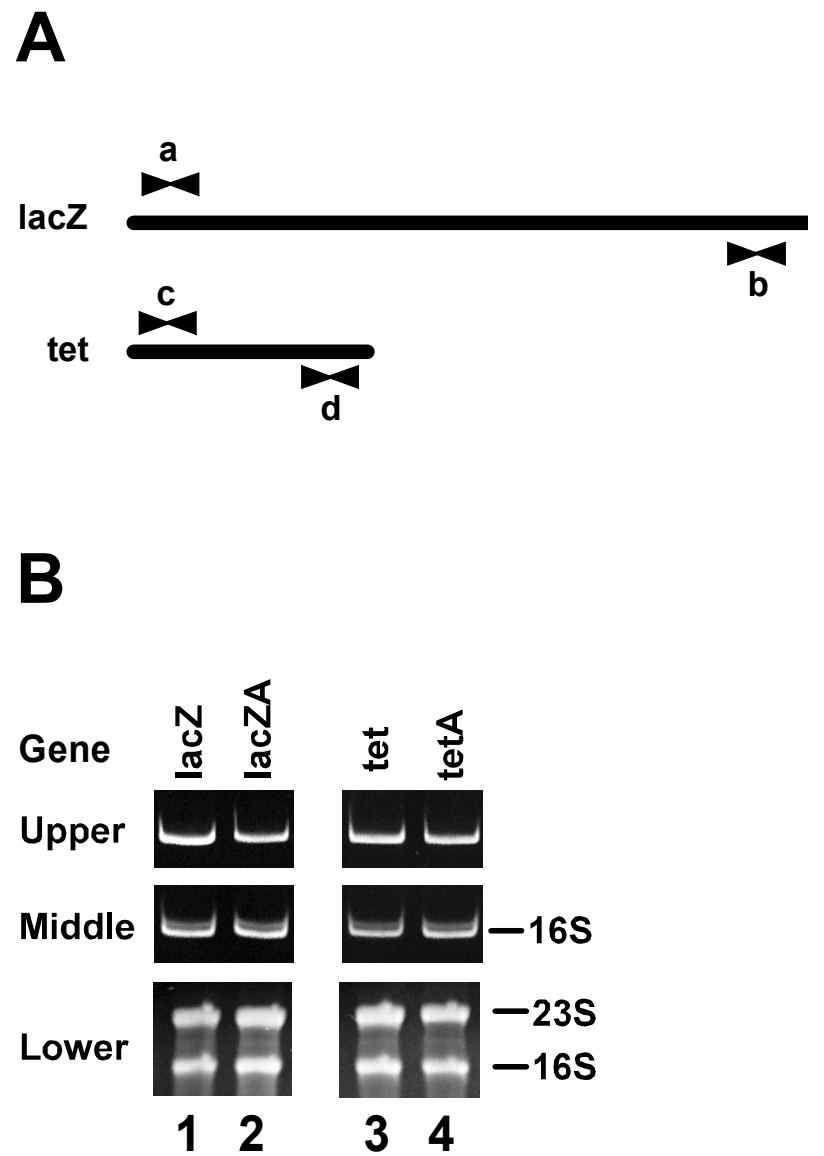

Figure 2.13 RT-PCR experiments to analyze the cDNA products synthesized from mRNA of lacZ and tet genes. (A) PCR primers to detect the proximal products (near the start codon of lacZ or tet genes; primer pairs a or c) and the distal products of cDNA (near the stop codon of lacZ or tet gene; primer pairs b and d). (B) RT-PCR experiments were performed as described under Materials and Methods. The lower panel is a $1.2 \%$ agarose gel containing $1 \%$ formaldehyde to show the integrity of the RNA samples used for the RT-PCR experiments. The middle panel is a $12 \%$ polyacrylamide gel in $1 \times \mathrm{TAE}$ buffer to show the PCR products of the cDNA synthesized from $16 \mathrm{~S}$ rRNA samples isolated from $E$. coli strain VS111/pZXD51 carrying different supercoiling-reporter plasmids. The upper panel is also a $12 \%$ polyacrylamide gel in $1 \times \mathrm{TAE}$ buffer to show the PCR products of $l a c Z$ and tet gene cDNA synthesized from the RNA samples isolated from $E$. coli strain VS111/pZXD51 carrying different supercoiling-reporter plasmids pZXD60 (lane 1), 60A (lane 2), 63 (lane 3), and 63A (lane 4) after $10 \mathrm{~min}$ of IPTG induction. Primer pair a was used to detect the proximal products of lacZ (lanes 1 and 2). Primer pair c was used detect the proximal products of tet (lanes 3 and 4). Labels: lacZ, the lacZ gene; lacZA, the lacZ gene with an amber mutation in the start codon; tet, the tet gene; tetA, the tet gene with an amber mutation in the start codon. There is no difference for the proximal PCR products between E. coli strains carrying pZXD60 and 60A and also between $E$. coli strains carrying pZXD63 and 63A. 


\subsection{References}

Albert, A.C., Spirito,F., Figueroa-Bossi,N., Bossi,L., Rahmouni,A.R., 1996. Hypernegative template DNA supercoiling during transcription of the tetracyclineresistance gene in topA mutants is largely constrained in vivo. Nucleic Acids Res. 24, 3093-3099.

Bai, L., Santangelo,T.J., Wang,M.D., 2006. Single-molecule analysis of RNA polymerase transcription. Annu. Rev. Biophys. Biomol. Struct. 35, 343-360.

Bates,A.D., Maxwell,A., 2005. DNA Topology, 2nd edition edition. Oxford University Press, Oxford, UK.

Brunner, M., Bujard,H., 1987. Promoter recognition and promoter strength in the Escherichia coli system. EMBO J. 6, 3139-3144.

Champoux, J.J., 2001. DNA topoisomerases: structure, function, and mechanism. Annu. Rev. Biochem. 70, 369-413.

Chen, D., Bowater,R., Dorman,C.J., Lilley,D.M., 1992. Activity of a plasmid-borne leu500 promoter depends on the transcription and translation of an adjacent gene. Proc. Natl. Acad. Sci. U. S. A 89, 8784-8788.

Cook, D.N., Ma,D., Pon,N.G., Hearst,J.E., 1992. Dynamics of DNA supercoiling by transcription in Escherichia coli. Proc. Natl. Acad. Sci. U. S. A 89, 10603-10607.

Cozzarelli,N.R., Wang,J.C., 1990. DNA Topology and Its Biological Effects. Cold Spring Harbor Laboratory Press, Cold Spring Harbor, NY.

Deana, A., Belasco,J.G., 2005. Lost in translation: the influence of ribosomes on bacterial mRNA decay. Genes Dev. 19, 2526-2533.

Deneke, J., Ziegelin,G., Lurz,R., Lanka,E., 2000. The protelomerase of temperate Escherichia coli phage N15 has cleaving-joining activity. Proc. Natl. Acad. Sci. U. S. A $97,7721-7726$.

Dunaway, M., Ostrander,E.A., 1993. Local domains of supercoiling activate a eukaryotic promoter in vivo. Nature 361, 746-748.

Eckert, B., Beck,C.F., 1989. Overproduction of transposon Tn10-encoded tetracycline resistance protein results in cell death and loss of membrane potential. J. Bacteriol. $171,3557-3559$.

Golding, I., Cox,E.C., 2004. RNA dynamics in live Escherichia coli cells. Proc. Natl. Acad. Sci. U. S. A 101, 11310-11315. 
Golding, I., Paulsson,J., Zawilski,S.M., Cox,E.C., 2005. Real-time kinetics of gene activity in individual bacteria. Cell 123, 1025-1036.

Hase, T., Nakai, M., Masamune,Y., 1989. Transcription of a region downstream from lambda ori is required for replication of plasmids derived from coliphage lambda. Mol. Gen. Genet. 216, 120-125.

Kandhavelu, M., Mannerstrom,H., Gupta,A., Hakkinen,A., Lloyd-Price,J., Yli-Harja,O., Ribeiro,A.S., 2011. In vivo kinetics of transcription initiation of the lar promoter in Escherichia coli. Evidence for a sequential mechanism with two rate-limiting steps. BMC. Syst. Biol. 5, 149.

Lanzer, M., Bujard,H., 1988. Promoters largely determine the efficiency of repressor action. Proc. Natl. Acad. Sci. U. S. A 85, 8973-8977.

Leng, F., McMacken,R., 2002. Potent stimulation of transcription-coupled DNA supercoiling by sequence-specific DNA-binding proteins. Proc. Natl. Acad. Sci. U. S. A $99,9139-9144$.

Leng, F., Amado,L., McMacken,R., 2004. Coupling DNA supercoiling to transcription in defined protein systems. J. Biol. Chem. 279, 47564-47571.

Leng, F., Chen,B., Dunlap,D.D., 2011. Dividing a supercoiled DNA molecule into two independent topological domains. Proc. Natl. Acad. Sci. U. S. A 108, 1997319978.

Liu, L.F., Wang,J.C., 1987. Supercoiling of the DNA template during transcription. Proc. Natl. Acad. Sci. U. S. A 84, 7024-7027.

Lockshon, D., Morris,D.R., 1983. Positively supercoiled plasmid DNA is produced by treatment of Escherichia coli with DNA gyrase inhibitors. Nucleic Acids Res. 11, 2999-3017.

Lodge, J.K., Kazic,T., Berg,D.E., 1989. Formation of supercoiling domains in plasmid pBR322. J. Bacteriol. 171, 2181-2187.

Lutz, R., Bujard,H., 1997. Independent and tight regulation of transcriptional units in Escherichia coli via the $\mathrm{LacR} / \mathrm{O}$, the TetR/O and AraC/I1-I2 regulatory elements. Nucleic Acids Res. 25, 1203-1210.

Lutz, R., Lozinski,T., Ellinger,T., Bujard,H., 2001. Dissecting the functional program of Escherichia coli promoters: the combined mode of action of Lac repressor and AraC activator. Nucleic Acids Res. 29, 3873-3881.

Lynch, A.S., Wang,J.C., 1993. Anchoring of DNA to the bacterial cytoplasmic membrane through cotranscriptional synthesis of polypeptides encoding membrane proteins or proteins for export: a mechanism of plasmid hypernegative 
supercoiling in mutants deficient in DNA topoisomerase I. J. Bacteriol. 175, $1645-1655$.

Ma, D., Cook,D.N., Pon,N.G., Hearst,J.E., 1994. Efficient anchoring of RNA polymerase in Escherichia coli during coupled transcription-translation of genes encoding integral inner membrane polypeptides. J. Biol. Chem. 269, 15362-15370.

McClure, W.R., 1985. Mechanism and control of transcription initiation in prokaryotes. Annu. Rev. Biochem. 54, 171-204.

Mielke, S.P., Fink,W.H., Krishnan,V.V., Gronbech-Jensen,N., Benham,C.J., 2004. Transcription-driven twin supercoiling of a DNA loop: a Brownian dynamics study. J. Chem. Phys. 121, 8104-8112.

Nelson, P., 1999. Transport of torsional stress in DNA. Proc. Natl. Acad. Sci. U. S. A 96, 14342-14347.

Nilsson, G., Belasco,J.G., Cohen,S.N., von,G.A., 1987. Effect of premature termination of translation on mRNA stability depends on the site of ribosome release. Proc. Natl. Acad. Sci. U. S. A 84, 4890-4894.

Opel, M.L., Hatfield,G.W., 2001. DNA supercoiling-dependent transcriptional coupling between the divergently transcribed promoters of the ilvYC operon of Escherichia coli is proportional to promoter strengths and transcript lengths. Mol. Microbiol. 39, 191-198.

Pedersen, M., Nissen,S., Mitarai,N., Lo,S.S., Sneppen,K., Pedersen,S., 2011. The functional half-life of an mRNA depends on the ribosome spacing in an early coding region. J. Mol. Biol. 407, 35-44.

Pruss, G.J., 1985. DNA topoisomerase I mutants. Increased heterogeneity in linking number and other replicon-dependent changes in DNA supercoiling. J. Mol. Biol. $185,51-63$.

Pruss, G.J., Drlica,K., 1986. Topoisomerase I mutants: the gene on pBR322 that encodes resistance to tetracycline affects plasmid DNA supercoiling. Proc. Natl. Acad. Sci. U. S. A 83, 8952-8956.

Ravin, N.V., Ravin,V.K., 1999. Use of a linear multicopy vector based on the minireplicon of temperate coliphage N15 for cloning DNA with abnormal secondary structures. Nucleic Acids Res. 27, e13.

Rhee, K.Y., Opel,M., Ito,E., Hung,S., Arfin,S.M., Hatfield,G.W., 1999. Transcriptional coupling between the divergent promoters of a prototypic LysR-type regulatory system, the ilvYC operon of Escherichia coli. Proc. Natl. Acad. Sci. U. S. A 96, 14294-14299. 
Saecker, R.M., Record,M.T., Jr., deHaseth,P.L., 2011. Mechanism of bacterial transcription initiation: RNA polymerase - promoter binding, isomerization to initiation-competent open complexes, and initiation of RNA synthesis. J. Mol. Biol. 412, 754-771.

Samul, R., Leng,F., 2007. Transcription-coupled hypernegative supercoiling of plasmid DNA by T7 RNA polymerase in Escherichia coli topoisomerase I-deficient strains. J. Mol. Biol. 374, 925-935.

Seidel, R., Dekker,C., 2007. Single-molecule studies of nucleic acid motors. Curr. Opin. Struct. Biol. 17, 80-86.

Snoep, J.L., van der Weijden,C.C., Andersen,H.W., Westerhoff,H.V., Jensen,P.R., 2002. DNA supercoiling in Escherichia coli is under tight and subtle homeostatic control, involving gene-expression and metabolic regulation of both topoisomerase I and DNA gyrase. Eur. J. Biochem. 269, 1662-1669.

Stuber, D., Bujard,H., 1981. Organization of transcriptional signals in plasmids pBR322 and pACYC184. Proc. Natl. Acad. Sci. U. S. A 78, 167-171.

Stupina, V.A., Wang,J.C., 2004. DNA axial rotation and the merge of oppositely supercoiled DNA domains in Escherichia coli: effects of DNA bends. Proc. Natl. Acad. Sci. U. S. A 101, 8608-8613.

Stupina, V.A., Wang,J.C., 2005. Viability of Escherichia coli topA mutants lacking DNA topoisomerase I. J. Biol. Chem 280, 355-360.

Tan, J., Shu,L., Wu,H.Y., 1994. Activation of the leu-500 promoter by adjacent transcription. J. Bacteriol. 176, 1077-1086.

Taniguchi, Y., Choi,P.J., Li,G.W., Chen,H., Babu,M., Hearn,J., Emili,A., Xie,X.S., 2010. Quantifying E. coli proteome and transcriptome with single-molecule sensitivity in single cells. Science 329, 533-538.

Tsao, Y.P., Wu,H.Y., Liu,L.F., 1989. Transcription-driven supercoiling of DNA: direct biochemical evidence from in vitro studies. Cell 56, 111-118.

Uptain, S.M., Kane,C.M., Chamberlin,M.J., 1997. Basic mechanisms of transcript elongation and its regulation. Annu. Rev. Biochem. 66, 117-172.

Wang, J.C., 1996. DNA topoisomerases. Annu. Rev. Biochem. 65, 635-692.

Wang, James C., 2009. Untangling the Double Helix: DNA Entanglement and the Action of the DNA Topoisomerases. Cold Spring Harbor Laboratory Press.

Wang, J.C., Lynch,A.S., 1993. Transcription and DNA supercoiling. Curr. Opin. Genet. Dev. 3, 764-768. 
Wang, M.D., Schnitzer,M.J., Yin,H., Landick,R., Gelles,J., Block,S.M., 1998. Force and velocity measured for single molecules of RNA polymerase. Science 282, $902-$ 907.

Wu, H.Y., Shyy,S.H., Wang,J.C., Liu,L.F., 1988. Transcription generates positively and negatively supercoiled domains in the template. Cell 53, 433-440.

Zechiedrich, E.L., Khodursky,A.B., Bachellier,S., Schneider,R., Chen,D., Lilley,D.M., Cozzarelli,N.R., 2000. Roles of topoisomerases in maintaining steady-state DNA supercoiling in Escherichia coli. J. Biol. Chem. 275, 8103-8113. 


\section{Chapter 3: Activating the Salmonella typhimurium leu-500 promoter by transcription-coupled DNA supercoiling in vivo}

\subsection{Abstract}

Transcription is able to modulate localized DNA topology both in vitro and in vivo. This phenomenon has been nicely explained by a "twin-supercoiled-domain" model of transcription in which a transcribing RNA polymerase is able to induce the formation of a transient positive supercoiled domain ahead of the RNA polymerase and a negatively supercoiled domain behind it. Transcription-induced localized, topological change of chromosome is expected to remodel chromosomal structure and greatly influence DNA transactions, such as transcription, DNA replication, and recombination. In this chapter, we developed an in vivo system to study TCDS and its effects on the supercoilingsensitive leu-500 promoter. This system consists of an E. coli topA strain VS111(DE3) and a linear plasmid DNA template in which the leu-500 promoter is divergently coupled to the T7 promoter. Additionally, a luciferase gene is under the control of the leu-500 promoter. Using the highly sensitive luciferase assay and RT-PCR experiment, we demonstrated that transient TCDS was able to activate the $l e u-500$ promoter. Our results are consistent with the hypothesis in which transcription is a major chromosomal remodeling force in $E$. coli cells.

\subsection{Introduction}

It has been well known that transcription and DNA topology are mutually linked (Fisher, 1984; Pruss and Drlica, 1989; Wang and Lynch, 1993). Effects of transcription on DNA topology have been studied for many years. In 1983, Lockshon and Morris 
found plasmid pBR322 isolated from E. coli cells becomes positively supercoiled after exposure to DNA gyrase inhibitors (Lockshon and Morris, 1983). In a later study by Pruss (Pruss, 1985), it was demonstrated that pBR322 isolated from E. coli or $S$. typhimurium topA mutants lacking DNA topoisomerase I is hypernegatively supercoiled. Based on these studies, In 1987, Liu and Wang proposed the "twin-supercoiled-domain" model, to explain TCDS (Liu and Wang, 1987). They hypothesized that as the size of the RNA transcript increases, it will be more difficult for the transcribing complex to rotate around the DNA double helix. Therefore, at a critical point, it is more practical for the DNA to rotate around its own helical axis to produce a transient positively supercoiled domain ahead of the RNA polymerase and a transient negatively supercoiled domain behind it. In bacteria, DNA gyrase functions to convert a part of the transient positive supercoils to "permanent" negative supercoils, whereas DNA topoisomerase I and IV function to relax a fraction of the transient negative supercoils (Adachi et al., 1989).

DNA topology was able to affect the transcriptional efficiency of certain genes. Although both negative and positive supercoiling have been reported to inhibit transcription of some genes (Brahms et al., 1985; Wang, 1992; Gralla, 1996), it appears that negative supercoiling usually stimulates transcription. The best example came from the study of the prokaryotic leu-500 promoter in S. typhimurium and E. coli, which is normally inactive, but it can be activated by negative supercoiling of DNA templates (Lilley and Higgins, 1991; Tan et al., 1994). The leu-500 mutation is a single A-to-G point mutation in the -10 region of the promoter controlling the leu operon which results in leucine auxotrophy (Mukai and Margolin, 1963; Dubnau and Margolin, 1972). The AT 
to $\mathrm{GC}$ mutation is expected to increase the energy barrier for the formation of a functional transcription open complex. This phenotype can be suppressed by a mutation in the topoisomerase I gene which results in a loss of topoisomerase I's activities (Trucksis et al., 1981). Intriguingly, Lilley and Higgins demonstrated that the activation of the leu-500 promoter was only dependent on the top $A$ background but did not correlate with the level of global supercoiling, as measured for extracted plasmid DNA (Lilley and Higgins, 1991). When the leu-500 promoter alone was cloned into a plasmid, it could no longer be activated in the topA strains (Lilley and Higgins, 1991; Chen et al., 1992). These results suggested that an "unknown" regulating element is responsible for the activation of the leu-500 promoter. Results from Dr. Wu's group and Dr. Lilley's group showed that transcription-driven localized supercoiling rather than the global superhelical density is responsible for activation of the leu-500 promoter (Chen et al., 1992; Tan et al., 1994), suggesting that the "unknown" regulating element is TCDS. More recently, on the basis of a series of careful analyses, $\mathrm{Wu}$ and co-workers have proposed a promoter relay mechanism to explain the expression of genes in the ilvIH-leuO-leuABCD gene cluster which is coordinated in a sequential manner (Fang and Wu, 1998; Fang and Wu, 1998). The key component in this model is TCDS, which causes transient localized structural changes on DNA templates.

While it is clear that TCDS plays an essential role in the activation of the leu-500 promoter, a detailed mechanism explaining how TCDS regulates gene expression is still elusive. Many studies showed that transcription has significant effects on DNA topology (Dröge, 1994). For example, transcription can induce DNA supercoiling in the presence 
of $E$. coli DNA topoisomerase I or gyrase. Models such as the "twin-supercoiled-domain" model of transcription have been proposed (Liu and Wang, 1987), but they cannot completely explain all experimental results (Drolet et al., 1994; Chen and Lilley, 1999). In addition, many aspects of transcription-coupled DNA supercoiling have yet to be explored. A well-controlled system is definitely required for further studies. In addition, many DNA transactions such as the initiation of DNA replication, recombination, and transcription are coupled to transcription. In many cases, the transient topological changes of DNA templates induced by transcription are responsible for the initiation of these DNA transactions (Dröge, 1994). Thus, a study of transcription-coupled DNA supercoiling and its activation of gene expression in vivo are of biological significance and fundamental interest. In this chapter, we established an in vivo system to study transient TCDS and its effects on the supercoiling-sensitive leu-500 promoter. Our results showed that transient TCDS was indeed able to activate the leu-500 promoter in E. coli cells.

\subsection{Methods}

\subsubsection{Materials}

Ethidium bromide, Kanamycin, lysozyme and chloroquine were purchased from Sigma-Aldrich Corporation (St. Louis, MO). Ampicillin and bovine serum albumin (BSA) were obtained from Fisher Scientific (Fairlawn, NJ). Isopropyl- $\beta$-Dthiogalactopyranoside (IPTG) was obtained from Anatrace, Inc (Maumee, Ohio). All restriction enzymes, T4 DNA ligase, and T4 polynucleotide kinase were bought from New England Biolabs (Beverly, MA). Pfu DNA polymerase was purchased from 
Stratagene, Inc. (La Jolla, CA). All synthetic oligonucleotides used as primers were obtained from MWG-Biotech, Inc. (Huntsville, AL). QIAprep Spin Miniprep Kit, QIAquick Gel Extraction Kit, RNeasy Mini Kit, and QIAquick Nucleotide Removal Kit were bought from QIAGEN, Inc. (Valencia, CA). ThermoScript RT-PCR System plus Platinum ${ }^{\circledR}$ Taq DNA polymerase was purchased from Invitrogen, Inc. (Carlsbad, CA). Power SYBR Green PCR Master Mix was obtained from Applied Biosystems, Inc. (Carlsbad, CA). Luciferase Assay System is a product of Promega Corporation (Madison, WI). SYBR ${ }^{\circledR}$ Gold Nucleic Acid Gel Stain was purchased from Life Technologies (Grand Island, NY).

\subsubsection{Bacterial strains and plasmids}

Escherichia coli strain VS111 $\left[\mathrm{F}^{-}, \lambda^{-}, r p h-I, \Delta t o p A\right]$ and MG1655 $\left[\mathrm{F}^{-}, \lambda^{-}, r p h-I\right]$ were obtained from the Coli Genetic Stock Collection/E. coli Genetic Resource Center (CGSC) at Yale University. The linear plasmids pZXD4, pZXD51, and circular plasmid pZXD14 were described in chapter 2 of this dissertation.

All circular plasmids constructed in this work were derived from plasmid pBR322. Plasmid pZXD64 was constructed by introducing a unique AgeI site into the upstream region of the tet gene of pZXD14 using PCR-based, site-directed mutagenesis. Then, the tet gene between the unique AgeI and BsmI sites of pZXD64 was replaced by a 3,068 bp lacZ gene DNA fragment of plasmid pYC2/CT/lacZ (Life Technologies, Grand Island, NY) to generate pZXD65. Next, four Rho-independent E. coli rrnB T1 terminators from plasmid pLUC1 were inserted into XbaI site of pGL3 (Promega Corporation, Wisconsin, WI) to yield pZXD67. A 2,511 bp HindIII-SpeI DNA fragment of pZXD67 carrying a 
modified firefly (Photinus pyralis) luciferase gene (the codon usage was optimized for mammalian cells) and four Rho-independent E. coli $r r n B$ T1 terminators was inserted between the HindIII and SpeI sites of pZXD65 to produce pZXD70. Plasmid pZXD74 was created by silently removing the EcoRI site in the downstream region of lacZ gene of plasmid pZXD70 without changing the open reading frame of lacZ gene using PCRbased, site-directed mutagenesis. Plasmid pZXD76 was generated after a XbaI site was inserted into the downstream region of the luciferase gene of plasmid pZXD74. Then, a 1,688 bp DNA fragment of pZE15luc carrying a firefly (Photinus pyralis) luciferase gene (the codon usage was optimized for bacterial cells) was inserted into the HindIII and Xbal sites of pZXD76 to yield pZXD77.

In this study, a few plasmids that differ in the distance and DNA composition between the $\mathrm{T} 7$ and leu-500 promoters were constructed. pZXD97 was created by inserting a $72 \mathrm{bp}$ synthetic deoxyoligonucleotide containing the leu-500 promoter and a unique BamHI site into the HindIII and EcoRI sites of pZXD77. pZXD99 was produced by inserting a 53 bp synthetic deoxyoligonucleotide into the BamHI and EcoRI sites of pZXD97. pZXD94 was constructed in two steps. First, a 72 bp synthetic deoxyoligonucleotide containing the leu-500 promoter and a unique AvrII site was inserted into the HindIII and EcoRI sites of pZXD77 to create pZXD92. Second, a $720 \mathrm{bp}$ DNA fragment of pZXD57 (pZXD57 was described in chapter 2) carrying part of GFPuv gene was inserted into AvrII and EcoRI sites of pZXD92 to yield pZXD94. pZXD93 was created by inserting a $47 \mathrm{bp}$ synthetic deoxyoligonucleotide into the AvrII and EcoRI sites of pZXD92. pZXD100 was produced by inserting a 31 bp synthetic deoxyoligonucleotide into the BamHI and EcoRI sites of pZXD97. pZXD102, pZXD104 
were created by inserting one or two copies of 52 bp synthetic deoxyoligonucleotide into the unique BamHI site of pZXD99, respectively. The distance between the T7 and the leu-500 promoters for different plasmids are listed in Table 3.2.

Plasmids pZXD82, 83, 84, 85, and 86 were constructed by replacing the T7 promoter with E. coli promoters $\mathrm{P}_{\mathrm{T} 7 \mathrm{~A} 1 / \mathrm{O} 4}, \mathrm{P}_{\text {tac }}, \mathrm{P}_{\text {lacUV55 }}, \mathrm{P}_{\text {lac }}$ and $\mathrm{P}_{\text {lacL8 }}$ between the EcoRI and XhoI sites of pZXD77, respectively.

The linear plasmid pZXD80 was constructed by inserting a 6,833bp BglII-SpeI (from pZXD77) fragment carrying a $\mathrm{T} 7$ promoter and the leu-500 promoter in the divergent orientations as described above into the BgIII-NheI sites of pZXD4. Similarly, the linear plasmid pZXD103 was constructed by inserting a 6,763bp BglII-SpeI (from pZXD99) fragment carrying a T7 promoter and the leu-500 promoter in the divergent orientation into the BgIII-NheI sites of pZXD4. Plasmids pZXD87, 88, 89, 90, and 91 were constructed by inserting a $~ 6.9 \mathrm{~kb}$ BglII-SpeI (from pZXD82, 83, 84, 85, and 86) fragment carrying a $\mathrm{P}_{\mathrm{T7A} 1 / \mathrm{O} 4}, \mathrm{P}_{\mathrm{tac}}, \mathrm{P}_{\text {lacUV55 }}, \mathrm{P}_{\text {lac }}$ and $\mathrm{P}_{\text {lacL8 }}$ promoter and the leu-500 promoter in the divergent orientations as described above into the BglII-NheI sites of pZXD4, respectively.

\subsubsection{Luciferase Assay}

Luciferase Assay was used to verify the expression of luciferase in various E. coli strains carrying different plasmid DNA templates. Briefly, E. coli cells carrying different plasmids were grown overnight in LB containing $50 \mu \mathrm{g} / \mathrm{ml}$ of ampicillin or Kanamycin. The overnight culture was then diluted (1:100) in fresh LB containing $50 \mu \mathrm{g} / \mathrm{ml}$ of ampicillin or Kanamycin in the presence of different concentrations of IPTG, and grown 
until the optical density at $600 \mathrm{~nm}$ reached approximately 0.5 . Next, $50 \mu 1$ of cells were mixed with $10 \mu \mathrm{l}$ of $1 \mathrm{M} \mathrm{K}_{2} \mathrm{HPO}_{4}(\mathrm{pH} 7.8)$ and $20 \mathrm{mM}$ EDTA, quickly frozen in liquid nitrogen for $3 \mathrm{~min}$, and equilibrated to room temperature for $30 \mathrm{~min}$ to yield about $60 \mu \mathrm{l}$ of cell lysate. Then, the cell lysate was mixed with $300 \mu 1$ freshly prepared lysis mix containing $1 \times$ cell culture lysis reagent $(\mathrm{CCLR}), 1.25 \mathrm{mg} / \mathrm{ml}$ lysozyme, and $2.5 \mathrm{mg} / \mathrm{ml}$ BSA, and incubated for $10 \mathrm{~min}$ at room temperature. Finally, $100 \mu \mathrm{l}$ of Luciferase Assay Reagent (Promega Corporation, Madison, WI) was added to $20 \mu 1$ of the cell lysate and used for light measurement by using a lunometer (Biocounter, Titusville, FL) with an integration time of $10 \mathrm{~s}$.

\subsubsection{RNA isolation, cDNA synthesis, and polymerase chain reaction (PCR)}

Total RNA were isolated from E. coli cells using QIAGEN RNeasy Kit as described by the manufacturer. To determine the integrity of the total RNA samples, $16 \mathrm{~S}$ and $23 \mathrm{~S}$ rRNA were resolved by electrophoresis in a $1.2 \%$ agarose gel in $1 \times$ MOPS buffer containing formaldehyde (20 mM MOPS, $8 \mathrm{mM}$ sodium acetate anhydrous and $1 \mathrm{mM}$ EDTA, $\mathrm{pH} 7.0$, and $1 \%$ formaldehyde). After electrophoresis, agarose gels were stained with ethidium bromide, destained, and photographed under UV light. cDNA were synthesized from total RNA samples using ThermoScript RT-PCR System. $2.76 \mu \mathrm{g}$ of RNA was mixed with random hexamer primers $(50 \mathrm{ng} / \mu \mathrm{l})$ and four deoxynucleotide triphosphates (dNTPs; final concentration: $1 \mathrm{mM}$ ). The mixtures were incubated at $65{ }^{\circ} \mathrm{C}$ for $5 \mathrm{~min}$ and transferred on ice for another $5 \mathrm{~min}$ to remove secondary structures of RNA. The denatured RNA samples were then mixed with $1 \times$ cDNA synthesis buffer with a total volume of $20 \mu 1$ containing $5 \mathrm{mM}$ DTT, 40 units of RNaseOut, and 15 units of 
ThermoScript Reverse Transcriptase, and incubated at $25{ }^{\circ} \mathrm{C}$ for $10 \mathrm{~min}$ followed by 50 ${ }^{\circ} \mathrm{C}$ for 50 min to synthesize cDNA. The cDNA synthesis mixtures were transferred to an $85{ }^{\circ} \mathrm{C}$ water bath for $5 \mathrm{~min}$ to terminate the reactions. After the synthesis step, the reaction mixtures were mixed with 2 units of RNase $\mathrm{H}$ and incubated at $37{ }^{\circ} \mathrm{C}$ for $20 \mathrm{~min}$ to remove the RNA templates.

PCR Reactions were carried out using cDNA samples synthesized as described above. A $50 \mu 1$ PCR reaction contains $1 \times$ PCR Buffer without $\mathrm{Mg}^{2+}, 1 \mathrm{mM} \mathrm{MgCl} 2,0.2$ mM dNTPs, $0.2 \mu \mathrm{M}$ of each primer, $0.5 \mu \mathrm{l}$ cDNA and 2 units of Platinum Taq DNA polymerase. The reactions started at $94{ }^{\circ} \mathrm{C}$ for 2 min, proceeded 16 cycles (for linear plasmids, used $21 \mathrm{cycles}$ instead) of $94{ }^{\circ} \mathrm{C}$ for $30 \mathrm{sec}, 55{ }^{\circ} \mathrm{C}$ for $30 \mathrm{sec}$ and $72{ }^{\circ} \mathrm{C}$ for 1 min, and terminated at $72{ }^{\circ} \mathrm{C}$ for $10 \mathrm{~min}$. Subsequently, the PCR products were analyzed by electrophoresis in a $12 \%$ polyacrylamide gel in $1 \times \mathrm{TAE}$ buffer. After electrophoresis, polyacrylamide gels were stained with ethidium bromide, destained, and photographed under UV light.

\subsubsection{Real-time PCR Assays}

Real-time PCR assays were carried out using MiniOpticon Real-time PCR system (Bio-rad, Hercules, CA). A $20 \mu \mathrm{l}$ reaction contains $0.5 \mu \mathrm{cDNA}, 0.5 \mu \mathrm{M}$ of each primer and $10 \mu 1$ of Power SYBR Green PCR Master Mix (2X). The reaction started at $95{ }^{\circ} \mathrm{C}$ for $10 \mathrm{~min}$ and continued for 40 cycles at $95^{\circ} \mathrm{C}$ for $15 \mathrm{~s}$ and $60{ }^{\circ} \mathrm{C}$ for $1 \mathrm{~min}$. The $\mathrm{C}_{\mathrm{q}}$ values (quantification cycle values) were calculated from exponential phase of each PCR amplification reaction as recommended by the manufacturer. 


\subsubsection{In vivo transcription-supercoiling (T-S) assay}

E. coli cells carrying different plasmids were grown overnight in LB containing $50 \mu \mathrm{g} / \mathrm{ml}$ of ampicillin. The overnight culture was then diluted $(1: 100)$ in fresh LB containing $50 \mu \mathrm{g} / \mathrm{ml}$ of ampicillin and different concentrations of IPTG grown until optical density of cells at $600 \mathrm{~nm}$ reached approximately 0.5 . Plasmid DNA was purified using QIAGEN Miniprep Kit. The topological state of each DNA preparation was analyzed by electrophoresis in a 1\% agarose gel in $1 \times$ TAE buffer ( $40 \mathrm{mM}$ Tris-acetate, 1 mM EDTA, $\mathrm{pH} 7.8$ ) containing $5 \mu \mathrm{g} / \mathrm{ml}$ of chloroquine. After electrophoresis, agarose gels were stained with SYBR Gold and photographed under UV light. The Net Intensity of DNA topoisomers was determined using KODAK 1D Image Analysis Software. The percentage of hypernegative DNA supercoils was calculated by dividing the intensity of hypernegatively supercoiled DNA band with the total intensity of all DNA topoisomers.

\subsection{Results and Discussion}

\subsubsection{Design an in vivo system to examine the activation of the S. typhimurium leu-}

\section{0 promoter by transient TCDS}

Previous studies showed that TCDS was able to activate the S. typhimurium leu500 promoter (Lilley and Higgins, 1991; Tan et al., 1994; Mojica and Higgins, 1996; Chen et al., 1998). Although it was demonstrated that transcription-driven localized supercoiling rather than the global superhelical density was responsible for the activation of the leu-500 promoter (Mojica and Higgins, 1996), it is not clear whether transient TCDS is capable of activating the coupled leu-500 promoter. The main reason for causing this vagueness is that previous studies almost solely relied on circular plasmids 
for determining the topological change of the DNA templates (Tan et al., 1994; Mojica and Higgins, 1996; Chen et al., 1998). In this case, it is difficult to judge whether the effects come from the transient or permanent supercoiling process. In this study, we established an in vivo system, consisting of a circular plasmid or a linear plasmid and $E$. coli topA strain VS111(DE3) or wild type strain MG1655(DE3) to study transcriptional activation of the supercoiling sensitive leu-500 promoter by T7 RNA polymerase. Figure 3.1 shows two plasmids that were constructed for this study. Plasmid pZXD99 is a circular plasmid derived from plasmid pBR322 (New England Biolab, Inc., Beverly, MA). It carries two divergently-coupled promoters: a unique T7 promoter for bacteriophage T7 RNA polymerase and a weak leu-500 promoter for E. coli RNA polymerase. The distance between these two promoters is $77 \mathrm{bp}$ (the distance was calculated between the -35 region of the leu-500 promoter and the beginning of the $\mathrm{T} 7$ promoter). No other promoter-like sequences were found between these two promoters and also around these two promoters. Plasmid pZXD99 also contains a lacZ gene under the control of the T7 promoter and a luciferase gene under the control of the weak leu500 promoter. In this case, the expression levels initiated from these two promoters can be easily monitored (de Wet et al., 1985). Additionally, two sets of four Rho-independent rrnB T1 transcription terminators were used to terminate transcription initiated from these two promoters efficiently (Leng and McMacken, 2002). The presence of these two sets of transcription terminators enabled us to restrict transcription to selected regions of the circular plasmid. Plasmid pZXD103 is a linear plasmid derived from coliphage N15based, low-copy-number plasmid pZXD4 (N V Ravin and Ravin, 1999). To construct pZXD103, the large BgIII-SpeI fragment (6,763 bp) including the leu-500 promoter, the 
$\mathrm{T} 7$ promoter, luc, lacZ, and two sets of four Rho-independent rrnB $\mathrm{T} 1$ transcription terminators was cloned into the multiple cloning site of pZXD4. In this case, transcriptional activation of the leu-500 promoter can be examined in a linear plasmid background. Because linear DNA templates cannot be supercoiled (N V Ravin and Ravin, 1999; Deneke et al., 2000; Ravin, 2003), TCDS initiated from the T7 promoter is always transient. As mentioned above, we used a few E. coli strains for this study including a topA strain VS111(DE3) and a wild-type strain MG1655(DE3) (Table 3.1) in which the expression of T7 RNA polymerase is IPTG-inducible and the expression level is dependent on the IPTG concentration added to the cell culture (Samul and Leng, 2007). Using these two strains, we were able to study the activation of the leu-500 promoter by TCDS initiated from the T7 promoter.

We also made a few plasmid DNA templates (both circular and linear plasmids) to test whether the distance and DNA sequence composition between these two promoters are critical for the activation of the leu-500 promoter by TDCS (Table 3.2). Additionally, a series of plasmid DNA templates were constructed to examine whether TCDS initiated from an E. coli promoter is able to activate the divergently-coupled leu500 promoter and whether promoter strength is critical for the activation as well. All plasmids constructed in this study are summarized in Table 3.2.

\subsubsection{Transient TCDS is able to activate the supercoiling-sensitive $l e u-500$ promoter}

In order to examine whether TCDS by T7 RNA polymerase is able to activate the supercoiling-sensitive leu-500 promoter, plasmid pZXD99 was transformed into E. coli topA strain VS111(DE3) and IPTG was added to the cell culture to induce the 
transcription by T7 RNA polymerase. Since luciferase assays are extremely sensitive, we were measuring the firefly luciferase activities to monitor the activation of the leu-500 promoter. As shown in Figure 3.2, in the absence of IPTG, some luciferase activities were measured, indicating that the weak leu-500 promoter was able to direct the initiation of transcription of the luciferase gene. Interestingly and also as expected, the addition of IPTG to the cell culture greatly stimulated the luciferase activities. At $50 \mu \mathrm{M}$ of IPTG, the luciferase activity increases approximately 10-fold. We also transformed pZXD99 into a wild type strain $M G 1655(D E 3)$ and carried out the luciferase assays. IPTG was also able to stimulate the luciferase activities in the wild type strain. However, the stimulation level was significantly reduced, suggesting that the activation of the leu-500 promoter is greatly enhanced by a top $A$ background. Additionally, we carried out a control experiment in which two compatible plasmids were transformed into VS111(DE3) strain. The first plasmid pZXD95 is a circular plasmid and carries a luciferase gene under the control of the leu-500 promoter. This plasmid does not contain a T7 promoter. The second plasmid is a linear plasmid and carries a $\mathrm{T} 7$ promoter controlling the expression of lacZ gene. As demonstrated in Figure 3.2, IPTG could not stimulate the luciferase activities. These results suggest that transcription by T7 RNA polymerase in the same plasmid DNA template is required for the stimulation of the luciferase activities. Since the leu-500 promoter is divergently coupled to the T7 promoter, TCDS by T7 RNA polymerase is most likely the mechanism for the activation of the supercoiling-sensitive leu-500 promoter and the stimulation of luciferase activities. Indeed, our supercoiling assays showed that transcription by T7 RNA polymerase significantly supercoiled the 
transcribed DNA template pZXD99 in the topA strain VS111(DE3) (please see below for details).

Next, we decided to examine whether TCDS by T7 RNA polymerase in a linear plasmid DNA template is able to stimulate the luciferase activities under the control of the supercoiling-sensitive leu-500 promoter. Since linear plasmids cannot be supercoiled (N V Ravin and Ravin, 1999; Deneke et al., 2000; Ravin, 2003), TCDS driven by T7 RNA polymerase is transient. We transformed the linear plasmid pZXD103 (Figure 3.1) into E. coli topA strain VS111(DE3) and performed luciferase assays. In the absence of IPTG, we were able to detect a very small amount of luciferase activities, indicating that the weak leu-500 promoter was capable of initiating some transcription of the luc gene. Nevertheless, the luciferase activities were 20 to 30 fold lower than those in VS111(DE3) carrying the circular plasmid pZXD99. There are two reasons for causing the lower luciferase activities. The first reason is the copy number difference between $E$. coli cells carrying these two plasmids. Plasmid pZXD99 is derived from pBR322 and each cell should contain about 15 to 20 copies of this plasmid. Plasmid pZXD103 is derived from the low copy-number, linear plasmid pG591 (N V Ravin and Ravin, 1999) and each cell only carries approximately 1 to 3 copies of the plasmid. Indeed, our unpublished results showed that $\operatorname{VS111(DE3)}$ is able to carry 10 more times of plasmid pZXD99 than plasmid pZXD103. In this case, E. coli cells carrying pZXD99 should produce at least 10-fold of firefly luciferase as E. coli cells harboring pZXD103. The second reason stems from the topology difference between these two plasmids in E. coli cells. Circular plasmids in $E$. coli cells are usually supercoiled with an average superhelical density of $\sim-0.06$ (Bauer et al., 1980; Vologodskii, 1992). Indeed, we determined the supercoiling density of 
pZXD99 to be $\sim-0.06$ in $\operatorname{VS111(DE3)~in~the~absence~of~IPTG~(please~see~below~for~}$ details). As mentioned above, linear plasmids cannot be supercoiled in vivo. Because the leu-500 promoter is sensitive to DNA supercoiling (Lilley and Higgins, 1991; Tan et al., 1994), the topology difference should also contribute to the difference of luciferase activities in topA strain VS111(DE3) carrying pZXD99 or pZXD103. In the next step, we added different concentrations of IPTG to E. coli topA strain VS111(DE3) harboring pZXD103 to initiate transcription from the T7 promoter. As expected, IPTG was able to significantly stimulate the luciferase activities. At $20 \mu \mathrm{M}$ of IPTG, the luciferase activities almost increased 4-fold (Figure 3.2B). Control experiments showed that the stimulation of the luciferase activities was dependent on the transcription of the lac $Z$ gene in the same plasmid (Figure 3.2B). Since the leu-500 promoter controlling the transcription of the luciferase gene is divergently coupled to the T7 promoter in the linear plasmid pZXD103, the transient TCDS generated from the transcription of T7 RNA polymerase should be the mechanism for the activation of the luciferase activities. Similar results were obtained for the wild type strain MG1655(DE3) carrying plasmid pZXD103 (Figure 3.2B).

In this study, we also carried out RT-PCR experiments to study the stimulation of the leu-500 promoter by TCDS generated by T7 RNA polymerase. E. coli strains VS111(DE3) and MG1655(DE3) harboring plasmid pZXD99 were used. As shown in Figure $3.2 \mathrm{C}$ and D, the addition of IPTG into both E. coli cell cultures significantly stimulated the transcription of the divergently-coupled leu-500 promoter. These results clearly demonstrated that at the transcriptional level, transient TCDS driven by T7 RNA polymerase was able to activate the supercoiling-sensitive leu-500 promoter in vivo. 


\subsubsection{The distance and DNA sequence between the divergently-coupled leu-500 promoter and T7 promoter significantly influence the efficiency of TCDS and the activation of the $l e u-500$ promoter}

Previous studies showed that the distance between the two divergently-coupled promoters is important for the activation of the leu-500 promoter by TCDS (Brahms et al., 1985; Chen et al., 1993; Tan et al., 1994; Spirito and Bossi, 1996; Fang and Wu, 1998; Ravin and Lane, 1999; Ravin et al., 2000), we, therefore, decided to change the distance between the leu-500 promoter and the T7 promoter and examine whether the distance and DNA composition between these two promoters affect the efficiency of the activation of the leu-500 promoter by TCDS. For this purpose, we constructed two groups of plasmid DNA templates. The first group of plasmid DNA templates includes pZXD100, pZXD102, and pZXD104 which are derived from pZXD99. Synthetic DNA fragments were used to change the distance between the two promoters. In the absence of IPTG, $E$. coli topA strain VS111(DE3) harboring one of these plasmids had similar luciferase activities, indicating that the DNA sequence inserting between the two divergentlycoupled promoters did not significantly affect the leu-500 promoter and did not introduce new promoter activities near the leu-500 promoter. Similar to E. coli strain VS111(DE3) harboring pZXD99, IPTG was also able to significantly activate the luciferase activities for $\operatorname{VS111(DE3)}$ carrying these three plasmids to a similar level. These results suggest that for topA strain $\operatorname{VS111(DE3)}$ the distance between the two divergently-coupled promoters is not very critical for the activation of the leu-500 promoter by TCDS. The second group of plasmid DNA templates contains plasmids pZXD77, pZXD92, pZXD93, pZXD94, and pZXD97. First, DNA fragments different from those used in the first group 
of DNA plasmids were inserted between the two divergently-coupled promoters. Additionally, we varied the distance between these two promoters from $36 \mathrm{bp}$ to $750 \mathrm{bp}$. Surprisingly, although we did not find promoter-like sequences in the DNA fragments inserted between these two promoters, we saw a significant increase of the luciferase activities for E. coli topA strain $V S 111(D E 3)$ carrying one of these plasmids in the absence of IPTG. For instance, the luciferase activity of VS111(DE3) carrying pZXD77 was measured to be 12,158 RLU, 4 times more than that of $V S 111(D E 3)$ harboring pZXD99. For VS111(DE3) carrying pZXD93, the luciferase activity was even higher and was measured to be 68433,24 -fold as that of VS111(DE3) containing pZXD99. Although the mechanisms that cause the increase of the luciferase activities have not been determined yet, a possible reason is that we accidently introduced promoter-like sequences in the region. In this case, the new promoters were able to initiate transcription of the luciferase gene. Another possible reason is that the DNA structure was changed when we introduced the DNA sequences into the region between the two divergentlycoupled promoters. Furthermore, we may introduce some DNA-binding sequences into the region. In this case, certain transcriptional factors bind to the DNA sequence between the two promoters and stimulate transcription of the luciferase gene. Nevertheless, our results shown in Figure 3.3B demonstrated that IPTG was able to stimulate the luciferase activities for E. coli strain VS111(DE3) carrying these plasmid DNA templates, suggesting that TCDS by T7 RNA polymerase was capable of activating the leu-500 promoter in all these circular plasmid templates.

In this dissertation, we also carried out luciferase assays and RT-PCR experiments for E. coli strains $V S 111(D E 3)$ and $M G 1655(D E 3)$ carrying circular plasmid pZXD77 or 
linear plasmid pZXD80. Our results are shown in Figure 3.4. Similar to the results for $E$. coli strains harboring pZXD99 or pZXD103, IPTG was able to stimulate the luciferase activities at protein and RNA levels in the topA strain VS111(DE3) and the wild type strain $M G 1655(D E 3)$. These results suggest that transient TCDS by T7 RNA polymerase is capable of activating the leu-500 promoter. Interestingly, the activation is dependent on IPTG concentration. The luciferase activities reached the highest point when the IPTG concentration was $20 \mu \mathrm{M}$ in the cell culture for E. coli cells containing the circular plasmid pZXD77 and $10 \mu \mathrm{M}$ for E. coli cells harboring the linear plasmid pZXD80. Higher concentrations of IPTG result in less luciferase activities. For wild type E. coli strain $M G 1655$ (DE3), $100 \mu \mathrm{M}$ of IPTG inhibited the luciferase activities. These results suggest that too much supercoiling may inhibit the leu-500 promoter's activities. Regardless, further studies are required to rule out other possibilities.

\subsubsection{The activation of the leu-500 promoter is dependent on the promoter strength of $E$. coli RNA polymerase}

So far, we only demonstrated that transient TCDS by T7 RNA polymerase was able to activate the divergently-coupled $l e u-500$ promoter. One question that arises from this study is whether transient TCDS by E. coli RNA polymerase is capable of activating the coupled leu-500 promoter and whether promoter strength affects the activation. In order to answer this question, we constructed two sets of plasmid DNA templates: five circular and five linear plasmids that carry different strengths of IPTG-inducible E. coli promoters, i.e., $\mathrm{P}_{\mathrm{T} 7 \mathrm{~A} 1 / 04}, \mathrm{P}_{\mathrm{tac}}, \mathrm{P}_{\mathrm{lacUv}}, \mathrm{P}_{\mathrm{lac}}$, and $\mathrm{P}_{\text {lacL8 }}$ (Lanzer and Bujard, 1988); Figure 3.5; Table 3.2). we then transformed these two unique sets of DNA templates into E. coli 
strains (topA and wild type) overexpressing LacI (Table 3.1) and tested the IPTGinducible stimulation of luciferase activities. Our results are shown in Figure 3.6. As expected, IPTG was able to stimulate the luciferase activities for E. coli strains (both topA and wild type) carrying these circular and linear plasmids, suggesting that transient TCDS by E. coli RNA polymerase was also able to activate the leu-500 promoter. Interestingly and also as expected, the stimulation of luciferase activities is dependent on promoter strength. For example, $50 \mu \mathrm{M}$ of IPTG ( $1 \mathrm{mM}$ of IPTG for E. coli topA strain VS111 harboring linear plasmids pZXD87, 88, 89, 90 and 91) was able to stimulate the luciferase activities for plasmids containing $\mathrm{P}_{\mathrm{T7A} 1 / 04}, \mathrm{P}_{\mathrm{tac}}$, and $\mathrm{P}_{\mathrm{lacUv} 5}$ and however, could not stimulate luciferase activities for plasmid carrying $\mathrm{P}_{\text {lac }}$ and $\mathrm{P}_{\text {lacL8}}$; the stimulation level is correlated with the promoter strength for both circular and linear plasmids (Figure 3.6C and D). Since our results discussed in chapter 2 demonstrated that TCDS in topA strains is dependent on promoter strength, we concluded here that transient TCDS by E. coli RNA polymerase was able to greatly influence the nearby promoters' activities in E. coli cells.

\subsubsection{Transcription-coupled hypernegative supercoiling of plasmid is correlated} with the activation of the $l e u-500$ promoter in the circular plasmid DNA templates

In this dissertation, we also examined the supercoiling status of the circular plasmid pZXD77 in E. coli topA strain VS111(DE3). In the absence of IPTG, plasmid pZXD77 (Table 3.2) isolated from E. coli topA strain VS111(DE3) has a supercoiling density of $\sim-0.06$. Adding IPTG to the cell culture to induce the production of T7 RNA polymerase significantly increased the supercoiling density of plasmid pZXD77 and 
resulted in the generation of hypernegatively supercoiled DNA (Figure 3.7). Consistent with previously published results by our group (Samul and Leng, 2007), the production of hypernegatively supercoiled DNA was dependent on the IPTG concentration and correlated with the activation of the leu-500 promoter in different E. coli strains. These results clearly suggest that TCDS induced by RNA polymerases is the mechanism responsible for the activation of the $l e u-500$ promoter.

\subsection{Conclusions}

In this chapter, we successfully established an in vivo system to study transient TCDS and the activation of the supercoiling-sensitive leu-500 promoter. This system consists of an E. coli topA strain VS111(DE3) and a linear plasmid derived from linear coliphage N15. Because linear plasmid DNA templates cannot be supercoiled, TCDS initiated from $\mathrm{T} 7$ promoter by $\mathrm{T} 7 \mathrm{RNA}$ polymerase is transient. Using this unique system and the highly sensitive luciferase assays, we discovered that transient TCDS by both T7 and E. coli RNA polymerases was able to stimulate the supercoiling-sensitive leu-500 promoter. These results suggest that transcription in E. coli cells is a major chromosomal remodeling force. 
Table 3.1. Escherichia coli strains used in this study

\begin{tabular}{lll}
\hline \hline Strain & Genotype & Source \\
\hline VS111 & $\mathrm{F}^{-} \lambda^{-} i l v G-r f b-50 r p h-I \Delta t o p A$ & E. coli Genetic Resource Center \\
VS111(DE3) & VS111strains with $\lambda$ (DE3) & E. coli Genetic Resource Center \\
VS111/pZXD51 & VS111strain containing plasmid & In this work \\
& pZXD51 & \\
VS111/pZS4Int-laci & VS111strain containing plasmid & In this work \\
& pZS4Int-laci & \\
MG1655 & $\mathrm{F}^{-}, \lambda^{-} i l v G-r f b-50 r p h-1$ & E. coli Genetic Resource Center \\
$M G 1655(D E 3)$ & MG1655 strains with $\lambda(\mathrm{DE} 3)$ & E. coli Genetic Resource Center \\
$M G 1655 / p Z X D 51$ & MG1655 strain containing & In this work \\
& plasmid pZXD51 & \\
$M G 1655 / p Z S 4 I n t-l a c i$ & MG1655 strain containing & In this work \\
& plasmid pZS4Int-laci & \\
\hline
\end{tabular}


Table 3.2. Plasmids constructed in this study

\begin{tabular}{llll}
\hline Plasmid & Promoter & $\begin{array}{l}\text { Distance between two } \\
\text { promoters }\end{array}$ & Type \\
\hline pZXD77 & T7 & $147 \mathrm{bp}$ & Circular \\
pZXD82 & T7A1/O4 & $152 \mathrm{bp}$ & Circular \\
pZXD83 & tac & $158 \mathrm{bp}$ & Circular \\
pZXD84 & lacUV5 & $158 \mathrm{bp}$ & Circular \\
pZXD85 & lac & $158 \mathrm{bp}$ & Circular \\
pZXD86 & lacL8 & $158 \mathrm{bp}$ & Circular \\
pZXD92 & T7 & $36 \mathrm{bp}$ & Circular \\
pZXD93 & T7 & $77 \mathrm{bp}$ & Circular \\
pZXD94 & T7 & $750 \mathrm{bp}$ & Circular \\
pZXD97 & T7 & $36 \mathrm{bp}$ & Circular \\
pZXD99 & T7 & $77 \mathrm{bp}$ & Circular \\
pZXD100 & T7 & $55 \mathrm{bp}$ & Circular \\
pZXD102 & T7 & $129 \mathrm{bp}$ & Circular \\
pZXD104 & T7 & $181 \mathrm{bp}$ & Circular \\
pZXD80 & T7 & $147 \mathrm{bp}$ & Linear \\
pZXD87 & T7A1/O4 & $152 \mathrm{bp}$ & Linear \\
pZXD88 & tac & $158 \mathrm{bp}$ & Linear \\
pZXD89 & lacUV5 & $158 \mathrm{bp}$ & Linear \\
pZXD90 & lac & $158 \mathrm{bp}$ & Linear \\
pZXD91 & lacL8 & $158 \mathrm{bp}$ & Linear \\
pZXD103 & T7 & $77 \mathrm{bp}$ & Linear \\
\hline
\end{tabular}



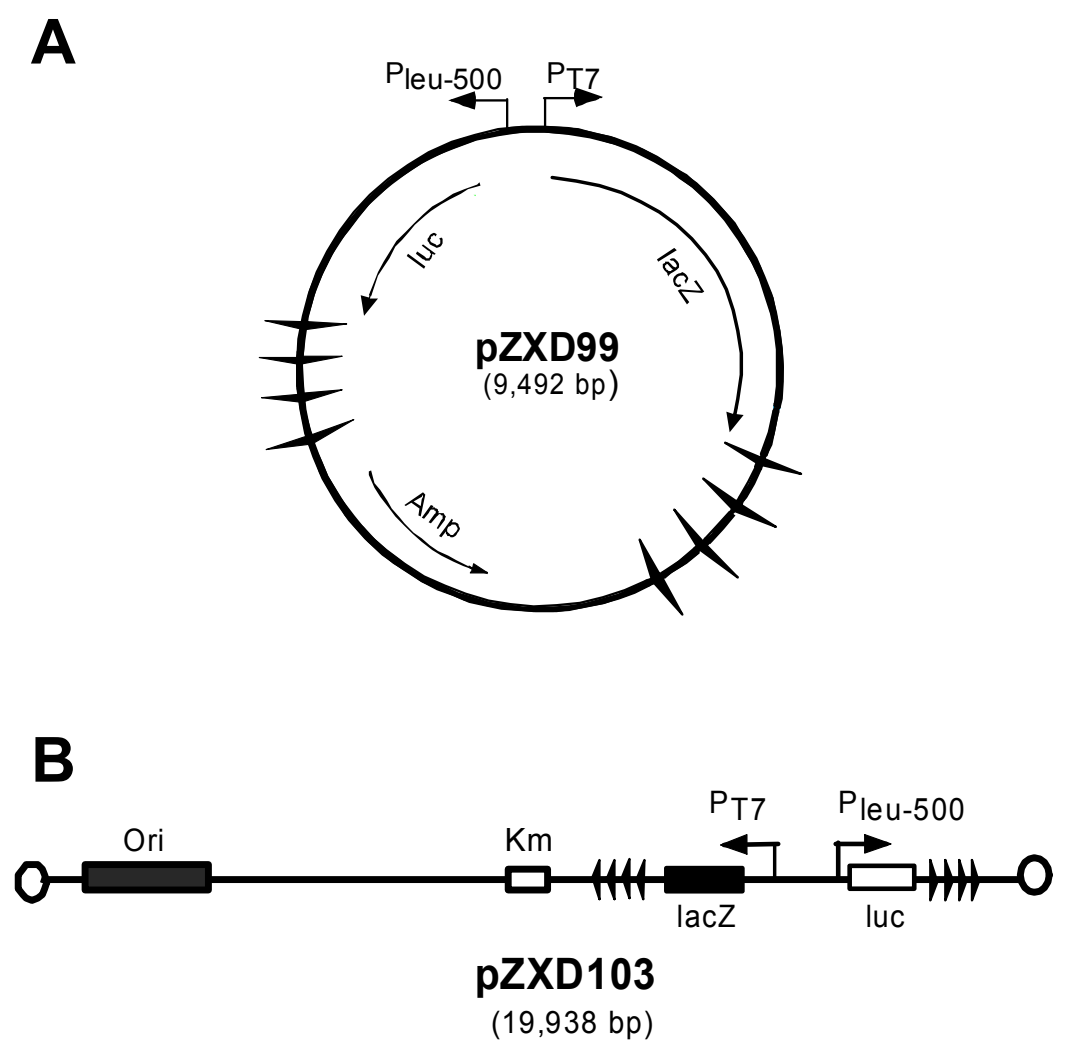

Figure 3.1 Circular plasmid pZXD99 and linear plasmid pZXD103 were constructed to study TCDS in vivo. (A) The circular plasmid pZXD99 was derived from pBR322. (B) The linear plasmid pZXD103 was derived from linear coliphage N15-based, low-copy number plasmid pZXD4 (pZXD4 was described in chapter 2). Plasmid DNA templates were constructed as described under Materials and Methods. Both of them contain a lac $Z$ gene under the control of the T7 promoter and a luciferase gene under the control of the weak leu-500 promoter. There are two sets of four Rho-independent rrnB T1 transcription terminators (winged triangles) on each side of the plasmids to terminate transcription initiated from two promoters. In this case, the transcription unit between the promoter and terminators could be controlled precisely. 
A

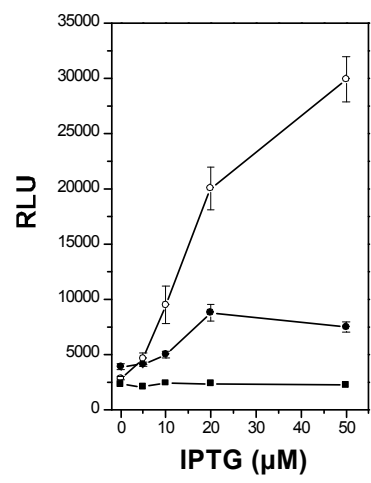

C

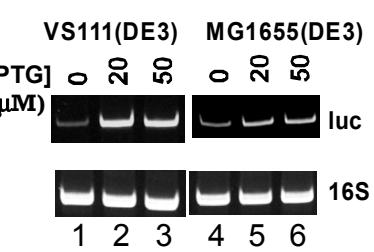

B

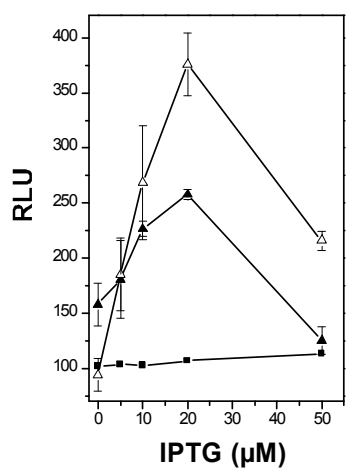

D



Figure 3.2 Luciferase activity was stimulated by the addition of IPTG in E. coli topA strain $V S 111(D E 3)$ or wild type strain $M G 1655(D E 3)$ containing circular plasmid pZXD99 or linear plasmid pZXD103. Luciferase assays were performed as described under Materials and Methods. Different concentrations of IPTG (ranging from $5 \mu \mathrm{M}$ to $50 \mu \mathrm{M})$ were added to the cell culture to stimulate luciferase activity. Light produced was measured by a lunometer. (A) Luciferase assay for circular plasmid pZXD99 in wild type strain $M G 1655(D E 3)$ (solid circles) or topA strain VS111(DE3) (open circle); Control experiment for E. coli topA strain $V S 111(D E 3)$ harboring circular plasmid pZXD95, in which there is no T7 promoter, was shown in solid square. (B) Luciferase assay for linear plasmid pZXD103 in wild type strain $M G 1655(D E 3)$ (solid triangles) or topA strain VS111(DE3) (open triangles); Control experiment for E. coli topA strain VS111(DE3) harboring linear plasmid pZXD91, in which there is no T7 promoter, was shown in solid square. (C) RT-PCR analysis of cDNA products of mRNA transcribed from circular plasmid pZXD99 in E. coli topA strain VS111(DE3) or wild type strain MG1655(DE3) to study the stimulation of luciferase activity by T7 RNA polymerase. RT-PCR experiments were performed as described under Materials and Methods. The upper and lower panels are $12 \%$ polyacrylamide gel in $1 \times$ TAE buffer to show the PCR products of luciferase gene and $16 \mathrm{~S}$ rRNA cDNA synthesized from the RNA samples isolated from E. coli topA strain VS111(DE3) (1-3) or wild type strain MG1655(DE3) (4-6) without IPTG and with $20 \mu \mathrm{M}, 50 \mu \mathrm{M}$ of IPTG induction. (D) The ratios were calculated for RT-PCR analyses of PCR products pZXD99 in E. coli topA strain VS111(DE3) (1-3) or wild type strain $M G 1655(D E 3)$ from (C). 

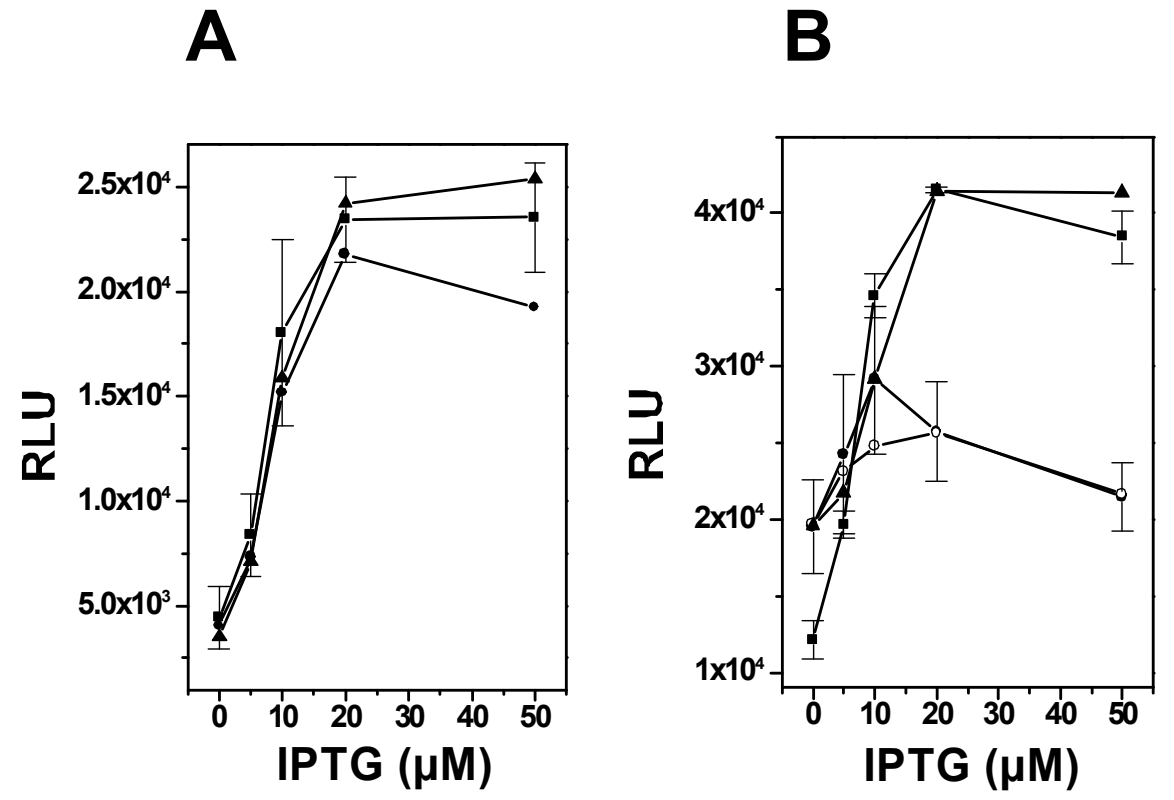

Figure 3.3 Circular plasmids that differ in the distance and DNA sequence composition between two promoters were constructed to examine the stimulation of luciferase activity by T7 RNA polymerase after the addition of IPTG in E. coli topA strain VS111(DE3). Two groups of plasmid DNA templates that differ in the distance and DNA sequence composition between the $\mathrm{T} 7$ promoter and leu-500 promoter were constructed and transformed into the E. coli topA strain VS111(DE3). Luciferase assays were performed as described under Materials and Methods. Different concentrations of IPTG (ranging from $5 \mu \mathrm{M}$ to $50 \mu \mathrm{M}$ ) were added to the cell culture to stimulate luciferase activity. Light produced was measured by a lunometer. (A) First group of plasmid DNA templates includes pZXD100, pZXD102, and pZXD104. The distance between two promoters are: $55 \mathrm{bp}$ (solid triangles), $129 \mathrm{bp}$ (solid square) and $181 \mathrm{bp}$ (solid circles), respectively. (B) Second group of plasmid DNA templates includes pZXD94, pZXD77, pZXD92 and pZXD97. The distances between two promoters are: $750 \mathrm{bp}$ (solid triangles), $147 \mathrm{bp}$ (solid square), $36 \mathrm{bp}$ (solid circles) and $36 \mathrm{bp}$ (different sequence, open circles). 

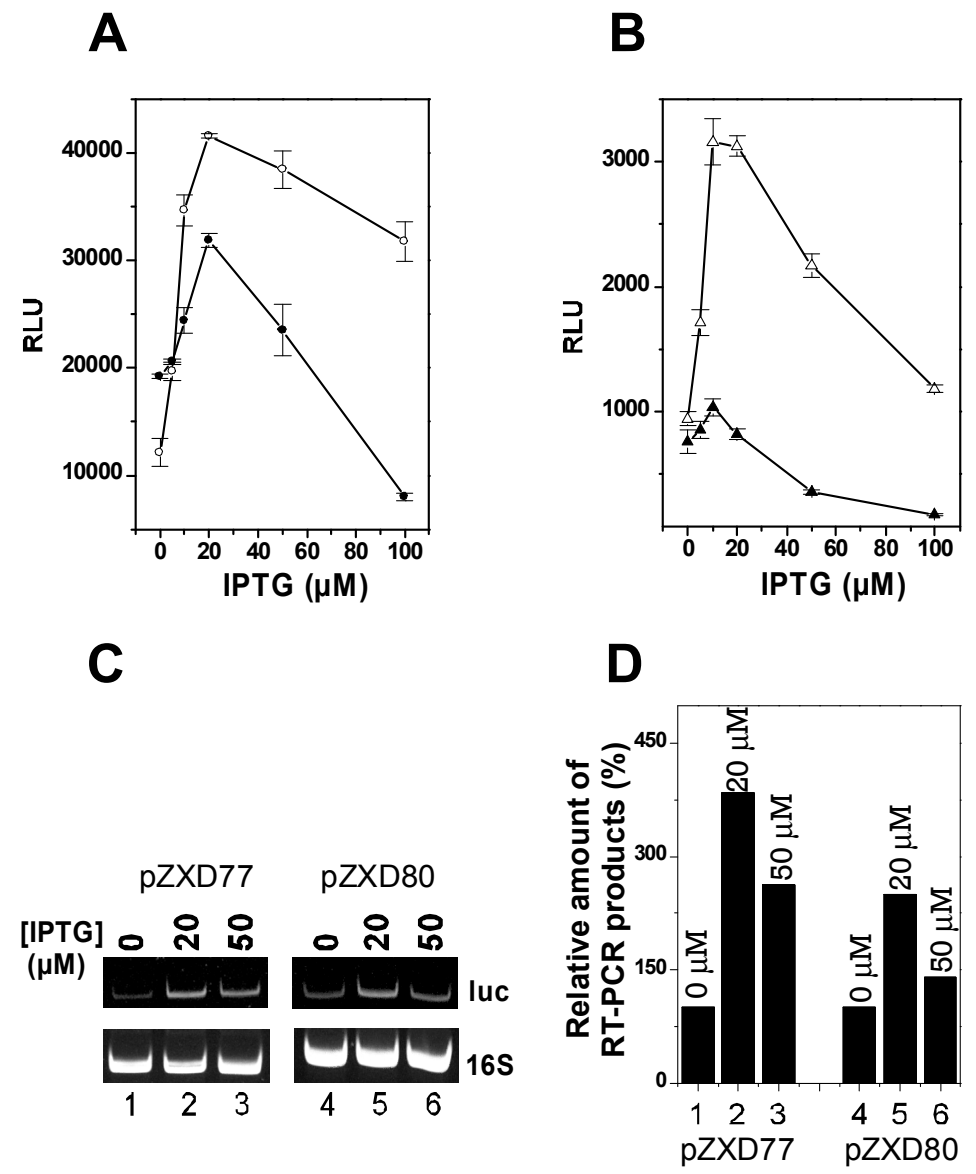

Figure 3.4 Luciferase activity was stimulated by the addition of IPTG in E. coli topA strain $V S 111(D E 3)$ or wild type strain $M G 1655(D E 3)$ containing circular plasmid pZXD77 or linear plasmid pZXD80. Luciferase assays were performed as described under Materials and Methods. Different concentrations of IPTG (ranging from $5 \mu \mathrm{M}$ to $100 \mu \mathrm{M})$ were added to the cell culture to stimulate luciferase activity. Light produced was measured by a lunometer. (A) Luciferase assay for circular plasmid pZXD77 in wild type strain MG1655(DE3) (solid circles) or topA strain VS111(DE3) (open circle). (B) Luciferase assay for linear plasmid pZXD103 in wild type strain MG1655(DE3) (solid triangles) or topA strain VS111(DE3) (open triangles). (C) RT-PCR analysis of cDNA products of mRNA transcribed from circular plasmid pZXD77 (1-3) or linear plasmid pZXD80 (4-6) in E. coli topA strain VS111(DE3) was used to study the stimulation of luciferase activity by T7 RNA polymerase. RT-PCR experiments were performed as described under Materials and Methods. The upper and lower panels are 12\% polyacrylamide gel in $1 \times \mathrm{TAE}$ buffer to show the PCR products of luciferase gene and $16 \mathrm{~S}$ rRNA cDNA synthesized from the RNA samples isolated from E. coli strain VS111(DE3) without IPTG and with $20 \mu \mathrm{M}, 50 \mu \mathrm{M}$ of IPTG induction. (D) The ratios were calculated for RT-PCR analyses of PCR products pZXD77 (1-3) or pZXD80 (4-6) in E. coli topA strain $V S 111(D E 3)$ from (C). 



Figure 3.5 An in vivo system to study E. coli RNA polymerase induced TCDS. This system contains two plasmids, a linear plasmid pZXD51 (as described in chapter 2) or a circular plasmid pZS4Int-laci that overexpresses LacI and (A) Circular plasmid pZXD82 that carries T7A1/O4 promoter. The circular plasmids were derived from plasmid pBR322 and constructed as detailed under Materials and Methods. They harbor an IPTGinducible promoter with different strengths and a transcription unit between the promoter and a set of four Rho-independent $E$. coli rrnB T1 terminators (winged triangles). (B) The DNA sequence of five different E. coli promoters $\mathrm{P}_{\mathrm{T} 7 \mathrm{~A} / \mathrm{O} 4}, \mathrm{P}_{\mathrm{tac}}, \mathrm{P}_{\text {lacUV5 }}, \mathrm{P}_{\mathrm{lac}}$, and $\mathrm{P}_{\text {lacL8. }}$ The underlines represent the lac O1 operators. (C) Linear plasmid pZXD87 carries T7A1/O4 promoter. The linear plasmids were derived from plasmid pZXD4 (as described in chapter 2) and constructed as detailed under Materials and Methods. They harbor an IPTG-inducible promoter with different strengths and a transcription unit between the promoter and a set of four Rho-independent E. coli rrnB T1 terminators (winged triangles). 

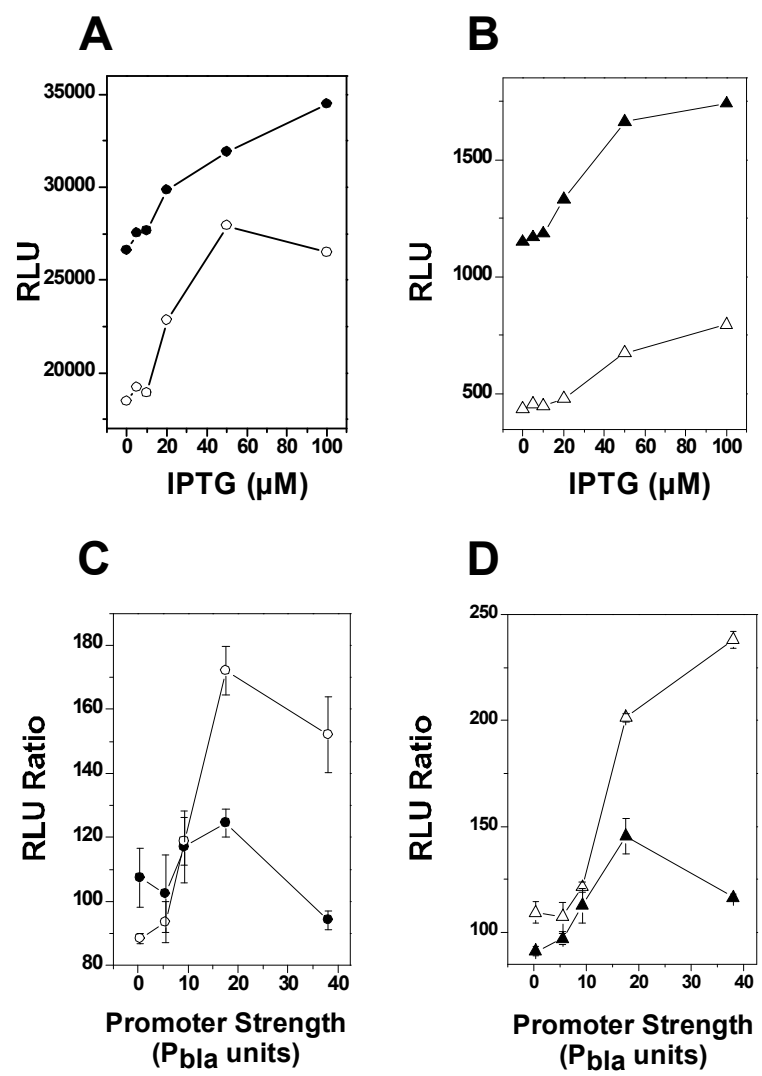

Figure 3.6 Circular plasmids and linear plasmids were transformed into E. coli topA strain VS111 or wild type strain MG1655 to examine the stimulation of the luciferase activity by $E$. coli RNA polymerase after the addition of IPTG. Luciferase assays were performed as described under Materials and Methods. Different concentrations of IPTG (ranging from $5 \mu \mathrm{M}$ to $100 \mu \mathrm{M}$ ) were added to the cell culture to stimulate luciferase activity. Light produced was measured by a lunometer. (A) Luciferase assay for circular plasmid pZXD83 that carries tac promoter in E. coli wild type strain MG1655 (solid circles) or topA strain VS111 (open circle). (B) Luciferase assay for linear plasmid pZXD88 that carries tac promoter in E. coli wild type strain MG1655 (solid triangles) or topA strain VS111 (open triangles). (C) (D) The expression level of luciferase gene by $E$. coli RNA polymerase after the addition of IPTG in E. coli topA strain VS111 or wild type strain MG1655 containing different plasmids is correlated with promoter strength. Luciferase assays were performed as described under Materials and Methods. $50 \mu \mathrm{M}$ of IPTG (for E. coli topA strain VS111 harboring linear plasmids, $1 \mathrm{mM}$ of IPTG was used) was added to the cell culture to stimulate luciferase activity. (C) Circular plasmids pZXD82, 83, 84, 85, and 86 in E. coli wild type strain $M G 1655$ (solid circles) or topA strain VS111 (open circle). (D) Linear plasmids pZXD87, 88, 89, 90, and 91 in E. coli wild type strain $M G 1655$ (solid triangles) or topA strain VS111 (open triangles). Promoter strength in $P_{b l a}$ units was obtained from Lanzer and Bujard (1988). 


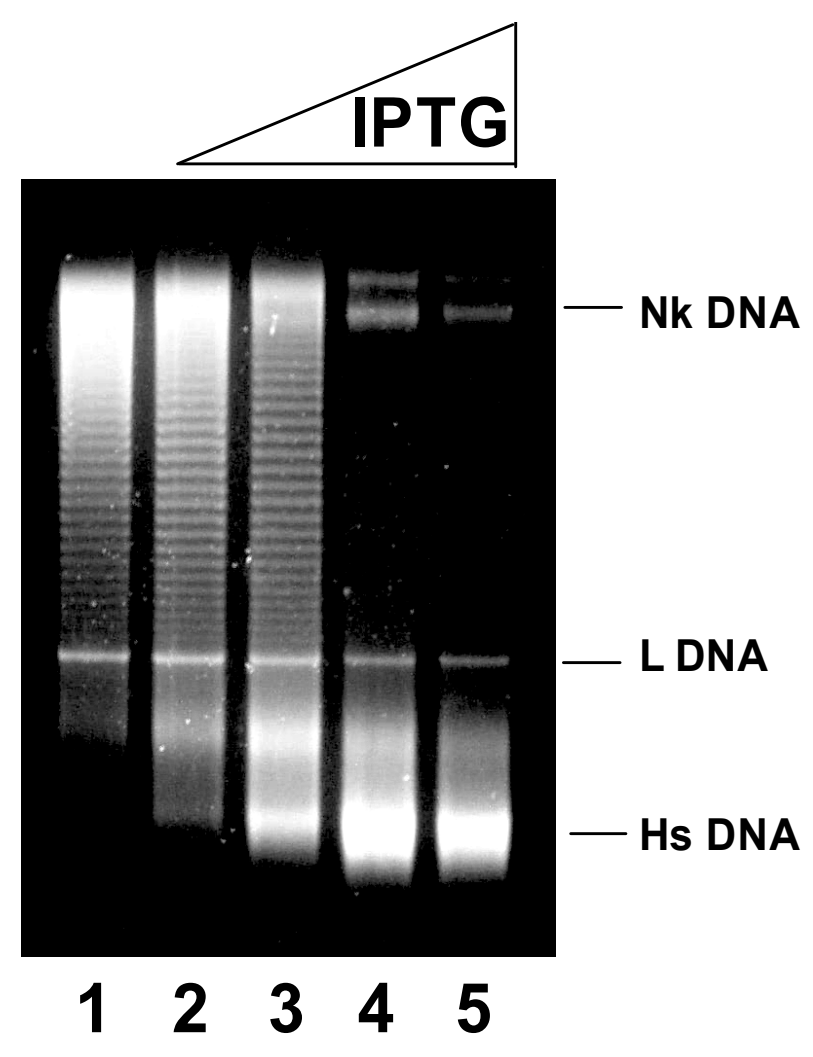

Figure 3.7 Transient TCDS in E. coli strain VS111(DE3) is responsible for the activation of leu-500 promoter. The in vivo T-S assays were performed as described under Materials and Methods. DNA topoisomers were resolved by electrophoresis in a $1 \%$ agarose gel containing $5 \mu \mathrm{g} / \mathrm{ml}$ chloroquine and stained with SYBR Gold. TCDS is dependent on IPTG concentration for circular plasmid pZXD77 in E. coli topA strain VS111(DE3). Lane 1 contained the DNA sample isolated from $E$. coli cells prior to IPTG induction. Lanes 2-5 contained the DNA samples isolated from E. coli cells with $5 \mu \mathrm{M}, 10 \mu \mathrm{M}, 20$ $\mu \mathrm{M}$, and $50 \mu \mathrm{M}$ IPTG induction, respectively. The percentage of hypernegatively supercoiled DNA is proportional to the IPTG concentration. 


\subsection{References}

Adachi, Y., Käs, E., Laemmli, U. K., 1989. Preferential, cooperative binding of DNA topoisomerase II to scaffold-associated regions. EMBO J 8, 3997-4006.

Bauer, W. R., F. H. C. Crick, White, J. H., 1980. Supercoiled DNA. Sci. Am 243, 110143.

Brahms, J. G., Dargouge, O., Brahms, S., Ohara, Y., Vagner, V., 1985. Activation and inhibition of transcription by supercoiling. Journal of Molecular Biology 181, $455-465$.

Chen, D., Bachellier, S., Lilley, D. M. J., 1998. Activation of the leu-500 Promoter by a Reversed Polarity tetA Gene. Journal of Biological Chemistry 273, 653-659.

Chen, D., Bowater, R., Dorman, C. J., Lilley, D. M., 1992. Activity of a plasmid-borne leu-500 promoter depends on the transcription and translation of an adjacent gene. Proceedings of the National Academy of Sciences 89, 8784-8788.

Chen, D., Bowater, R. P., Lilley, D. M. J., 1993. Activation of the leu-500 promoter: A topological domain generated by divergent transcription in a plasmid. Biochemistry 32, 13162-13170.

Chen, D., Lilley, D. M. J., 1999. Transcription-induced hypersupercoiling of plasmid DNA. Journal of Molecular Biology 285, 443-448.

Deneke, J., Ziegelin, G., Lurz, R., Lanka, E., 2000. The protelomerase of temperate Escherichia coli phage N15 has cleaving-joining activity. Proceedings of the National Academy of Sciences 97, 7721-7726.

Dröge, P., 1994. Protein tracking-induced supercoiling of DNA: A tool to regulate DNA transactions in vivo? BioEssays 16, 91-99.

Drolet, M., Bi, X., Liu, L. F., 1994. Hypernegative supercoiling of the DNA template during transcription elongation in vitro. Journal of Biological Chemistry 269, 2068-2074.

Dubnau, E., Margolin, P., 1972. Suppression of promoter mutations by the pleiotropic supx mutations. Mol Gen Genet 117, 91-112.

Fang, M., Wu, H.-Y., 1998. A Promoter Relay Mechanism for Sequential Gene Activation. Journal of Bacteriology 180, 626-633.

Fang, M., Wu, H.-Y., 1998. Suppression of leu-500 Mutation in topA ${ }^{+}$Salmonella typhimurium Strains. Journal of Biological Chemistry 273, 29929-29934. 
Fisher, L. M., 1984. Genetics: DNA supercoiling and gene expression. Nature 307, 686687.

Gralla, J. D., 1996. Activation and repression of E. coli promoters. Current Opinion in Genetics \&amp; Development 6, 526-530.

Lanzer, M., Bujard, H., 1988. Promoters largely determine the efficiency of repressor action. Proceedings of the National Academy of Sciences 85, 8973-8977.

Lilley, D. M. J., Higgins, C. F., 1991. Local DNA topology and gene expression: the case of the leu-500 promoter. Molecular Microbiology, Blackwell Publishing Ltd. 5, 779-783.

Liu, L. F., Wang, J. C., 1987. Supercoiling of the DNA template during transcription. Proceedings of the National Academy of Sciences 84, 7024-7027.

Lockshon, D., Morris, D. R., 1983. Positively supercoiled plasmid DNA is produced by treatment of Escherichia coli with DNA gyrase inhibitors. Nucleic Acids Research 11, 2999-3017.

Mojica, F. J. M., Higgins, C. F., 1996. Localized domains of DNA supercoiling: topological coupling between promoters. Molecular Microbiology 22, 919-928.

Mukai, F. H., Margolin, P., 1963. Analysis of unlinked suppressors of an $0^{\circ}$ mutation in Salmonella. Proc Natl Acad Sci U S A. 50, 140-148.

Pruss, G. J., 1985. DNA topoisomerase I mutants: Increased heterogeneity in linking number and other replicon-dependent changes in DNA supercoiling. Journal of Molecular Biology 185, 51-63.

Pruss, G. J., Drlica, K., 1989. DNA supercoiling and prokaryotic transcription. Cell 56, 521-523.

Ravin, N., Lane, D., 1999. Partition of the Linear Plasmid N15: Interactions of N15 Partition Functions with the sop Locus of the F Plasmid. Journal of Bacteriology 181, 6898-6906.

Ravin, V., Ravin, N., Casjens, S., Ford, M. E., Hatfull, G. F., Hendrix, R. W., 2000. Genomic sequence and analysis of the atypical temperate bacteriophage N15. Journal of Molecular Biology 299, 53-73.

Ravin, N. V., 2003. Mechanisms of replication and telomere resolution of the linear plasmid prophage N15. FEMS Microbiology Letters 221, 1-6.

Samul, R., Leng, F., 2007. Transcription-coupled Hypernegative Supercoiling of Plasmid DNA by T7 RNA Polymerase in Escherichia coli Topoisomerase I-Deficient Strains. Journal of Molecular Biology 374, 925-935. 
Spirito, F., Bossi, L., 1996. Long-distance effect of downstream transcription on activity of the supercoiling-sensitive leu-500 promoter in a topA mutant of Salmonella typhimurium. J Bacteriol 178, 7129-7137.

Tan, J., Shu, L., Wu, H. Y., 1994. Activation of the leu-500 promoter by adjacent transcription. Journal of Bacteriology 176, 1077-1086.

Trucksis, M., Golub, E. I., Zabel, D. J., Depew, R. E., 1981. Escherichia coli and Salmonella typhimurium supX genes specify deoxyribonucleic acid topoisomerase I. J Bacteriol 147, 679-681.

Vologodskii, A. V., 1992. Topology and physics of circular DNA. CRC Press, Boca Roton

Wang, J. C., Lynch, A. S., 1993. Transcription and DNA supercoiling. Current Opinion in Genetics \&amp; Development 3, 764-768.

Wang, J. C., Gartenbarg, M, R., 1992. Positive supercoiling of DNA greatly diminishes mRNA synthesis in yeast. Proc Natl Acad Sci U S A 89, 11461-11465. 


\section{Chapter 4: Conclusions and Future Directions}

\subsection{Conclusions}

The primary objectives of this dissertation are: 1) to demonstrate that transcription is a major chromosomal remodeling force in E. coli cells; 2) to explore whether TCDS is able to greatly influence coupled DNA transactions, e.g., to activate a divergentlycoupled leu-500 promoter in vivo. To accomplish the objectives, two series of studies in E. coli wild-type and top $A$ strains were performed.

In chapter 2, using a newly established two-plasmid system, we examined the effect of promoter strength on TCDS. Our results suggest that TCDS in topA strains is dependent on promoter strength. More importantly, we demonstrated that transcriptioncoupled hypernegative supercoiling of plasmid DNA did not require the expression of a membrane-insertion protein for strong promoters, although it might require cotranscriptional synthesis of a polypeptide. In addition, we found that the expression of a membrane-insertion tet gene was not sufficient for the production of hypernegatively supercoiled DNA. Our results can be explained by the "twin-supercoiled-domain" model of transcription, which suggested that friction force applied to E. coli RNA polymerase plays a critical role in the generation of hypernegatively supercoiled DNA.

In chapter 3, we developed an in vivo system to study how TCDS activates a divergently-coupled, supercoiling-sensitive $l e u-500$ promoter in E. coli cells. Our results demonstrated that transient TCDS induced by either T7 or E. coli RNA polymerase was able to activate the leu-500 promoter. These observations suggested that TCDS may be a general mechanism for activating transcription in vivo. 
Taken together, the results presented in this dissertation demonstrated that transcription is a major chromosomal remodeling force in E. coli cells and is able to activate a divergently coupled, supercoiling-sensitive $l e u-500$ promoter.

\subsection{Future Directions}

Future research on this topic may focus on these three areas:

1) Examining factors that regulate the activating of the leu-500 promoter by transient TCDS in E. coli cells. Since we established a plasmid-based system to study the activation of the $l e u-500$ promoter, it should be relatively straightforward to test what factors affect the activation of the leu-500 promoter by TCDS. These factors include the distance between the two divergently-coupled promoters, the length of RNA transcripts, the expression of a membrane-associated protein, and the presence of a topological barrier between the promoters.

2) Identifying new supercoiling-sensitive promoters in E. coli cells. My dissertation also provided a new method to screen and identify new supercoiling-sensitive promoters in the future.

3) Establishing a defined protein system to study the activation of the leu-500 promoter in vitro. 
VITA

XIAODUO ZHI

Born, Beijing, China

2002-2006

B.S. Biological Sciences

Capital Normal University

Beijing, China

$2007-2013$

Doctoral Candidate

Teaching Assistant

Research Assistant

Doctoral Evidence Acquisition

Florida International University

Miami, Florida, USA

\section{PUBLICATIONS AND PRESENTATIONS}

Xu, X., Zhi, X., and Leng, F. (2012) Determining DNA supercoiling enthalpy by isothermal titration calorimetry. Biochimie, 94(12): 2665-2672.

Zhi, X. and Leng, F. (2013) Dependence of transcription-coupled DNA supercoiling on promoter strength in Escherichia coli Topoisomerase I deficient strains. Gene, 514(2):8290.

Xiaoduo Zhi and Fenfei Leng. Transcription-coupled Hypernegative Supercoiling of Plasmid DNA by Escherichia coli RNA polymerase in Escherichia coli Topoisomerase IDeficient Strains. FASEB, Saxtons River, Vermont, USA, June 19-24, 2011 (poster presentation).

Xiaoduo Zhi and Fenfei Leng. Dependence of Transcription-Coupled DNA Supercoiling on Promoter Strength in Escherichia coli Topoisomerase I Deficient Strains. Bacteria, Archaea and Phages meeting, Cold Spring Harbor, NY, USA, August 21-25, 2012 (poster presentation). 